\title{
Prediction and early intervention in employees at risk for sickness absence due to psychosocial health complaints
}

Citation for published version (APA):

Duijts, S. F. (2007). Prediction and early intervention in employees at risk for sickness absence due to psychosocial health complaints. [Doctoral Thesis, Maastricht University]. Universiteit Maastricht. https://doi.org/10.26481/dis.20071107sd

Document status and date:

Published: 01/01/2007

DOI:

10.26481/dis.20071107sd

Document Version:

Publisher's PDF, also known as Version of record

Please check the document version of this publication:

- A submitted manuscript is the version of the article upon submission and before peer-review. There can be important differences between the submitted version and the official published version of record.

People interested in the research are advised to contact the author for the final version of the publication, or visit the DOI to the publisher's website.

- The final author version and the galley proof are versions of the publication after peer review.

- The final published version features the final layout of the paper including the volume, issue and page numbers.

Link to publication

\footnotetext{
General rights rights.

- You may freely distribute the URL identifying the publication in the public portal. please follow below link for the End User Agreement:

www.umlib.nl/taverne-license

Take down policy

If you believe that this document breaches copyright please contact us at:

repository@maastrichtuniversity.nl

providing details and we will investigate your claim.
}

Copyright and moral rights for the publications made accessible in the public portal are retained by the authors and/or other copyright owners and it is a condition of accessing publications that users recognise and abide by the legal requirements associated with these

- Users may download and print one copy of any publication from the public portal for the purpose of private study or research.

- You may not further distribute the material or use it for any profit-making activity or commercial gain

If the publication is distributed under the terms of Article $25 \mathrm{fa}$ of the Dutch Copyright Act, indicated by the "Taverne" license above, 
PREDICTION AND EARLY INTERVENTION IN EMPLOYEES

AT RISK FOR SICKNESS ABSENCE DUE TO PSYCHOSOCIAL HEALTH COMPLAINTS 
Prediction and early intervention in employees at risk for sickness absence due to psychosocial health complaints

Saskia F.A. Duijts

ISBN: 9789090222899

Coverphoto: Maurice P.A. Zeegers

Lay-out: Jos Bruystens, Maastricht

Printed by: Wilco, Amersfoort

(C) 2007, S.F.A. Duijts

All rights reserved. No part of this thesis may be reproduced or transmitted in any form or by any means, electronic or mechanical, including photocopying, recording or any information storage or retrieval system, without permission in writing from the author, or, when appropriate, from the publishers of the publications. 


\section{Prediction and Early Intervention in Employees at RisK fOR SickNess AbSENCE DUE TO PSYCHOSOCIAL HEALTH COMPLAINTS}

\section{PROEFSCHRIFT}

ter verkrijging van de graad van doctor aan de Universiteit Maastricht, op gezag van de Rector Magnificus, Prof. mr. G.P.M.F. Mols, volgens het besluit van het College van Decanen, in het openbaar te verdedigen op woensdag 7 november 2007 om 14.00 uur

door SASKIA FRANCISCA ANTHONY DUIJTS 


\section{PROMOTOR}

Prof. dr. ir. P.A. van den Brandt

CO-PROMOTORES

Dr. ing. IJ. Kant

Dr. G.M.H. Swaen

\section{BEOORDELINGSCOMMISIE}

Prof. dr. G. I. J. M. Kempen (voorzitter)

Prof. dr. A. R. Arntz

Prof. dr. F. J. H. van Dijk (Coronel Instituut voor Arbeid en Gezondheid, Amsterdam)

Prof. dr. J. A. Knottnerus

Prof. dr. F. J. N. Nijhuis

The project was funded by the Health Research and Development Council (ZorgOnderzoek Nederland), The Netherlands (grant nr. 2200.0105). The performance of the coaching intervention was made possible by additional funding of SoFoKleS (Sociaal Fonds voor de KennisSector).

The studies presented in this thesis were conducted at the Department of Epidemiology (Maastricht University), and were embedded in the Care and Public Health Research Institute (CAPHRI). CAPHRI participates in the Netherlands School of Primary Care (CaRe). CaRe was accredited by the Royal Netherlands Academy of Arts and Sciences (KNAW).

Financial support for the printing of this thesis was kindly provided by the Department of Epidemiology and the Occupational Health Epidemiology program (Maastricht University). 
Niets is onvoorstelbaar 



\section{CONTENTS}

$\begin{array}{llr}\text { Chapter } 1 & \text { Introduction } & 9\end{array}$

$\begin{array}{lll}\text { Chapter } 2 & \text { A meta-analysis of observational studies identifies } & 21\end{array}$

predictors of sickness absence

Chapter 3 Prediction of sickness absence: the development of a 43 screening instrument

Chapter $4 \quad$ Advantages and disadvantages of an objective

selection process for early intervention in employees

at risk for sickness absence

Chapter $5 \quad$ Psychometric characteristics and external validation of a screening instrument to identify employees at risk for sickness absence due to psychosocial health complaints

Chapter 6 The compatibility between characteristics of employees at risk for sickness absence and components of a preventive coaching intervention

Chapter 7 Effectiveness of a preventive coaching intervention for employees at risk for sickness absence due to psychosocial health complaints: results of a randomized controlled trial 
Samenvatting (Summary in Dutch)

Dankwoord (Acknowledgements in Dutch)

About the author

List of publications

181 
INTRODUCTION 

In Western societies, sickness absence represents a major public health problem. ${ }^{1}$ Both financial and health related issues contribute to this concern. Costs associated with sickness absence are high, since they not only include disability benefits, but also costs of lost productivity and replacements. This has made sickness absence one of the top policy priorities for European Union governments.2, 3 The impact of work on health has shifted, analogous to the change in developed civilizations from industrial to service economies in the last decades, from physical to mental.4 Many unhealthy chemical, ergonomic, biological and physical exposures at work have been eliminated or substantially reduced, along with accompanying diseases that can initiate sickness absence. Conversely, other features with regard to work appeared, that might affect employee health and wellbeing as well. 5 These changes indicate a need for new ways to manage sickness absence.

Psychosocial health complaints, such as depression, fatigue, stress and work-family conflicts, are common in the community and in primary care, and leading causes of sickness absence in the Western world nowadays. ${ }^{1,6}$ In the Netherlands, the sickness absence rate was around 5\% during the past years,7 and about one in three employees seen by their occupational physician were absent from work because of psychosocial health complaints. ${ }^{8}, 9$ Although the incidence of sickness absence due to such complaints is higher for women, the duration of these sick leaves is longer for men. ${ }^{10,11}$ Also, the nature of work, organizational changes and the large amounts and pressure at work contribute to high levels of psychosocial absenteeism. ${ }^{12}$ Whether psychosocial health complaints develop into a sickness absence spell or not, depends on personal characteristics of the worker, for example sex or higher age, on the working conditions of a job, for example high physical demands and workload, or on the social protection system, for example level of sickness compensation.13

Reintegration after psychosocial absenteeism seems to be associated with more difficulties and generally takes longer than return to work following physical problems. Employees gradually adapt to the new situation at home, and colleagues at work learn to get the work done without their absent coworker. For both employers and society, the consequences of this type of sickness absence involve associated costs and reduced productivity. ${ }^{14}$ It is hypothesized that early intervening in employees at increased risk for sickness absence due to psychosocial health complaints will reduce these complaints, and subsequently future sickness absence. However, this preventive approach requires that employees at increased risk can be identified and that the 
early intervention is effective. Both the prediction and the efficacy of early intervening are the main topics of this thesis.

A part of this assumption concerns the prediction of employees at increased risk for sickness absence due to psychosocial health complaints. Up to now, early intervention programs, e.g. physical activity at work, are merely aimed at reducing particular health complaints and improving wellbeing. Selection of employees eligible for these programs primarily occurred through personal enlistment of employees. ${ }^{15}$ Also, supervisors or personnel officers who recognize employees struggling with psychosocial health difficulties support participation in early intervention programs. In current practice, early intervention programs are initiated when the employee, supervisor or personnel officer explicitly summons for assistance, in case of psychosocial health complaints or impending sickness absence, and if it is within the bounds of possibilities of the company. ${ }^{16}$ As a result, the efficacy of these interventions could not be studied properly. Therefore, one could ask oneself if this is the most adequate selection method, when it comes to effective prediction and early intervention. Employees who are aware of an explicit problem do not automatically have to be those who benefit most from an early intervention program. Also, intervening with those frequently on sick leave does not have to be the timeliest strategy to prevent forthcoming sickness absence. To enable a new way of managing sickness absence due to psychosocial health complaints, it is essential to know which employees are at risk for sickness absence, so as to target those who would probably benefit most from preventive intervention. Furthermore, there must be an appropriate and effective early intervention program that suits the characteristics of these identified 'at risk' employees. This concerns the other part of the hypothesis.

At the moment, most interventions in workplace settings have a rather curative character, i.e. they are aimed at reintegration of employees already on sick leave, e.g. Hlobil et al. ${ }^{17}$ Also, many studies investigated the effectiveness of interventions to prevent long-term absenteeism in sick-listed employees, e.g. Brouwers et al. ${ }^{18}$ Van der Klink et al showed in a randomized controlled trial the effectiveness of an intervention for intensive individual supervision by occupational physicians. Employees with psychosocial health complaints who received intensive supervision returned to work earlier than employees without intensive supervision. ${ }^{19}$ According to Dutch legislation, every employee on sick leave must be provided with socio-medical counseling and treatment. Subsequently, evaluation can only take place by comparing interven- 
tions, since not providing counseling or treatment is not an option. In addition, there are interventions with a more preventive approach, aimed at for example reducing stress at work or improving overall physical activity, in order to reduce the risk for future sick leave, e.g. Cooper ${ }^{20,}{ }^{21}$ and Bernaards et al. ${ }^{21}$ Also, a recent study elucidated whether self-completed questionnaires could identify employees at risk for allcauses sickness absence. ${ }^{22}$ However, no study investigated the effect of an early intervention in employees at risk for sickness absence due to psychosocial health complaints. And until today, it has remained unclear how this approach, both the first and second part of the hypothesis, should be put into practice. These considerations led to the formulation of the main research topics of this thesis.

\section{Research themes}

Two main research themes will be described in this thesis. The first theme concerns the prediction of employees at increased risk for sickness absence due to psychosocial health complaints, using a screening instrument. In addition, the willingness of employees to be screened for their risk of sickness absence and their motivation to participate in a non-requested developed preventive program are described. The second theme is the effectiveness of this early intervention for employees at risk for sickness absence due to psychosocial health complaints, to reduce complaints, to improve their general state of wellbeing, and subsequently to reduce sick leave. Both themes form part of a randomized controlled trial, in which employees of several companies participated. In the remainder of this chapter, background information on the research themes will be given and, subsequently, the chapters will be introduced in which the underlying main research objectives will be addressed.

\section{Prediction of sickness absence due to psychosocial health complaints}

Numerous epidemiological studies have investigated predictive factors for sickness absence. Demographics, 23, 24 (mental) health related factors, 25-27 psychosocial work characteristics $28-30$ and organizational factors $31-33$ are examples of factors of which the association with sickness absence is explored. In contrast to several somatic reasons for sickness absence, psychosocial causes for sickness absence, and factors influencing future psychosocial absenteeism, are rarely described. Michie et al (2003) presented a systematic review on work related factors and psychological ill health and sickness absence.34 However, the included studies were merely cross-sectional, and only concerned the association between work related characteristics and the abovementioned outcome measures. Hence, to have an up-to-date and complete overview 
of the causal relation between various predictive factors and psychosocial absenteeism, a meta-analysis on longitudinal studies is performed as part of this thesis. Since several independent studies are quantified in this meta-analysis, and the included studies not often explicitly described sickness absence due to psychosocial health complaints as the main outcome measure, the data of the Maastricht Cohort Study on 'Fatigue at Work' are additionally used to identify predictive factors. 35

Sick leaves due to psychosocial health complaints, encompassing both the psychological and social cluster of the International Classification of Primary Care, are identified in this prospective Maastricht Cohort Study, in which over 12,000 employees were followed for three years. The differentiation of the psychosocial concept from all-causes sickness absence is important, since the exploration of predictive factors for this specific type of sickness absence can yield other results than the assessment of sickness absence due to, for example, cardiovascular disorders. Also, preventive interventions for sickness absence due to psychosocial health complaints might be different from those directed at, for example, sickness absence due to low back pain, e.g. ergonomic interventions. The purpose of identifying these predictive factors is to enable screening of individuals at high risk for a particular outcome, 36 in the present context, to identify employees who are at risk for sickness absence due to psychosocial health complaints. A complementary and even more important purpose of screening is a more detailed assessment of those at risk, to target key problems unique to the individual employee, which can be addressed in interventions. 36,37 With this, it is important to realize that a certain time period is necessary to develop psychosocial health complaints of such a level that a rather healthy employee is unable to work, and consequently that interventions need a specified follow-up to be effective. To our knowledge, no previous study combined predictive factors for sickness absence due to psychosocial health complaints into a screening instrument to objectively identify employees eligible for early intervening. $3^{8}$ 


\section{Early intervention in employees at risk for sickness absence due to psychosocial health complaints}

Next to the objective screening instrument to identify employees at risk for sickness absence due to psychosocial health complaints, and sufficient motivation to participate, there must be an effective preventive intervention program to increase wellbeing and reduce sickness absence. Numerous interventions in workplace settings such as cognitive-behavioral approaches and relaxation techniques, proved to be effective in improving perceived quality of life, or reducing stress-related complaints. ${ }^{19}$ Regarding sickness absence, previous studies were mainly curative or aimed at musculoskeletal disorders as main cause for absenteeism.39 In this thesis, coaching is evaluated as a promising early intervention to reduce future sickness absence due to psychosocial health complaints.

Bassi et al (1998) state that coaching is not a new approach.40 In the fifties, coaching symbolized a teacher-student relationship. The supervisor educated the employee in requisite skills for the job. In the seventies, the role of the coach in sport is introduced, and in the eighties, mentoring, career and management development and team performance were central themes in coaching. For several years, coaching was only applied when problems at work occurred.41 Nowadays, coaching is principally an approach to enhance wellbeing and performance in personal life and work domains, to improve functioning, achieve goals, and manage stress in non-clinical populations. 42

Preventive coaching is directed at employees who are not on sick leave and whose problems can be interpreted as relatively mild. Accordingly, preventive coaching can be seen as a rather healthy intervention. The involvement of the related supervisor in the coaching program, and the fact that the defined problems are mainly work-related or a combination of work and personal related issues, demonstrates the occupational nature of this intervention. Problem-solving is an important component of the preventive coaching program. 43 Previous research showed that employees with psychosocial health complaints have weaker problem-solving skills in comparison with employees without these complaints. 44 In the preventive coaching program, employees learn to reduce emotional and psychosocial distress as a result of negative lifeevents, by unraveling their difficulties effectively through increasing problem-solving skills.44 The hypothesis is that this approach would diminish psychosocial health complaints and consequently would reduce the risk for sickness absence. The preven- 
tive coaching intervention in this study is performed by coaches from the Capability organization, partner in this research project. 42

In conclusion, to assess the effectiveness of prediction and early intervention on sickness absence due to psychosocial health complaints and on general wellbeing, certain fundamental prerequisites have to be met. An objective screening instrument for the prediction of employees at increased risk of sickness absence due to psychosocial health complaints must be available, employees must be willing to be screened for the risk of sickness absence, selected employees need to be motivated to participate in a non-requested intervention, and there must be an appropriate and effective intervention program.

\section{Outline of the thesis}

The two main research objectives of this thesis are: (1) to develop and test a concise screening instrument for prediction of employees at increased risk for sickness absence due to psychosocial health complaints, and to assess the motivation of selected employees to participate in a developed early intervention program; and (2) to assess the effect of preventive coaching for employees at risk for sickness absence due to psychosocial health complaints on general wellbeing and sick leave.

For the first main research objective, a meta-analysis is conducted to provide an overview of predictive factors for sickness absence due to psychosocial health complaints. The results of this meta-analysis are described in chapter 2 . The availability of such an overview is important for the development of a screening instrument, consisting of a combination of these factors. In chapter 3 , the wide spectrum of potential predictive (mental) health, psychosocial and organizational factors for sickness absence is explored, using data of the Maastricht Cohort Study on 'Fatigue at Work', and the development and internal validation of the screening instrument is described. The objective selection process, preceding the randomized controlled trial, is evaluated in chapter 4 . Different stages of this selection process, throughout which employees either dropped out or are excluded, are compared with a more usual subjective selection process. Also, the characteristics of ineligible and ultimately selected employees, for participation in the trial, are described. In chapter 5, exploratory factor analysis is performed to investigate the structure of the developed screening instrument. Internal consistency reliability of the identified scales is assessed and predictive validity is investigated, using gathered objective sickness absence data as criteri- 
on measure. Also, the external validity of the screening instrument is tested, by means of sickness absence data of participating companies.

To address the second main research objective, the compatibility of features of the intervention and characteristics of the study population are explored. Herewith, the appropriateness of preventive coaching as an early intervention for a study population at risk for sickness absence due to psychosocial health complaints is assessed. The results of this comparison are described in chapter 6 . Additionally, the effectiveness of the preventive coaching intervention for employees at risk for sickness absence is explored. In chapter 7 , the main results of the effect of coaching on sickness absence due to psychosocial health complaints and wellbeing related factors, such as fatigue and work-family conflict, are described. Finally, the major findings of this thesis are reflected in the epilogue, chapter 8. 


\section{References}

1 Luz J, Green MS. Sickness absenteeism from work - a critical review of the literature. Public Health Rev 1997;25(2):89-122.

2 Grundemann RWM, van Vuuren CV. Preventing absenteeism at the workplace. Dublin: European Foundation for the Improvement of Living and Working Conditions; 1997.

3 Whitaker SC. The management of sickness absence. Occup Environ Med 2001;58(6):420-4; quiz 424,410 .

van der Klink JJ. Back in Balance. The development and evaluation of an occupational health intervention for work-related adjustment disorders. Amsterdam: University of Amsterdam; 2002. Jansen NWH. Working time arrangements, work-family conflict and fatigue. Maastricht: Maastricht University; 2003.

6 North FM, Syme SL, Feeney A, Shipley M, Marmot M. Psychosocial work environment and sickness absence among British civil servants: the Whitehall II study. Am J Public Health $1996 ; 86(3): 332-40$.

7 Ziekteverzuimcijfers. Voorburg/ Heerlen: Centraal Bureau voor de Statistiek; 2007.

8 Veerman TJ, Schoenmaker CG, Cuelenaere B, Bijl RV. Psychische arbeidsongeschiktheid. Een overzicht van actuele feiten en cijfers. Utrecht: Trimbos Instituut; 2000.

9 Schaufeli WB, Kompier MA. Managing job stress in the Netherlands. International Journal of Stress Management 2001;8:15-34.

10 Hensing G, Alexanderson K, Allebeck P, Bjurulf P. Sick-leave due to psychiatric disorder: higher incidence among women and longer duration for men. Br J Psychiatry 1996;169(6):740-6.

11 Stansfeld S, Feeney A, Head J, Canner R, North F, Marmot M. Sickness absence for psychiatric illness: the Whitehall II Study. Soc Sci Med 1995;40(2):189-97.

12 Cox T, Griffiths A. The nature and measurement of work stress: theory and practice. In: Wilson JR, Corlett E, Nigel E, editors. Evaluation of human work: a practical ergonomics methodology. 2 ed. Londen: Taylor \& Francis; 1995. p. 783-803.

13 Benavides FG. III health, social protection, labour relations, and sickness absence. Occup Environ Med 2006;63(4):228-9.

14 Borritz M, Rugulies R, Christensen KB, Villadsen E, Kristensen TS. Burnout as a predictor of selfreported sickness absence among human service workers: prospective findings from three year follow up of the PUMA study. Occup Environ Med 2006;63(2):98-106.

15 Linton SJ, Boersma K, Jansson M, Svard L, Botvalde M. The effects of cognitive-behavioral and physical therapy preventive interventions on pain-related sick leave: a randomized controlled trial. Clin J Pain 2005;21(2):109-19.

16 Duijts SFA, Kant I, Swaen GMH. Advantages and disadvantages of an objective selection process 
to enable preventive intervening in employees at risk for sickness absence. BMC Public Health 2007; 7 (67).

17 Hlobil H, Staal JB, Twisk J, Koke A, Ariens G, Smid T, et al. The effects of a graded activity intervention for low back pain in occupational health on sick leave, functional status and pain: 12month results of a randomized controlled trial. J Occup Rehabil 2005;15(4):569-80.

18 Brouwers EP, Tiemens BG, Terluin B, Verhaak PF. Effectiveness of an intervention to reduce sickness absence in patients with emotional distress or minor mental disorders: a randomized controlled effectiveness trial. Gen Hosp Psychiatry 2006;28(3):223-9.

19 van der Klink JJ, Blonk RW, Schene AH, van Dijk FJ. The benefits of interventions for work-related stress. Am J Public Health 2001;91(2):270-6.

20 Cooper CL. The changing nature of work: workplace stress and strategies to deal with it. Med Lav 2006;97(2):132-6.

21 Bernaards CM, Jans MP, van den Heuvel SG, Hendriksen IJ, Houtman IL, Bongers PM. Can strenuous leisure time physical activity prevent psychological complaints in a working population? Occup Environ Med 2006;63(1):10-6.

22 Roelen CA, van der Pol TR, Koopmans PC, Groothoff JW. Identifying workers at risk of sickness absence by questionnaire. Occup Med (Lond) 2006;56(7):442-6.

23 Krantz G, Ostergren PO. Do common symptoms in women predict long spells of sickness absence? A prospective community-based study on Swedish women 40 to 50 years of age. Scand J Public Health 2002;30(3):176-83.

24 Knutsson A, Goine H. Occupation and unemployment rates as predictors of long term sickness absence in two Swedish counties. Soc Sci Med 1998;47(1):25-31.

25 Jansen N, Kant I, Swaen GMH, Janssen PPM, Schröer CAP. Fatigue as a predictor of sickness absence: results form the Maastricht Cohort Study on fatigue at work. Occup Environ Med 2003;6o(suppl I):i71-i76.

26 De Croon EM, Sluiter JK, Frings-Dresen MHW. Need for recovery after work predicts sickness absence: A 2-years prospective cohort study in truck drivers. J Psychosom Res 2003;55:331-339.

27 Bourbonnais R, Mondor $M$. Job strain and sickness absence among nurses in the province of Quebec. Am J Ind Med 2001;39(2):194-202.

28 Ala-Mursula L, Vahtera J, Kivimaki M, Kevin MV, Pentti J. Employee control over working times: associations with subjective health and sickness absences. J Epidemiol Community Health 2002;56(4):272-8.

29 Gimeno D, Benavides FG, Amick III BC, Benach J, Martinez JM. Psychosocial factors and work related sickness absence among permanent and non-permanent employees. J Epidemiol Community Health 2004;58:870-876.

30 Rael EG, Stansfeld SA, Shipley M, Head J, Feeney A, Marmot M. Sickness absence in the 
Whitehall II study, London: the role of social support and material problems. J Epidemiol Community Health 1995;49(5):474-81.

31 Vaananen A, Kalimo R, Toppinen-Tanner S, Mutanen P, Peiro JM, Kivimaki M, et al. Role clarity, fairness, and organizational climate as predictors of sickness absence: a prospective study in the private sector. Scand J Public Health 2004;32(6):426-34.

32 Godin I, Kittel F. Differential economic stability and psychosocial stress at work: associations with psychosomatic complaints and absenteeism. Soc Sci Med 2004;58(8):1543-53.

33 Markham SE. Declining organizational size and increasing unemployment rates: predicting employee absenteeism from within- and between plant perspectives. Academy of Management Journal 1991;34:952-965.

34 Michie S, Williams S. Reducing work related psychological ill health and sickness absence: a systematic literature review. Occup Environ Med 2003;60(1):3-9.

35 Kant I, Bultmann U, Schroer C, Beurskens A, Amelsvoort Lv, Swaen G. An epidemiological approach to study fatigue in the working population: The maastricht cohort study. OEM 2003;6o(supl 1):i32-i39.

36 Linton SJ, Boersma K. Early identification of patients at risk of developing a persistent back problem: the predictive validity of the Orebro Musculoskeletal Pain Questionnaire. Clin J Pain 2003;19(2):80-6.

37 Waddell G, Burton AK, Main CJ. Screening to identify people at risk of long-term incapacity for work - A conceptual and scientific review. Londen: Royal Society of Medicine Press; 2003.

38 Duijts SFA, Kant I, Landeweerd JA, Swaen GMH. Prediction of sickness absence: the development of a screening instrument. Occupational and Environmental Medicine 2006;63:564-569.

39 Arnetz BB, Sjogren B, Rydehn B, Meisel R. Early workplace intervention for employees with musculoskeletal-related absenteeism: a prospective controlled intervention study. J Occup Environ Med 2003;45(5):499-506.

40 Bassi L, Cheney S, Lewis E. Trends in workplace learning: supply and demand in interesting times. Training \& Development 1998;52:51-77.

41 Brouns M, Sibbes J, Tap R. Coaching - A world to win. The Hague: Ministery of Social Affairs and Employment; 2002.

42 Duijts SFA, Kant I, van den Brandt PA, Swaen GMH. The compatibility between characteristics of employees at risk for sickness absence and components of a preventive coaching intervention. Int J of Evid Bas Coach \& Ment 2007;5(1):19-29.

43 D'Zurilla TJ, Goldfried MR. Problem solving and behavior modification. J Abnorm Psychol 1971;78(1):107-26.

44 Nezu AM, Ronan GF. Life stress, current problems, problem solving, and depressive symptoms: an integrative model. J Consult Clin Psychol 1985;53(5):693-7. 


\section{A META-ANALYSIS OF OBSERVATIONAL STUDIES IDENTIFIES PREDICTORS OF SICKNESS ABSENCE}

\section{Saskia FA Duijts ${ }^{1}$}

IJmert Kant ${ }^{1}$

Gerard MH Swaen ${ }^{1,2}$

Piet A van den Brandt ${ }^{1}$

Maurice PA Zeegers 3

1 Department of Epidemiology, Maastricht University, Maastricht, The Netherlands

2 Dow Chemical Terneuzen, Terneuzen, The Netherlands

3 Department of Public Health and Epidemiology, University of Birmingham, Birmingham, United Kingdom 


\section{Abstract}

\section{Objective}

About one in every three employees seen by their occupational physician are absent from work because of psychosocial health complaints. To implement preventive measures, it is necessary to identify predictors for this type of sickness absence.

\section{Study design and Setting}

A meta-analysis was carried out to quantify the association between predictive factors and psychosocial sickness absence, and to assess clinical outcomes and heterogeneity. Eligible for inclusion were prospective studies that examined this association, and provided sufficient information to estimate summary odds ratios.

\section{Results}

20 prospective studies were included. Significant summary odds ratios for sick leave $>3$ days were found for being unmarried 1.37 (95\% Cl 1.15-1.64), experiencing psychosomatic complaints 1.79 ( $95 \% \mathrm{Cl} 1.54-2.07$ ), using medication 3.13 ( $95 \% \mathrm{Cl} 1.71-5.72$ ), having a burnout 2.34 ( $95 \% \mathrm{Cl} 1.59-3.45)$, suffering from psychological problems 1.97 (95\% Cl 1.37-2.85), having low job control 1.28 (95\% Cl 1.23-1.33), having low decision latitude 1.33 (95\% Cl 1.16-1.56) and experiencing no fairness at work 1.30 (95\% Cl 1.181.45).

\section{Conclusion}

This study shows that predictors of sickness absence can be identified in a homogeneous manner. The results provide leads to public health interventions to successfully improve psychosocial health and to reduce sickness absence. 


\section{INTRODUCTION}

Sickness absence is a complex phenomenon. ${ }^{1}$ It can be the result of various causes, such as musculoskeletal or psychosocial complaints, and the occurrence and course can be influenced by a range of factors, such as demographics, health (behaviour), mental health, work, personal and organizational factors. ${ }^{2-5}$ The magnitude of sickness absence due to psychosocial health complaints is substantial and represents a major concern in Western societies. ${ }^{6}$ These complaints encompass both psychological conditions, such as depression, as well as social problems, such as work family conflicts.7 In the Netherlands, about one in every three employees seen by their occupational physician are absent from work because of psychosocial health complaints. ${ }^{8}$ For the individual, reintegration after psychosocial absenteeism causes more difficulties and generally takes longer than return to work following physical problems. For both employers and society, the consequences of this type of sickness absence involve enhanced payments and reduced productivity. 9 Because of the economic and social impact of sickness absence due to psychosocial health complaints, early intervening is an all-important matter and should receive profound attention in occupational health practice. At this moment, a randomized controlled trial on the effectiveness of preventive intervening in employees at risk for sickness absence due to psychosocial health complaints is in progress. In order to enable identification of at risk employees, insight in predictive factors for sickness absence due to psychosocial health complaints is needed. For the trial, the predictive factors were detected using data of the Maastricht Cohort Study on Fatigue at Work (MCS).7, 10 Employees who reported sickness absence due to e.g. fatigue or conflicts at work were identified and predictive factors for this specific type of sickness absence were assessed. Hereafter, an instrument consisting of these factors was developed, to screen employees for their risk of sickness absence, and to early intervene with these employees in order to prevent sickness absence due to psychosocial health complaints.7 Results of the trial will be known in April 2007. To have a large-scale overview of research on influential factors, and to provide the results of the trial a scientific basis, the current meta-analysis attempted to identify predictive factors for sickness absence due to psychosocial health complaints. The multiversity of sickness absence promotes the exploration of factors for separate causes of the concept. That is, studying sickness absence due to for example musculoskeletal problems might ascertain other predictive factors (e.g. ergonomic and physical factors) and probably other results, than the assessment of sickness absence due to psychosocial health complaints. However, in contrast to sev- 
eral somatic reasons for sickness absence, psychosocial causes for sickness absence are rarely explicitly described in studies. Moreover, numerous studies seem to explore all-causes sickness absence, since underlying diagnoses for sickness absence are not identified or reported. Consequently, the partition of psychosocial complaints from all-causes sickness absence is a complex and rather indefinite process. To optimize this extrication, and to increase the probability of assessing studies on sickness absence due to psychosocial health complaints, the omission of studies on sickness absence due to specific somatic complaints is essential. With this, the exclusion of all causes sickness absence studies can not be guaranteed, but the homogeneity of the remaining set of studies improves. Up to now, neither a systematic summary of previous studies nor a quantification of predictive factors for sickness absence due to psychosocial health complaints has been conducted. Above all, no attention has been given to the expected presence of heterogeneity when studying this association. Our hypothesis is that clarification of these issues could provide imperative leads to public health interventions to prevent sickness absence due to psychosocial health complaints. The objective of this study is to review all epidemiologic studies up to August 2006 exploring predictive factors for sickness absence due to psychosocial health complaints, by assessing the clinical outcomes of selected studies and by quantifying the association. 


\section{Methods}

\section{Search strategy}

Publications were identified through computerised Medline, PsycINFO and Embase searches for studies that have been published up to August 2006, with no language restrictions. The keywords used were rather broad, i.e. sickness absence and its determinants, and involved combinations of demo*, health, mental health, fatigue, psycho*, person*, organ*, econ*, environment*, predict*, absenteeism, sick leave and sickness absence. Additionally, references cited in published original and review papers were examined until no further studies were found. Eligible for inclusion in this meta-analysis were all prospective studies that addressed the influence of potentially predictive factors, such as sociodemographic factors, health (behaviour), mental health, psychosocial work factors, personal factors and organizational factors, on sickness absence due to psychosocial health complaints. Also, studies that provided sufficient information to estimate an odds ratio ac well as its associated standard error were suitable for inclusion. The International Classification of Primary Care (ICPC) was used to recognize the psychosocial health complaints, in which both psychological and social problems were included. Studies that addressed a specific disease or condition as the main cause for sickness absence, such as musculoskeletal, cardiovascular and respiratory conditions, were omitted. With this, the homogeneity of the set of remaining studies increased, but the exclusion of all causes sickness absence studies could not be guaranteed. This selection method might be disputable, but is thought to be the most optimal manner to retrieve studies on the association between predictive factors and sickness absence due to psychosocial health complaints.

\section{Data extraction}

Several hundreds of references and abstracts were scanned for eligibility to select those relevant for our purposes and to determine the main focus of the articles. Qualitative and quantitative information was extracted from each paper by two reviewers. For one reviewer, the original papers were blinded for authors, affiliations, journal name, publication year and acknowledgements. The reviewers independently assessed the following qualitative items: general information (i.e. geographic area of the study), population characteristics (i.e. type of subjects and setting), study characteristics (i.e. design, type of predictor, measures, and follow-up time), study outcome (i.e. occurrence of sick leave ${ }^{11}$ ) and type of sickness absence data (i.e. self 
reported data or data from employer's records). 'Occurrence of sick leave' data were divided into two periods, i.e. medically uncertified ( $\leq 3$ working days) and medically certified sick leaves (> 3 working days). This partition was based on the lowest duration of certified sick leaves found in the included studies (i.e. > 3 days). In addition, the study characteristic 'minimum duration of sick leave' was used as a factor in the sensitivity analyses to investigate its potential reason for heterogeneity. Furthermore, original quantitative data that allowed us to pool crude or adjusted odds ratios, and their corresponding standard errors, were extracted from the articles in order to estimate the association between a range of predictive factors and sickness absence due to psychosocial health complaints. Adjusted effects were estimated using the most complete models, i.e. all models were adjusted for demographic factors and additional factors such as behavioural risks (e.g. smoking, alcohol), health status, occupation and baseline sickness absence. Data that could not be obtained directly were recalculated when necessary. When adjusted odds ratios could not be calculated, two-way tables were constructed to calculate the unadjusted odds ratios and corresponding standard errors. ${ }^{12}$ Results reported in rate ratios, i.e. the quotient of the incidence rates in the exposed and non-exposed group, were considered comparable to results reported in odds ratios. When there was disagreement between reviewers on qualitative or quantitative data, it was discussed until consensus was reached.

\section{Statistical analysis}

We pooled odds ratios if at least two studies reported data on the relation between a specific predictive factor and sickness absence. However, when the reported results within a single study (population) were stratified for different categories of a specific predictive factor, we estimated an intrastudy effect (IOR). Standard metaanalytic procedures assume that results within a given analysis are independent. Our sorting of quantitative data, extracted from the included articles, into definite categories of predictive factors ensured that all of the summary odds ratios (SOR) would be based on independent samples. 13 We used the Stata statistical software package (StataCorp, College Station, TX) ${ }^{14}$ to weight log odds ratios by the inverse of their variances to obtain a pooled measure and the corresponding $95 \%$ confidence interval. When results from the fixed and random effects models were different, we presented the latter as it represents a more conservative approach. Heterogeneity was investigated by evaluating whether confidence intervals around the individual effect sizes of pooled studies overlapped sufficiently and by using the DerSimonian 
and Laird Q statistic $(p<0.10) .15$ To explore possible reasons for the observed heterogeneity, sensitivity analyses were performed on the following study characteristics: geographical area, measures of predictive factors, follow-up time and minimum duration of sick leave. 


\section{Results}

\section{Study characteristics}

Approximately 200 references were identified in total. The publications were scanned, particularly on the cause of sickness absence, and initially 56 epidemiologic studies of predictive factors for sickness absence due to psychosocial health complaints were found to be relevant. Thirty-six of these articles were excluded - eleven because a cross-sectional study design was used, twenty-four because no sufficient data could be extracted, and one because extremely fatigued employees were included at baseline. The remaining 20 articles that were included in the review ${ }^{1,2,16-33}$ described prospective cohort studies, were published in English and were, with the exception of one ${ }^{18}$, all performed in Europe (Table 1 ).

\section{Table 1}

Characteristics of studies on the association between predictive factors and sickness absence due to psychosocial health complaints

\begin{tabular}{|c|c|c|c|c|c|c|}
\hline Ref & Country (year) & Participants, setting & Predictor(s) ${ }^{*}$ & Measurest & FU‡ & Min dur § \\
\hline 1 & Netherlands (2003) & Employees from different sectors & $\mathrm{MH}$ & Quest; employer's records & 6 & 42 \\
\hline 2 & France (1998) & Electricity firm employees & PS & Quest; employer's records & 12 & 7 \\
\hline 16 & Finland (2002) & Municipal employees & $\mathrm{SD}, \mathrm{H}, \mathrm{PS}$ & Quest; employer's records & 36 & 3 \\
\hline 17 & Netherlands (2003) & Employees from different sectors & $\mathrm{H}, \mathrm{MH}, \mathrm{PS}$ & Quest; employer's records & 18 & 90 \\
\hline 18 & Canada (2001) & Nurses & $\mathrm{SD}, \mathrm{H}, \mathrm{MH}, \mathrm{PS}$ & Quest; employer's records & 20 & 5 \\
\hline 19 & Netherlands (2003) & Truck drivers & $\mathrm{SD}, \mathrm{PS}, 0$ & Quest; self-report abs data & 24 & 14 \\
\hline 20 & Norway (2003) & Nurses' aides & $\mathrm{SD}, \mathrm{H}, \mathrm{MH}, \mathrm{PS}$ & Quest; self-report abs data & 3 & 3 \\
\hline 21 & Belgium (2004) & Employees from different sectors & $\mathrm{H}, \mathrm{MH}, \mathrm{PS}, \mathrm{O}$ & Quest; employer's records & 12 & 7 \\
\hline 22 & USA (1981) & Manufacturing employees & SD,PS,P,O & Quest; employer's records & 12 & 14 \\
\hline 23 & Finland (2000) & Hospital staff & $\mathrm{PS}, 0$ & Quest; employer's records & 24 & 4 \\
\hline 24 & Finland (2001) & Hospital employees & $\mathrm{SD}, \mathrm{H}, \mathrm{MH}, \mathrm{PS}, \mathrm{P}$ & Quest; employer's records & 24 & 3 \\
\hline 25 & Sweden (1998) & Manufacturing employees & 0 & Employer's records & 12 & 30 \\
\hline 26 & Sweden (2002) & Employees from different sectors & $\mathrm{SD}, \mathrm{H}, \mathrm{MH}, \mathrm{PS}$ & Quest; employer's records & 12 & 14 \\
\hline 27 & France (2003) & Electricity firm employees & SD,PS & Quest; employer's records & 72 & 7 \\
\hline 28 & England (1996) & Civil servants & PS & Quest; employer's records & 12 & 7 \\
\hline 29 & England (1995) & Civil servants & PS & Quest; employer's records & 12 & 7 \\
\hline 30 & Finland (2003) & Industrial employees & $\mathrm{SD}, \mathrm{H}, \mathrm{MH}, \mathrm{PS}, \mathrm{O}$ & Quest; employer's records & 21 & 4 \\
\hline 31 & Finland (2004) & Industrial employees & $\mathrm{PS}, 0$ & Quest; employer's records & 21 & 4 \\
\hline 32 & Finland (2004) & Municipal employees & PS & Quest; employer's records & 66 & 3 \\
\hline 33 & Belgium (2003) & Health care employees & PS & Quest; employer's records & 12 & 10 \\
\hline
\end{tabular}

* Potential predictors: (SD) Sociodemographic factors; (H) Health; (MH) Mental health; (PS) Psychosocial work factors; (P) Personal factors; (0) Organizational factors; † Quest: self-administered questionnaire; self-report abs data: self-reported absence data; Employer's records: absence data from personnel department records; ‡ FU: Follow-up time in months; § Min dur: minimum duration of certified sick leave in days. 
The studies were carried out in a range of occupational settings, including the industrial sector, the health care sector, the public sector and the educational sector. Most studies investigated the association between a range of predictive factors and sickness absence - nine were focussed at sociodemographic factors (SD), 16, 18-20, 22, 24, 26, 27, 30 eight at health (behaviour) $(\mathrm{H}), 16-18,20,21,24,26,30$ eight at mental health $(\mathrm{MH})$, including fatigue, 1, 17, 18, 20, 21, 24, 26, 30 eighteen at psychosocial work factors (PS), 2, 16-24, 26-33 two at personal factors (P), 22, 24 and seven at organizational factors (O).19, 21-23, 25, 30, 31 Apart from one study that used employer's records to gather information about predictive factors, ${ }^{25}$ all studies used self-administered questionnaires to assess the influence of predictive factors on sickness absence due to psychosocial health complaints. Two studies used self-reported sickness absence data, ${ }^{19,}, 20$ and the remaining studies only used employer's records to determine the occurrence of sick leave (Table 1).

\section{Summary odds ratios}

Crude and adjusted intrastudy (IOR) and summary odds ratios (SOR) for the influence of predictive factors on occurrence of sick leave $\leq 3$ days (Table 2 ) and occurrence of sick leave $>3$ days (Table 3 ) were calculated by means of data extracted from the 20 included studies. Two-third of the presented effect sizes were determined using fixed effect pooling. Significant adjusted odds ratios, exclusively on occurrence of sick leave $\leq 3$ days, were found in four predictive factors, i.e. no exercising 1.19 (1.06-1.35), being exposed to job strain 1.20 (1.13-1.28), suffering from life events 1.14 (1.03-1.27) and going through reorganization 1.32 (1.15-1.52). Significant adjusted odds ratios on both occurrence of sick leave $\leq 3$ days and occurrence of sick leave $>3$ days were found in eight predictive factors, i.e. being unmarried 1.28 (1.14-1.44) and 1.37 (1.15-1.64) respectively, experiencing psychosomatic complaints 1.43 (1.08-1.90) and 1.79 (1.54-2.07), using medication 1.44 (1.32-1.58) and 3.13 (1.71-5.72), having a burnout 1.28 (1.23-1.34) and 2.34 (1.593.45), suffering from psychological problems 1.27 (1.23-1.31) and 1.97 (1.37-2.85), having low job control 1.27 (1.14-1.39) and 1.28 (1.23-1.33), having low decision latitude 1.23 (1.151.30) and 1.33 (1.13-1.56) and experiencing low fairness at work, 1.19 (1.06-1.33) and 1.30 (1.18-1.45). 
Finally, significant adjusted odds ratios, exclusively on occurrence of sick leave $>3$ days, were found in thirteen predictive factors, i.e. being low educated 1.85 (1.59-2.33), using alcohol 1.24 (1.02-1.52), being fatigued all the time 1.32 (1.04-1.69), enjoying low work time control 1.15 (1.10-1.20), enduring psychological job demands 1.15 (1.12-1.19), having low skill discretion 1.11 (1.02-1.20), having low decision authority 1.49 (1.04-2.13), being unsatisfied with the job 1.92 (1.49-2.50), having a physically demanding job 1.66 (1.451.90), experiencing a high need for recovery 2.15 (1.01-4.62), suffering from treats or violence 1.26 (1.10-1.44), being overcommitted 1.15 (1.03-1.29) and a low level of unemployment in the community 1.39 (1.03-1.89) (Table 2 and 3).

\section{Sensitivity analyses}

We further examined the intrastudy and summary odds ratios attained by random effect pooling, according to geographical area, measures of predictive factors, followup time and minimum duration of sick leave, in order to explore the influence of these parameters on the outcome estimates (Table 2 and 3). Sensitivity analyses revealed statistically significant effects of the parameter 'geographical area' in four random effect odds ratios, i.e. the crude and adjusted odds ratios of psychological problems on occurrence of sick leave $>3$ days ( $p=0.078$ and $p=0.003$ respectively); and the adjusted odds ratios of social support on occurrence of sick leave $\leq 3$ days $(p=0.006)$ and occurrence of sick leave $>3$ days $(p=0.053)$. In eight random effect intrastudy and summary odds ratios, differences in 'measures of predictive factors' might explain the heterogeneity in the associations. Because of a lack of observations per measurement, no specific $p$-values could be given. Sensitivity analyses revealed statistically significant effects of the parameter 'follow-up time', exclusively on occurrence of sick leave $>3$ days, in five random effect odds ratios, i.e. the crude odds ratio of education ( $p=0.018)$, the adjusted odds ratio of fatigue $(p=0.037)$, the crude odds ratio of psychological problems $(p=0.078)$, the crude odds ratio of physical demands $(p=0.008)$ and the adjusted odds ratio of reorganization $(p=0.002)$. Finally, sensitivity analyses revealed statistically significant effects of the parameter 'minimum duration of sick leave', exclusively on occurrence of sick leave > 3 days, in four random effect odds ratios, i.e. the crude odds ratio of education $(p=0.017)$, the adjusted odds ratio of fatigue $(p=0.031)$, the crude odds ratio of psychological problems $(p=0.078)$ and the adjusted odds ratio of reorganization $(p=0.029)$ (Table 2 and 3 ). 


\section{Table 2}

Crude and adjusted intrastudy odds ratios (IOR) and summary odds ratios (SOR) for the influence of predictive factors on occurrence of sick leave (duration $\leq 3$ days)

\begin{tabular}{|c|c|c|c|c|}
\hline \multirow{2}{*}{$\begin{array}{l}\text { Predictive factors } \\
\text { Sociodemographics }\end{array}$} & \multicolumn{2}{|c|}{ Crude odds ratios / reference(s) } & \multicolumn{2}{|c|}{ Adjusted odds ratios / reference $(\mathrm{s}) \ddagger$} \\
\hline & & & & \\
\hline Marital status (married vs. unmarried) & & & $\mathrm{IOR}$ & $1.28(1.14-1.44)^{*} / 24$ \\
\hline \multicolumn{5}{|l|}{ Health (behaviour) } \\
\hline Psychosomatic complaints (no 0; yes 1) & & & $\mathrm{IOR}$ & $1.43(1.08-1.90) t^{2} / 24$ \\
\hline Smoking (no 0; yes 1) & & & IOR & $0.91(0.76-1.09)^{*} / 24$ \\
\hline Alcohol (moderate vs. high) & & & $\mathrm{IOR}$ & $1.20(0.96-1.52)^{*} / 24$ \\
\hline Physical exercise (yes 0; no 1) & & & $\mathrm{IOR}$ & $1.19(1.06-1.35)^{*} / 24$ \\
\hline Medication use (no 0; yes 1) & $\mathrm{IOR}$ & $1.44(1.32-1.58)^{*} / 18$ & $\mathrm{IOR}$ & $1.44(1.32-1.58)^{*} / 18$ \\
\hline \multicolumn{5}{|l|}{ Mental health } \\
\hline Burnout (per SD) & IOR & $1.28(1.23-1.34)^{*} / 18$ & IOR & $1.28(1.23-1.34)^{*} / 18$ \\
\hline Psychological problems (no 0; yes 1) & $\mathrm{IOR}$ & $1.28(1.22-1.33)^{*} / 18$ & SOR & $1.27(1.23-1.31)^{*} / 18,24$ \\
\hline \multicolumn{5}{|l|}{ Psychosocial work factors } \\
\hline Job control (very much 1;not at all 4) & SOR & $1.49(1.04-2.08) t^{0} / 28,32$ & SOR & $1.27(1.14-1.39)^{*} / 24,28,32$ \\
\hline Work time control (high vs. low) & & & $\mathrm{IOR}$ & $0.93(0.83-1.23)^{*} / 24$ \\
\hline Psychological job demands (low 1; high 4) & SOR & $0.83(0.57-1.21) \dagger^{2} / 2,27,28$ & SOR & $0.96(0.71-1.30) t^{0} / 2,24,27,28,31$ \\
\hline Job strain (non-exposed vs. most exposed) & $\mathrm{IOR}$ & $1.20(1.13-1.28)^{*} / 18$ & $\mathrm{IOR}$ & $1.20(1.13-1.28)^{*} / 18$ \\
\hline Decision latitude (high 1;low 4) & IOR & $1.59(1.43-1.75)^{*} / 2,27$ & $\mathrm{IOR}$ & $1.23(1.15-1.30) *$ * 2,27 \\
\hline Social support (high 1;low 4) & SOR & $1.09(0.92-1.28) t^{0} / 2,18,27-29$ & SOR & $1.08(0.98-1.18) t^{1} / 2,18,24,27-29$ \\
\hline Fairness (very much 1;not at all 5) & & & $\mathrm{IOR}$ & $1.19(1.06-1.33) * / 31$ \\
\hline Treats/ violence (no 0; yes 1) & IOR & $1.13(0.97-1.32) t^{0} / 23$ & $\mathrm{IOR}$ & $1.09(0.98-1.21) t^{0} / 23$ \\
\hline \multicolumn{5}{|l|}{ Personal factors } \\
\hline Life events (not hard 1; extremely hard 3) & & & $\mathrm{IOR}$ & $1.14(1.03-1.27)^{*} / 24$ \\
\hline \multicolumn{5}{|l|}{ Organizational factors } \\
\hline Reorganization (no 0; yes 1) & & & $\mathrm{IOR}$ & $1.32(1.15-1.52)^{*} / 31$ \\
\hline
\end{tabular}

* Fixed effects modelling; † Random effects modelling; ${ }^{0}$ No statistically significant effect of included parameters; ${ }^{1}$ Statistically significant effect of geographical area; ${ }^{2}$ Statistically significant effect of measures; $¥$ Adjusted summary effects were estimated using the most complete models, i.e. all models were adjusted for demographic factors. Additional factors included in these associations were behavioural risks, health status, occupation and baseline sickness absence. 


\section{Table 3}

Crude and adjusted intrastudy odds ratios (IOR) and summary odds ratios (SOR) for the influence of predictive factors on occurrence of sick leave (duration $>3$ days)

\begin{tabular}{|c|c|c|c|c|}
\hline \multirow{2}{*}{$\begin{array}{l}\text { Predictive factors } \\
\text { Sociodemographics }\end{array}$} & \multicolumn{2}{|c|}{ Crude odds ratios / reference(s) } & \multicolumn{2}{|c|}{ Adjusted odds ratios / reference $(\mathrm{s}) \ddagger$} \\
\hline & & & & \\
\hline Age $(<40$ vs. $>40)$ & SOR & $1.03(0.97-1.09)^{*} / 16,19,20,26$ & & \\
\hline Sex (male 0; female 1) & $\mathrm{IOR}$ & $0.83(0.61-1.12)^{*} / 20$ & & \\
\hline Education (university vs. none) & SOR & $1.61(1.09-2.38) t^{3,4} / 16,19,26$ & IOR & $1.85(1.59-2.33)^{*} / 21$ \\
\hline Marital status (married vs. unmarried) & SOR & $1.05(1.01-1.10)^{*} / 16,19,26$ & IOR & $1.37(1.15-1.64)^{*} / 24$ \\
\hline \multicolumn{5}{|l|}{ Health (behaviour) } \\
\hline Psychosomatic complaints (no 0; yes 1) & SOR & $2.18(1.75-2.72)^{*} / 17,26$ & SOR & $1.79(1.54-2.07) t^{0} / 17,20,24,30$ \\
\hline Smoking (no 0; yes 1) & IOR & $1.31(1.11-1.56)^{*} / 16$ & $\mathrm{IOR}$ & $1.08(0.82-1.41)^{*} / 24$ \\
\hline Alcohol (moderate vs. high) & IOR & $1.00(0.85-1.16)^{*} / 16$ & IOR & $1.24(1.02-1.52)^{*} / 24$ \\
\hline BMI (per SD) & $\mathrm{IOR}$ & $1.54(1.28-1.86)^{*} / 16$ & & \\
\hline Physical exercise (yes 0; no 1) & IOR & $1.32(1.06-1.64) t^{2} / 16$ & SOR & $0.95(0.76-1.19) \dagger^{0} / 22,36$ \\
\hline Medication use (no 0; yes 1) & IOR & $3.13(1.71-5.72)^{*} / 18$ & $\mathrm{IOR}$ & $3.13(1.71-5.72)^{*} / 18$ \\
\hline Prior absence (no 0; yes 1) & IOR & $2.12(0.99-4.53) t^{2} / 19$ & & \\
\hline \multicolumn{5}{|l|}{ Mental health } \\
\hline Burnout (per SD) & $\mathrm{IOR}$ & $2.34(1.59-3.45)^{*} / 18$ & $\mathrm{IOR}$ & $2.34(1.59-3.45)^{*} / 18$ \\
\hline Fatigue (no fatigue vs. always fatigued) & SOR & $1.36(1.07-1.72) t^{0} / 1,17$ & SOR & $1.32(1.04-1.69) t^{3,4} / 1,17,20$ \\
\hline Psychological problems (no 0; yes 1) & SOR & $2.70(0.85-8.55) \dagger^{1,3,4} / 17,18$ & SOR & $1.97(1.37-2.85) \dagger^{1} / 17,18,24,30$ \\
\hline \multicolumn{5}{|l|}{ Psychosocial work factors } \\
\hline Job control (very much 1; not at all 4) & SOR & $1.43(1.08-1.92) t^{2} / 19,28,32$ & SOR & $1.28(1.23-1.33)^{*} / 16,21,24,28,32$ \\
\hline Work time control (high vs. low) & SOR & $1.22(1.15-1.28)^{*} / 16,20$ & SOR & $1.15(1.10-1.20)^{*} / 16,24$ \\
\hline Psychological job demands (low 1; high 4) & SOR & $\begin{array}{l}1.15(0.92-1.44) t^{0} / 17,19,20 \\
26-28,32\end{array}$ & SOR & $\begin{array}{l}1.15(1.12-1.19) t^{0} / 16,17,21,24,27 \\
28,31-33\end{array}$ \\
\hline Job strain (non-exposed vs. most exposed) & SOR & $1.48(1.09-2.01)^{*} / 18,26$ & SOR & $1.27(0.78-2.09) t^{0} / 18,33$ \\
\hline Skill discretion (high 1; low 4) & SOR & $1.18(1.03-1.33)^{*} / 32$ & SOR & $1.11(1.02-1.20)^{*} / 30,32$ \\
\hline Decision authority (high 1; low 4) & SOR & $1.27(1 \cdot 12-1.45)^{*} / 20,32$ & SOR & $1.49(1.04-2.13) t^{0} / 30,32$ \\
\hline Decision latitude (high 1; low 4) & SOR & $1.49(1.39-1.61)^{*} / 2,17,26,27$ & SOR & $1.33(1.13-1.56) t^{0} / 2,16,27,33$ \\
\hline Social support (high 1; low 4) & SOR & $\begin{array}{l}1.22(1.08-1.39) \dagger^{0} / \\
17,18,20,26-29,32\end{array}$ & SOR & $\begin{array}{l}1.08(1.00-1.16) t^{1} / 17,18,20,21,24 \\
27-30,32,33\end{array}$ \\
\hline Job satisfaction (very satisfied 1; dissatisfied 5) & $\mathrm{IOR}$ & $1.45(1.03-2.04)^{*} / 17$ & IOR & $1.92(1.49-2.50)^{*} / 17$ \\
\hline Physical demands (low vs. high) & SOR & $1.45(1.17-1.80) t^{3} / 19,20,32$ & IOR & $1.66(1.45-1.90)^{*} / 32$ \\
\hline Need for recovery (low vs. high) & $\mathrm{IOR}$ & $1.85(0.95-3.59) t^{2} / 19$ & $\mathrm{IOR}$ & $2.15(1.01-4.62)^{*} / 19$ \\
\hline Fairness (very much 1; not at all 5) & $\mathrm{IOR}$ & $1.30(1.12-1.54)^{*} / 20$ & IOR & $1.30(1.18-1.45)^{*} / 31$ \\
\hline Treats/ violence (no 0; yes 1) & $\mathrm{IOR}$ & $1.52(1.36-1.70)^{*} / 23$ & $\mathrm{IOR}$ & $1.26(1.10-1.44)^{*} / 23$ \\
\hline \multicolumn{5}{|l|}{ Personal factors } \\
\hline Life events (not hard 1; extremely hard 3) & & & $\mathrm{IOR}$ & $1.09(0.93-1.29)^{*} / 24$ \\
\hline Domestic responsibility (low vs. high) & IOR & $1.19(0.62-2.28)^{*} / 22$ & & \\
\hline \multicolumn{5}{|l|}{ Organizational factors } \\
\hline Overcommitment (no 0; yes 1) & & & IOR & $1.15(1.03-1.29)^{*} / 21$ \\
\hline Unemployment (no 0; yes 1) & IOR & $1.58(1.36-1.84) t^{2} / 25$ & IOR & $0.72(0.53-0.97) \dagger^{2} / 25$ \\
\hline Reorganization (no 0; yes 1) & IOR & $1.09(1.02-1.18)^{*} / 23$ & SOR & $1.25(0.94-1.68) t^{3,4} / 21,23,31$ \\
\hline Company size (<10 vs. >100) & $\mathrm{IOR}$ & $2.52(1.19-5.37)^{*} / 19$ & & \\
\hline
\end{tabular}

* Fixed effects modelling; † Random effects modelling; ${ }^{0}$ No statistically significant effect of included parameters; ${ }^{1}$ Statistically significant effect of geographical area; ${ }^{2}$ Statistically significant effect of measures; ${ }^{3}$ Statistically significant effect of follow-up time; ${ }^{4}$ Statistically significant effect of minimum duration of sick leave. $¥$ Adjusted summary effects were estimated using the most complete models, i.e. all models were adjusted for demographic factors. Additional factors included in these associations were behavioural risks, health status, occupation and baseline sickness absence. 
Intrastudy and summary odds ratios attained by random effect pooling in which 'measures of predictive factors' were a reason for heterogeneity, and in which no statistical effect of the parameters could be found, were further explored. As regards health related factors, the observed heterogeneity in the adjusted odds ratio of psychosomatic complaints and occurrence of sick leave $\leq 3$ days could be explained by the pooling of self-rated health and diagnosed illness. Separate pooling of these odds ratios resulted in 1.66 (1.45-1.91) and 1.25 (1.12-1.39), respectively. Also, a contrast is found in the results of physical exercise when looking at occurrence of sick leave $>3$ days. Pooling men and women separately might solve the observed heterogeneity in the crude association, resulting in 1.47 (1.32-1.59) and 1.18 (1.11-1.28), respectively. Regarding psychosocial work factors, the heterogeneity in the crude odds ratio of job control and occurrence of sick leave $>3$ days could be explained, since one of the included studies examined both self-rated and organizational rated job control in both men and women. Excluding this study from the overall pooling reveals an odds ratio of 1.25 (1.10-1.41). Similarly, the heterogeneity in the crude association between psychological job demands and occurrence of sick leave $\leq 3$ days can be attributed to the pooling of both self-reported and external reported job demands. Separate pooling of these odds ratios resulted in 0.97 (0.89-1.06) and 0.56 (0.48-0.66), respectively. The heterogeneity in the crude odds ratio of need for recovery and occurrence of sick leave $>3$ days could be explained by the pooling of two different classifications of need for recovery, specifically low versus medium and low versus high need for recovery. Separate pooling of these odds ratios resulted in 1.21 (0.64-2.30) and 2.42 (2.382.46), respectively. Of the remaining randomly pooled odds ratios, no specific reason of the observed heterogeneity could be found (Table 2 and 3 ). 


\section{Discussion}

\section{General findings}

In this meta-analysis, a thorough summary of studies exploring predictive factors for sickness absence due to psychosocial health complaints is given. Two-third of the presented effect sizes could be determined using fixed effect pooling, i.e. differences in study characteristics did not significantly influence the outcomes. In approximately $60 \%$ of the randomly determined effect sizes, possible explanations for heterogeneity could be revealed. The main results indicate that being unmarried, experiencing psychosomatic complaints, using medication, having a burnout, suffering from psychological problems, having low job control, having low decision latitude and experiencing no fairness at work are significant predictors for occurrence of sick leave, both uncertified short spells ( $\leq 3$ days) and certified sick leaves (> 3 days). Given the comprehensiveness of our analysis, we are unable to give a complete review of all predictive associations within the limits of this paper. We will however discuss the rationale of using psychosocial health complaints as a cause of sickness absence, interpret some noteworthy outcomes, present limitations, and give recommendations for clinicians and policymakers.

\section{Psychosocial health complaints}

This meta-analysis attempted to focus on studies regarding predictors of sickness absence due to psychosocial health complaints, rather than studies related to allcauses sickness absence. Though, not a single study uses the definition 'psychosocial health complaints' to label their main outcome. The rationale for still performing this meta-analysis concerns the necessity of early identifying employees at risk for this specific type of sickness absence, since they encounter more difficulties in returning to the workplace then other absentees. Also, the time period necessary to develop psychosocial health complaints of such a level that a rather healthy employee is unable to work differs from the necessary time period employees with somatic problems, such as musculoskeletal, cardiovascular or respiratory complaints, encounter. Herewith, there might be a significant difference between predictive factors for sickness absence due to psychosocial health complaints and those found in employees at risk for sickness absence due to abovementioned conditions. As a result of the exclusion of studies on predictors of sickness absence due to explicit somatic conditions, the probability of including studies with primarily 'psychological' and 'social' causes in apparently healthy employees increases. Even though the exclusion of all causes sick- 
ness absence studies can not be guaranteed, the homogeneity of the remaining set of studies improves. This selection method might be considered as erroneous, but is thought to be the most optimal manner to retrieve studies on the association between predictive factors and sickness absence due to psychosocial health complaints.

\section{Interpretation of findings}

As regards demographic factors, a slightly increased, but statistically insignificant and inconclusive summary odds ratio in the fixed effect pooling of age and occurrence of sick leave was found in this meta-analysis. This could be a consequence of the dissimilarity in the association. On the one hand, the incidence of sickness absence and the number of absences per person are highest among young workers. On the other hand, a positive correlation between age and the presence of chronic diseases, and consequently sickness absence, exists.34 A decreased insignificant crude odds ratio was found on the association between sex and sickness absence due to psychosocial health complaints. This might seem counter intuitive, since women have a higher rate of absence and more days of sickness absence than men. ${ }^{26}$ However, the effect was insignificant. So, no conclusions can be drawn from this result. Regarding health related factors, risk behaviours such as smoking, high alcohol use and high BMI are wellknown predictors of sickness absence. 35 Notwithstanding a few insignificant odds ratios, the results of this meta-analysis support this hypothesis, i.e. these behaviours are significantly predictive for both occurrence of sick leave $\leq 3$ days and occurrence of sick leave > 3 days. Mental health problems, such as fatigue, burnout and psychological problems, are main causes of extended sick leaves from work. Specifically, the results of this meta-analysis demonstrate statistically significant increased effects on sickness absence due to psychosocial health complaints. There as several reasons why, for example, fatigue may be an important predictive factor for this type of sickness absence. Firstly, there is a high prevalence of fatigued cases in the working population. Secondly, the fatigue state was found to be rather robust. Thirdly, fatigue can be a disabling condition. Finally, fatigue is an important symptom of psychosocial health complaints. ${ }^{1}$ To continue with psychosocial work factors, both statistically significant and insignificant results are found, mostly in the expected direction. A slightly decreased, but statistically insignificant odds ratio of work time control (high vs. low) is found in the fixed effect pooling of this predictive factor and occurrence of sick leave $\leq 3$ days. The results on occurrence of sick leave $>3$ days are significant and in the opposite, expected direction. These findings are supported by a recent meta- 
analysis suggesting that flex time scheduling, providing employees with control over the starting and ending times of a workday, is associated with lower absenteeism. ${ }^{6}$ In addition, sickness absence due to psychosocial health complaints is associated with job strain which results from the combination of high psychological demands and low decision latitude at work.37 The results of this meta-analysis support this theory. As regards personal factors, a large body of research suggests that there is a link between stressful life events and sickness absence. 35 Such life events are a potential source of psychological problems (e.g. anxiety, mental distress, low sense of coherence), and in this meta-analysis significantly predictive for occurrence of sick leave $\leq$ 3 days. To conclude with organizational factors, increased statistically significant results are found for excessive commitment, reorganization and company size. These predictive factors for sickness absence have received little research attention. 38 However, an empirical study on the longitudinal effect of organization size on absenteeism found that as the companies grew in size, absence became higher.39 The results of this meta-analysis are in line with these previous findings.

\section{Limitations}

Although we have made an accurate summary of predictive factors for sickness absence due to psychosocial health complaints, there still remain limitations that merit discussion. Sickness absence has a multifactor aetiology and numerous factors have proved to be associated with sickness absence. ${ }^{2}$ Consequently, comprehensiveness of a meta-analysis is difficult to reach and is subject to the existence of heterogeneity. It was not possible to infer a homogeneous association between all the predictive factors and this specific type of sickness absence. Further, some selected studies in this meta-analysis are based on the same population sample. Still, we decided to include those related studies since they present predictive factors that differ from each other to such an extent that entering these separate studies in the meta-analysis is considered necessary. For example, two studies are based on the Whitehall II cohort 28, 29, of which one sought to examine the association between psychosocial work environment and rates of sickness absence. Specifically, the predictive factors job control, job demands and social support were examined in this study. As regards 'social support', the role of clerical and office support were subjects of interest. The other study investigated the predictive factors social support and material problems. In particular, this study was aimed at three types of support, i.e. confiding/ emotional, practical and negative aspects of support. Despite the fact that the same sample was used, independent associations between specific predictive factors and sickness 
absence were investigated. These associations individually contribute to the results of this meta-analysis, and were therefore essential for inclusion. However, a distinction was made between related studies with different predictive factors, which are used in different sections of the meta-analysis, and related studies with different follow-up times or other parameter estimates. These studies were combined before inclusion in the meta-analysis. In definitions of meta-analysis, results can be pooled if at least two studies reported data on the relation between a specific predictive factor and sickness absence due to psychosocial health complaints. Nevertheless, many results of this meta-analysis appear to be based on one study only. To be complete, we decided to present intrastudy odds ratios when different categories or strata of a specific predictive factor for sickness absence could be pooled. The number of references in tables two and three, and the addition IOR or SOR, indicate on how many studies a pooled result is based, and consequently how to interpret these findings. Furthermore, all studies in this meta-analysis were prospective cohort studies. By predicting sickness absence due to psychosocial health complaints in a population of employees who were not on sick leave at the time of the measurement of the predictors, we tried to make the causal direction of predictive factors on sickness absence more plausible. Nevertheless, the possibility of bi-directional or solely reverse causation cannot be ruled out. ${ }^{18}$ This is because part of the relationship between predictive factors and sickness absence may still be explained by a crosssectional relationship at baseline between specific predictive factors and sickness absence history. ${ }^{1}$ Further, this meta-analysis only included studies that provided sufficient data to (re)calculate an odds ratio and its corresponding standard error on the association between particular predictive factors and sickness absence due to psychosocial health complaints. Inclusion of studies presenting correlations was considered, so as to calculate an average measure on the association. However, the correlation is not a valid measure of relationships in absence data, since they do not follow a normal distribution. Consequently, the number of studies eligible for inclusion was reduced. Also, we have made the choice to use a threshold of three days to distinguish medically uncertified and certified sickness absence. We consider the variety between studies being dealt with through inclusion of the study characteristic 'minimum duration of sick leave' in the sensitivity analyses. In addition, health status can be considered as an intermediate variable in the causal pathway leading to sickness absence. As a consequence, the inclusion of health may be questionable as a predictive factor. However, only studies which directly assessed the causal pathway between (mental) health and sickness absence due to psychosocial health complaints 
were included in this meta-analysis. In the results section, presentation of the findings was limited to the adjusted odds ratios, whereas both crude and adjusted outcomes were presented in the tables. These overall findings were presented to signify the effect of confounding factors, for which necessarily was corrected. Moreover, the assessment of qualitative items by two reviewers resulted in the identification of some study characteristics to be included in the sensitivity analyses. The major possibility of fixed effect pooling and the recognition of reasons for heterogeneity in several randomly pooled effect sizes demonstrated that differences between studies, in terms of e.g. measurements of sickness absence and population characteristics, were controlled for. Finally, we did not attempt to uncover unpublished observations and excluded studies that did not meet the predetermined criteria. Publication bias, which we have not statistically or visually identified, might arise by excluding these studies.

\section{Recommendations and conclusion}

Predictors of sickness absence due to psychosocial health complaints can be identified in a homogeneous manner. Though, the exclusion of all-causes sickness absence studies could not be guaranteed. Still, the findings provide imperative leads to public health interventions, to successfully improve psychosocial health and to reduce sickness absence. For instance, clinicians and policymakers should support exercising and reduce job strain to affect occurrence of sick leave $\leq 3$ days, and pay attention to alcohol use and the extent of unemployment in the community to influence occurrence of sick leave $>3$ days. Consideration of a large number of these factors could possibly reduce the economic and social impact, and modify the public health consequences of sickness absence due to psychosocial health complaints. 


\section{References}

1 Janssen N, Kant I, Swaen GMH, Janssen PPM, Schröer CAP. Fatigue as a predictor of sickness absence: results from the Maastricht cohort study on fatigue at work. Occup Environ Med 2003;60(Suppl 1):i71-6.

2 Niedhammer I, Bugel I, Goldberg M, Leclerc A, Gueguen A. Psychosocial factors at work and sickness absence in the Gazel cohort: a prospective study. Occup Environ Med 1998;55(11):73541.

3 Kristensen TS. Sickness absence and work strain among Danish slaughterhouse workers: An analysis of absence from work regarded as coping behaviour. Soc Sci Med 1991;32(1):15-27.

4 Savikko A, Alexanderson K, Hensing G. Do mental health problems increase sickness absence due to other diseases? Soc Psychiatry Psychiatr Epidemiol 2001;36(6):310-6.

5 Alexanderson K. Sickness absence: a review of performed studies with focused on levels of exposures and theories utilized. Scand J Soc Med 1998;26(4):241-9.

6 Luz J, Green MS. Sickness absenteeism from work - a critical review of the literature. Public Health Rev 1997;25(2):89-122.

7 Duijts SFA, Kant I, Landeweerd JA, Swaen GMH. Prediction of sickness absence: the development of a screening instrument. Occup and Environ Med 2006;63:564-569.

8 Schaufeli WB, Kompier MA. Managing job stress in the Netherlands. International Journal of Stress Management 2001;8:15-34.

9 Borritz M, Rugulies R, Christensen KB, Villadsen E, Kristensen TS. Burnout as a predictor of selfreported sickness absence among human service workers: prospective findings from three year follow up of the PUMA study. Occup Environ Med 2006;63(2):98-106.

10 Kant I, Bultmann U, Schroer C, Beurskens A, Amelsvoort Lv, Swaen G. An epidemiological approach to study fatigue in the working population: The maastricht cohort study. Occup Environ Med 2003;60(supl 1):i32-i39.

11 Hensing G, Alexanderson K, Allebeck P, Bjurulf P. How to measure sickness absence? Literature review and suggestion of five basic measures. Scand J Soc Med 1998;26(2):133-44.

12 Tan FE, Zeegers MP. An asymptotically unbiased estimator of exposed versus non-exposed odds ratio from reported dose-response data. Stat Methods Med Res 2001;10:311-23.

13 Zeegers MP, Jellema A, Ostrer H. Empiric risk of prostate carcinoma for relatives of patients with prostate carcinoma: a meta-analysis. Cancer 2003;97(8):1894-903.

14 Stata. Stata Statistical Software: Release 9.o. In: College station, TX: Stata Corporation; 2005.

15 Brockwell SE, Gordon IR. A comparison of statistical methods for meta-analysis. Stat Med 2001;20(6):825-40.

16 Ala-Mursula L, Vahtera J, Kivimaki M, Kevin MV, Pentti J. Employee control over working times: 
associations with subjective health and sickness absences. J Epidemiol Community Health 2002;56(4):272-8.

17 Andrea H, Beurskens AJHM, Metsemakers JFM, van Amelsvoort LGPM, van den Brandt PA, van Schayck CP. Health problems and psychosocial workenvironment as predictors of longterm sickness absence. Occup Environ Med 2003;60:295-300.

18 Bourbonnais R, Mondor M. Job strain and sickness absence among nurses in the province of Quebec. Am J Ind Med 2001;39(2):194-202.

19 De Croon EM, Sluiter JK, Frings-Dresen MHW. Need for recovery after work predicts sickness absence: A 2-years prospective cohort study in truck drivers. J Psychosom Res 2003;55:331-339. Eriksen W, Bruusgaard D, Knardahl S. Work factors as predictors of sickness absence: a three month prospective study of nurses' aides. Occup Environ Med 2003;60:271-8.

21 Godin I, Kittel F. Differential economic stability and psychosocial stress at work: associations with psychosomatic complaints and absenteeism. Soc Sci Med 2004;58(8):1543-53. Hammer TH, Landau JC, Stern RN. Absenteeism when workers have a voice: the case of employee ownership. Journal of Applied Psychology 1981;66:561-573. Kivimaki M, Elovainio M, Vahtera J. Workplace bullying and sickness absence in hospital staff. Occup Environ Med 2000;57(10):656-60.

24 Kivimaki M, Sutinen R, Vahtera J, Räsänen K, Töyry S, Ferrie JE, et al. Sickness absence in hospital physicians: 2 year follow up study on determinants. Occup Environ Med 2001;58:361-366.

25 Knutsson A, Goine H. Occupation and unemployment rates as predictors of long term sickness absence in two Swedish counties. Soc Sci Med 1998;47(1):25-31.

26 Krantz G, Ostergren PO. Do common symptoms in women predict long spells of sickness absence? A prospective community-based study on Swedish women 40 to 50 years of age. Scand J Public Health 2002;30(3):176-83.

27 Melchior M, Niedhammer I, Berkman LF, Goldberg M. Do psychosocial work factors and social relations exert independent effects on sickness absence? A six year prospective study of the GAZEL cohort. J Epidemiol Community Health 2003;57(4):285-93.

28 North FM, Syme SL, Feeney A, Shipley M, Marmot M. Psychosocial work environment and sickness absence among British civil servants: the Whitehall II study. Am J Public Health 1996;86(3):332-40.

29 Rael EG, Stansfeld SA, Shipley M, Head J, Feeney A, Marmot M. Sickness absence in the Whitehall II study, London: the role of social support and material problems. J Epidemiol Community Health 1995;49(5):474-81.

30 Vaananen A, Toppinen-Tanner S, Kalimo R, Mutanen P, Vahtera J, Peiro JM. Job characteristics, physical and psychological symptoms, and social support as antecedents of sickness absence among men and women in the private industrial sector. Soc Sci Med 2003;57(5):807-24. 
31 Vaananen A, Kalimo R, Toppinen-Tanner S, Mutanen P, Peiro JM, Kivimaki M, et al. Role clarity, fairness, and organizational climate as predictors of sickness absence: a prospective study in the private sector. Scand J Public Health 2004;32(6):426-34.

32 Vahtera J, Penti J, Kivimaki M. Sickness absence as a predictor of mortality among male and female employees. J Epidemiol Community Health 2004;58:321-6.

33 Verhaeghe R, Mak R, Maele Gv, Kornitzer M, Backer Gd. Job stress among middle-aged health care workers and its relation to sickness absence. Stress and Health 2003;19:265-274.

34 Steers RM, Rhodes SR. Knowledge and speculation about absenteeism. San Fransisco: JosseyBass; 1984.

35 Kivimaki M, Vahtera J, Elovainio M, Lillrank B, Kevin MV. Death or illness of a family member, violence, interpersonal conflict, and financial difficulties as predictors of sickness absence: longitudinal cohort study on psychological and behavioral links. Psychosom Med 2002;64(5):817-25.

36 Baltes B, Briggs TE, Huff JW. Flexible and compressed workweek schedules: a meta-analysis of their effects on work-related criteria. Journal of Applied Psychology 1999;84:496-513.

37 Karasek R, Theorell T. Healthy work: stress, productivity and the reconstruction of working life. New York: Basic Books; 1990.

38 Markham SE. Declining organizational size and increasing unemployment rates: predicting employee absenteeism from within- and between plant perspectives. Academy of Management Journal 1991;34:952-965.

39 Allen PT. Size of workforce, morale and absenteeism: a re-examination. British Journal of Industrial Relations 1982;20:83-100. 



\section{PREDICTION OF SICKNESS ABSENCE: \\ THE DEVELOPMENT OF A SCREENING INSTRUMENT}

Saskia FA Duijts ${ }^{1}$

IJmert Kant ${ }^{1}$

Jan A Landeweerd ${ }^{2}$

Gerard MH Swaen ${ }^{1,3}$

1 Department of Epidemiology, Maastricht University, Maastricht, The Netherlands

2 Department of Health Organization, Policy and Economics, Maastricht University, The Netherlands

3 Dow Chemical Terneuzen, Terneuzen, The Netherlands 


\section{Abstract}

\section{Objectives}

To develop a concise screening instrument for early identification of employees at risk for sickness absence due to psychosocial health complaints.

\section{Methods}

Data from the Maastricht Cohort Study on 'Fatigue at Work' were used to identify items to be associated with an increased risk of sickness absence. The analytic procedures univariate logistic regression, backward stepwise linear regression and multiple logistic regression were successively applied. For both men and women, sum scores were calculated, and sensitivity and specificity rates of different cut-off points on the screening instrument were defined.

\section{Results}

In women, results suggested that feeling depressed, having a burnout, being tired, being less interested in work, experiencing obligatory change in working days, and living alone, were strong predictors of sickness absence due to psychosocial health complaints. In men, statistically significant predictors were having a history of sickness absence, compulsive thinking, being mentally fatigued, finding it hard to relax, lack of supervisor support, and having no hobbies. A potential cut-off point of 10 on the screening instrument resulted in a sensitivity score of $41.7 \%$ for women and $38.9 \%$ for men, and a specificity score of $91.3 \%$ for women and $90.6 \%$ for men.

\section{Conclusions}

This study shows that it is possible to identify predictive factors for sickness absence and to develop an instrument for early identification of employees at risk for sickness absence. The results of this study increase the possibility for both employers and policymakers to implement interventions directed at the prevention of sickness absence. 


\section{INTRODUCTION}

In many countries throughout the Western world, psychosocial health complaints, such as depression, fatigue, stress and work family conflicts, represent important causes of sickness absence and disability. ${ }^{1,2}$ Once at home on sick leave due to these complaints, employees encounter difficulties in returning back into the workplace. $3 \mathrm{~A}$ better and more effective strategy would be early identification of employees at risk for sickness absence. For this reason, it is imperative to recognise predictive factors in order to screen employees, and subsequently to prevent sickness absence as much as possible through early intervention. 4 Numerous epidemiological studies have investigated factors such as sociodemographic factors, health and mental health, psychosocial work factors, personal factors and organizational factors, to be predictive of sickness absence. 5 The most consistent results within sociodemographic factors have been reported for age, which tends to be negatively related to sickness absence, and for gender - women have a higher rate of absence and more days of absenteeism than men. With regard to health and mental health factors, increased risks have been found for psychosomatic complaints, medication use, burnout and psychological problems on sickness absence. Studies examining the relation between psychosocial work factors and sickness absence have found that sickness absence is related to low job control and low decision latitude, and that there is evidence relating to aspects such as psychological job demands, job strain, job satisfaction and need for recovery. Studies that address the effect of personal factors on sickness absence suggest that stressful events in one's private life may relate to ill health, and thus to sickness absence. With regard to organizational factors, epidemiological studies predominantly report the consequences of prior absence on future sickness absence. 5 Taking these predictive factors into consideration, there are a number of options for looking at the management and prevention of sickness absence, which can be termed as primary, secondary and tertiary levels of intervention. ${ }^{6}$ Primary interventions focus on prevention among people who are not immediately at risk for sickness absence; secondary interventions focus on people who are suspected to be at risk for sickness absence or who are already frequently on sick leave; and tertiary interventions focus on those who are on sick leave, to prevent further deterioration of their wellbeing.7 From a public and preventive medicine perspective, primary prevention is generally regarded as the ideal point of intervention, ${ }^{8}$ with the exception of circumstances in which primary prevention is not possible or individual factors create health concerns for only some people. 9 When clearly identifiable predictive factors are present, pref- 
erence may be given to individual interventions with a secondary preventive emphasis. ${ }^{10}$ However, to bring secondary preventive measures within the occupational health field into practice, the combination of these identified predictive factors in a screening instrument would be usable. Regardless of the numerous studies into particular predictive factors of sickness absence, only few studies investigated the association between a range of predictive factors and sickness absence, but no study combined them in a screening instrument for early identification. The objectives of this study were to identify a set of predictive factors, using the data from the Maastricht Cohort Study on 'Fatigue at Work', to develop a concise screening instrument for early identification of employees at risk for sickness absence due to psychosocial health complaints, and to test its basic measures. 


\section{METHODS}

\section{Maastricht Cohort Study}

The Maastricht Cohort Study on 'Fatigue at Work' is a prospective study on a sample of 12,140 workers, employed by 45 different organisations, mostly located in the southern part of the Netherlands.11, 12 The heterogeneous group of employees represented a variety of jobs and educational levels, and a range of economic sectors and trades. Included were employees between the ages of 18 and 65 years (mean age 41.0 years). At baseline, $73,1 \%$ of the study population were men, $17,6 \%$ were government employees, $15,0 \%$ were employees from healthcare institutes, $50,4 \%$ of the employees worked in industry, and $17,0 \%$ were in services. The cohort study started in May 1998 and covers a period of three years, in which the participants received several selfadministered questionnaires. 13 The primary goal of the Maastricht Cohort Study was to identify risk factors involved in the aetiology and natural course of prolonged fatigue in the working population and to develop preventive measures and treatments, that can be used in occupational health settings. ${ }^{14}$

\section{Study population}

For development of the screening instrument, we have used the data from the Maastricht Cohort Study on employees who have completed and returned both the self-administered baseline questionnaire in May 1998 and the extensive one year follow up questionnaire in May 1999. This resulted in data on 9,655 workers. Employees were excluded from participation if they were fully or partially on sick leave ( $N=592)$, because of the potentially biased perception of the work situation of sick listed employees ${ }^{15,16}$ and because of the secondary preventive emphasis of this study. Secondly, employees who reported suffering from chronic psychosocial health complaints at baseline $(\mathrm{N}=279)$ were excluded. Including these employees would subvert the underlying principle of focusing on healthy employees who are 'at risk' for future sickness absence due to psychosocial health complaints. Thirdly, employees with more than one contract $(\mathrm{N}=385)$ were excluded. The need or the motivation to report sick in one job may lead to the systematic actual initiation of sickness absence in the other job. ${ }^{17}$ Finally, women who were pregnant or on maternity leave $(N=188)$ were excluded from participation. After application of these exclusion criteria, 8,211 cohort participants were available for analyses. 
For validation of the screening instrument, we used data from employees who completed and returned both the one year follow up questionnaire in May 1999 and the extensive two year follow up questionnaire in May $2000(\mathrm{~N}=7,975)$. After applying the above exclusion criteria, data on 6,780 employees were found to be suitable for analyses. The employees who responded to the questionnaires used for development of the screening instrument did not differ in gender, age distribution, and educational level from the employees who responded to the questionnaires used for validation of the screening instrument.

\section{Measures}

Sociodemographic and health related factors

Sociodemographic factors include age, sex, educational level, and variables concerning the private and financial situation, such as living conditions, care for children, leisure activities, and home help. The several questionnaires of the Maastricht Cohort Study also included questions about the presence of long term diseases, such as heart problems, stroke, cancer, diabetes, musculoskeletal problems, and chronic psychosocial problems. Self-rated health was assessed with one item from the Short Form Health Survey (SF-36) ${ }^{18}$, which is a widely used measure of general health status. ${ }^{19}$ The general health status item was scored on a five point scale $(1=$ excellent health, $2=$ very good health, $3=$ good health, $4=$ moderate health, $5=$ bad health).

\section{Mental health factors}

Fatigue was assessed with the 20 item self-reported Checklist Individual Strength (CIS). ${ }^{20,} 21$ The CIS covers several aspects of fatigue, such as severity (eight items), concentration (five items), motivation (four items) and physical activity (three items). The response on each item is scored on a seven point Likert scale ( $1=$ yes, that is true to 7 $=$ no, that is not true). Higher scores on these subscales indicate a higher degree of fatigue, more concentration problems, reduced motivation, or a lower level of physical activity. Burnout was assessed with the three subscales of the Dutch version of the Maslach Burnout Inventory-General Survey (MBI-GS)22, 23: exhaustion (five items), cynicism (five items) and professional efficacy (six items). All items are scored on a seven point frequency scale, ranging from o (never) to 6 (daily). High scores of exhaustion and cynicism and low scores on professional efficacy are indicative for burnout. Need for recovery was measured with a scale, derived from the Dutch Questionnaire on the Perception and Judgment of Work (VBBA).24, 25 The scale contains 11 dichotomous items, concerning the recuperation period after one day of work, 
for example 'it is difficult for me to relax at the end of a work day'. Higher scores on this scale indicate more complaints, i.e. a higher need for recovery. Furthermore, participants were asked to indicate if they had suffered from fatigue complaints in the preceding four months (yes or no) and if so, whether they felt that the cause of these complaints was psychological (yes or no), somatic (yes or no), or of an unknown nature (yes or no). Psychological distress was assessed with a Dutch version of the 12 item General Health Questionnaire (GHO-12).26, 27 The GHO-12 was developed as a screening instrument for detecting minor psychiatric disorders and contains items such as 'unhappy and depressed' and 'losing confidence in self'. A higher score on this four point scale indicates a higher level of psychological distress. Anxious mood was assessed with three items on anxiety: excessive worrying, compulsive behavior and compulsive thinking. A higher score indicates a higher level of anxious mood. ${ }^{28}$

\section{Psychosocial work factors and organizational factors}

Psychosocial work characteristics were measured with five subscales of a validated Dutch version of the Job Content Questionnaire (JCO)29, 30: psychological job demands (five items), skill discretion (six items), decision authority (three items), coworker social support (four items), and supervisor social support (four items). The response options for each item varied on a four point scale from 'strongly disagree' to 'strongly agree'. Participants were also asked to indicate whether they experienced conflicts with colleagues (yes or no) or conflicts with supervisors (yes or no). Additional data on organizational characteristics, such as 'working hours', and perception of work, such as 'commitment', 'job satisfaction', 'job security', 'physical and emotional demands', 'effort-reward imbalance', and 'role ambiguity', were gathered with the Dutch Questionnaire on the Perception and Judgment of Work (VBBA). ${ }^{24,25}$

\section{Sickness absence}

Data on sickness absence due to psychosocial health complaints were inventoried in the two extensive follow up questionnaires (May 1999 and May 2000). In both questionnaires, participants were asked to report the frequency of sickness absence in the previous four months, given the six possibilities: (1) never, (2) one time, (3) two times, (4) three times, (5) four times, (6) five times or more. In case of at least one ill report, they were asked to give information about the reason of their latest sick leave. A code has been allotted, in accordance with the International Classification of Primary Care (ICPC), to the reasons employees have given for their latest sickness absence. The following ICPC codes were used to identify employees who reported sick as a result of 
psychosocial health complaints: A04, P01-P26, P76, P78, Z01-Z29. Both short term and long term absence spells were included. Frequency and duration of self-reported sickness absence data were compared with available objective sickness absence data from company records to preclude self-report bias. ${ }^{31}$ Within these objective sickness absence data, no reasons or diagnoses for sick leave were present.

\section{Statistical analysis}

All analyses were performed separately for men and women, since females are more susceptible to sickness absence than men.32-36 Employees who reported sickness absence due to psychosocial health problems were compared with employees who did not report this form of sickness absence. Firstly, logistic regression analysis was used to examine the effect of each particular item at baseline on sickness absence after one year. All significant items in these univariate analyses ( $\chi^{2}$ test; $p<0.05$ ), complemented by a set of substantive variables as listed in literature, were selected. Secondly, backward stepwise linear regression analysis $(p<0.10)$ was used to further reduce items to be associated with a higher risk of sickness absence. Thirdly, multiple logistic regression analysis was conducted to determine unstandardised regression coefficients and their standard errors. Fourthly, sum scores of individual employees were computed by multiplying and adding up the unstandardised regression coefficients with the scores on the significant items. Finally, a receiver operator characteristic (ROC) analysis was performed to define both sensitivity and specificity, and to determine the screening instruments' most adequate cut-off point for sickness absence. The last two steps of the development of the screening instrument were repeated in order to achieve internal validation of the instrument. All statistical analyses were conducted using the Statistical Package for Social Sciences (SPSS) version 11.0 .37 


\section{REsULts}

\section{Selection step 1}

Univariate logistic regression analyses were used for the first selection of baseline items, with an effect on sickness absence due to psychosocial health complaints after one year. The analyses resulted in an extensive list for both men and women. The most important statistically significant factors were related to 'health', 'mental health' and 'psychosocial work characteristics'. For both men and women, the list was complemented by a set of substantive items, such as factors concerning the 'private situation' (data not shown).

\section{Selection step 2}

Backward stepwise linear regression analysis was used as second selection step for the reduction of items to be associated with a higher risk of sickness absence. The statistical analysis resulted in a final enumeration of items, for both men and women, associated with sickness absence due to psychosocial health complaints. Table 1a and $1 \mathrm{~b}$ show the relation between these specific predictive factors and the incidence proportion of sickness absence, as well as a presentation of corresponding odds ratios. In men (Table 1a), the following were significant predictors of sickness absence due to psychosocial health complaints: general health factors, such as having a history of sickness absence; mental health factors, such as compulsive thinking, being mentally fatigued, and finding it hard to relax at the end of a working day (VBBA); work related factors, such as lack of supervisor support (JCO); and factors concerning their private situation, such as having no hobbies. In women (Table 16 ), the following were strong predictors: general health factors, such as feeling unhappy and depressed (GHO-12); mental health factors, such as having a burnout, being tired when facing another day and being less interested in work (MBI-GS); work related factors, such as going through an obligatory change in working days and experiencing conflicts with colleagues (VBBA); and factors concerning their private situation, such as living alone (Table $1 a$ and $1 b)$. 


\section{Table 1a}

Odds ratios $(\mathrm{OR})$, corresponding confidence intervals and incidence proportion (I) of identified predictive factors and sickness absence due to psychosocial health complaints (men)

\begin{tabular}{|c|c|c|c|}
\hline General health factors & & OR & $I(\%)$ \\
\hline \multirow[t]{3}{*}{ Prior absence } & no vs. one time & $1.95(1.34-2.84)^{*}$ & 3.1 \\
\hline & no vs. two times & $3.32(1.81-6.10)^{*}$ & 5.1 \\
\hline & no vs. three times & $4.43(1.34-14.65)^{*}$ & 6.7 \\
\hline \multicolumn{2}{|l|}{ Mental health factors } & $\mathrm{OR}$ & $1(\%)$ \\
\hline Hard to relax after working day & no vs. yes & $2.91(2.06-4.12)^{*}$ & 4.2 \\
\hline Feeling exhausted after working day & no vs. yes & $2.65(1.83-3.83)^{*}$ & 3.3 \\
\hline Trouble concentrating after working day & no vs. yes & $2.51(1.77-3.57)^{*}$ & 4.0 \\
\hline \multirow[t]{3}{*}{ Compulsive thinking } & never vs. sometimes & $2.32(1.46-3.67)^{*}$ & 2.4 \\
\hline & never vs. often & $4.72(2.73-8.16)^{*}$ & 4.7 \\
\hline & never vs. always & $5.72(2.14-15.31)^{*}$ & 5.7 \\
\hline Being mentally fatigued & no vs. yes & $2.79(1.97-3.95)^{*}$ & 4.1 \\
\hline \multicolumn{2}{|l|}{ Work related factors } & $\mathrm{OR}$ & $I(\%)$ \\
\hline Being familiar with responsibilities & yes vs. no & $1.77(0.99-3.15)$ & 1.3 \\
\hline \multirow[t]{3}{*}{ Receiving support from supervisor } & fully agree vs. agree & $1.20(0.55-2.63)$ & 1.6 \\
\hline & fully agree vs. disagree & $2.80(1.26-6.24)^{*}$ & 3.7 \\
\hline & fully agree vs. fully disagree & $3.66(1.44-9.29)^{*}$ & 4.8 \\
\hline \multirow[t]{2}{*}{ In case of problems at work, going to } & family doctor( no vs. yes) & $2.76(1.69-4.50)^{*}$ & 5.2 \\
\hline & social worker ( no vs. yes) & $2.81(1.56-5.06)^{*}$ & 5.5 \\
\hline Experienced shocking things at work & no vs. yes & $2.49(1.11-5.60)^{*}$ & 6.7 \\
\hline Finding salary of colleagues reasonable & yes vs. no & $2.09(1.37-3.20)^{*}$ & 3.2 \\
\hline \multicolumn{2}{|l|}{ Private factors } & $\mathrm{OR}$ & $I(\%)$ \\
\hline Being satisfied with financial situation & yes vs. no & $2.42(1.68-3.49)^{*}$ & 4.1 \\
\hline Living together with partner & no vs. yes & $2.31(1.13-4.74)^{*}$ & 2.3 \\
\hline Doing small jobs in leisure time & yes vs. no & $1.62(1.14-2.31)^{*}$ & 3.0 \\
\hline Having hobbies in leisure time & yes vs. no & $2.37(1.39-4.06)^{*}$ & 4.7 \\
\hline Following additional education for the job & no vs. yes & $1.85(1.05-3.25)^{*}$ & 3.7 \\
\hline
\end{tabular}

${ }^{*} p<0.05$

\section{Selection step 3 and 4}

Multiple logistic regression analysis was used as third selection step to determine the unstandardised regression coefficients (B) and their corresponding standard errors (SE B) of the identified items. Subsequently, sum scores were computed for both men (range -7.69 to 0.40 ) and women (range -6.11 to 0.01 ) by multiplying and adding up the unstandardized regression coefficients with the scores on the significant items. 


\section{Table 1b}

Odds ratios (OR), corresponding confidence intervals and incidence proportion (I) of identified predictive factors and sickness absence due to psychosocial health complaints (women)

\begin{tabular}{|c|c|c|c|}
\hline \multicolumn{2}{|l|}{ General health factors } & \multirow{2}{*}{$\frac{\mathrm{OR}}{1.56(1.01-2.42)^{*}}$} & \multirow{2}{*}{$\frac{1(\%)}{5.1}$} \\
\hline Repetitive movements & no vs. yes & & \\
\hline Mental health factors & & $\mathrm{OR}$ & $I(\%)$ \\
\hline \multirow[t]{2}{*}{ Being shy amongst others } & never vs. sometimes & $0.57(0.36-0.91)^{*}$ & 3.3 \\
\hline & never vs. often & $0.94(0.32-2.76)$ & 5.4 \\
\hline Being mentally fatigued & no vs. yes & $2.79(1.80-4.33)^{*}$ & 7.2 \\
\hline \multirow[t]{5}{*}{ Tired facing another day } & never vs. seldom & $3.18(1.31-7.73)^{*}$ & 4.6 \\
\hline & never vs. regular & $8.59(3.36-21.93)^{*}$ & 11.5 \\
\hline & never vs. often & $3.57(0.98-12.96)$ & 5.1 \\
\hline & never vs. very frequent & $6.60(1.94-22.44)^{*}$ & 9.1 \\
\hline & never vs. daily & $5.50(1.95-15.55)^{*}$ & 7.7 \\
\hline \multirow[t]{4}{*}{ Burned out } & never vs. seldom & $2.34(1.12-4.88)^{*}$ & 4.5 \\
\hline & never vs. regular & $2.87(1.17-7.01)^{*}$ & 5.5 \\
\hline & never vs. often & $6.04(2.38-15.36)^{*}$ & 10.8 \\
\hline & never vs. very frequent & $8.44(3.28-21.69)^{*}$ & 14.5 \\
\hline \multirow[t]{5}{*}{ Being less interested in work } & never vs. seldom & $1.20(0.62-2.33)$ & 3.8 \\
\hline & never vs. regular & $1.32(0.46-3.79)$ & 4.2 \\
\hline & never vs. often & $4.06(1.51-10.94)^{*}$ & 11.9 \\
\hline & never vs. very frequent & $2.50(0.57-10.99)$ & 7.7 \\
\hline & never vs. daily & $2.73(0.34-21.72)$ & 8.3 \\
\hline \multirow[t]{3}{*}{ Feeling unhappy and depressed } & no vs. hardly & $1.56(0.86-2.83)$ & 3.4 \\
\hline & no vs. sometimes & $3.26(1.77-5.99)^{*}$ & 6.8 \\
\hline & no vs. often & $5.65(2.63-13.51)^{*}$ & 11.3 \\
\hline Work related factors & & $\mathrm{OR}$ & $\mathrm{I}(\%)$ \\
\hline \multirow[t]{3}{*}{ Playing useful part } & often vs. sometimes & $1.22(0.34-4.40)$ & 9.0 \\
\hline & often vs. hardly & $3.61(1.06-12.31)^{*}$ & 3.2 \\
\hline & often vs. never & $3.46(0.78-15.40)$ & 3.4 \\
\hline Obligatory change in working days & no vs. yes & $3.94(1.51-10.28)^{*}$ & 9.9 \\
\hline Experiencing work as too simple & no vs. yes & $2.25(1.31-3.86)^{*}$ & 7.5 \\
\hline Having conflicts with colleagues & no vs. yes & $2.57(1.29-5.12)^{*}$ & 8.7 \\
\hline \multirow[t]{3}{*}{ Being free from conflicting demands } & fully agree vs. agree & $1.17(0.41-3.31)$ & 3.2 \\
\hline & fully agree vs. disagree & $2.02(0.70-5.81)$ & 5.4 \\
\hline & fully agree vs. fully disagree & $1.64(0.36-7.54)$ & 4.4 \\
\hline Private factors & & OR & $1(\%)$ \\
\hline Having professional help at home & no vs. yes & $4.99(1.08-23.14)^{*}$ & 16.7 \\
\hline Having housekeeping help & no vs. yes & $1.55(0.98-2.46)$ & 5.3 \\
\hline \multirow[t]{2}{*}{ Keeping house } & no vs. yes, alone & $1.47(0.35-6.23)$ & 3.3 \\
\hline & no vs. together with partner & $2.06(0.49-8.62)$ & 4.6 \\
\hline Living alone & no vs. yes & $1.91(1.09-3.35)^{*}$ & 6.5 \\
\hline Having time left next to work/ family & yes vs. no & $2.28(1.59-3.27)^{*}$ & 2.9 \\
\hline
\end{tabular}

${ }^{*} p<0.05$ 


\section{Selection step 5}

The ability of the screening instrument to identify employees with or without selfreported sickness absence due to psychosocial health complaints was assessed by calculating sensitivity and specificity rates, and their corresponding confidence intervals, of different cut-off points (Table 2).

\section{Table 2}

Cut-off points (CP), and sensitivity and specificity rates (\%) for the development and the validation of the screening instrument

\begin{tabular}{|c|c|c|c|c|}
\hline \multirow{3}{*}{$\mathrm{CP}$} & \multicolumn{4}{|c|}{ Development of the screening instrument } \\
\hline & \multicolumn{2}{|l|}{$\overline{M e n}$} & \multicolumn{2}{|l|}{ Women } \\
\hline & $\mathrm{Se}^{*}(\mathrm{Cl})$ & Spt (CI) & $\mathrm{Se}^{*}(\mathrm{Cl})$ & $\mathrm{Spt}(\mathrm{Cl})$ \\
\hline 3 & $15.3(9.8-22.8)$ & $97.3(96.8-97.6)$ & $11.9(6.2-21.2)$ & $97.4(96.6-98.0)$ \\
\hline 5 & $22.9(16.2-31.2)$ & $95.3(94.7-95.8)$ & $22.6(14.5-33.3)$ & $95.6(94.6-96.5)$ \\
\hline 6 & $26.7(19.5-35.3)$ & $94.4(93.8-95.0)$ & $32.1(22.6-43.3)$ & $95.0(94.0-95.8)$ \\
\hline 8 & $33.4(25.7-42.4)$ & $92.5(91.8-93.1)$ & $34.5(24.7-45.8)$ & $93.0(91.9-94.1)$ \\
\hline 10 & $38.9(30.7-47.9)$ & $90.6(89.9-91.4)$ & $41.7(31.2-52.9)$ & $91.3(90.0-92.4)$ \\
\hline 20 & $58.8(49.8-67.2)$ & $80.7(80.0-81.7)$ & $57.1(45.9-67.7)$ & $81.3(79.5-82.9)$ \\
\hline 30 & $71.0(62.3-78.4)$ & $70.9(69.7-72.1)$ & $67.9(56.7-77.4)$ & $71.5(69.5-73.5)$ \\
\hline 40 & $80.2(72.1-86.4)$ & $60.9(60.0-62.1)$ & $78.6(68.0-86.5)$ & $61.4(59.2-63.5)$ \\
\hline \multirow{3}{*}{$\mathrm{CP}$} & \multicolumn{4}{|c|}{ Validation of the screening instrument } \\
\hline & \multicolumn{2}{|l|}{ Men } & \multicolumn{2}{|l|}{ Women } \\
\hline & $\mathrm{Se}^{*}(\mathrm{Cl})$ & Spt (CI) & $\mathrm{Se}^{*}(\mathrm{Cl})$ & $\mathrm{Spt}(\mathrm{Cl})$ \\
\hline 3 & $6.9(3.7-12.3)$ & $97.6(97.2-98.0)$ & $1.1(0.0-7.0)$ & 98.5 (97.7-99.0) \\
\hline 5 & $9.4(5.6-15.4)$ & $96.5(95.9-97.0)$ & $6.5(2.6-14.1)$ & $97.4(96.5-98.1)$ \\
\hline 6 & $10.1(6.0-16.1)$ & 95.9 (95.2-96.4) & 7.5 (3.3-15.4) & 96.1 (95.1-97.0) \\
\hline 8 & $13.8(9.1-20.4)$ & $94.2(93.5-94.8)$ & 7.5 (3.3-15.4) & 94.5 (93.3-95.5) \\
\hline 10 & $17.6(12.2-24.6)$ & $92.4(91.6-93.1)$ & 10.8 (5.6-19.3) & 92.8 (91.4-94.0) \\
\hline 20 & $35.8(28.5-43.9)$ & 84.9 (83.8-85.9) & $24.7(16.6-35.0)$ & $84.0(82.2-85.7)$ \\
\hline 30 & $49.1(41.1-57.1)$ & $76.3(75.1-77.5)$ & $36.6(27.0-47.2)$ & $73.6(71.4-75.7)$ \\
\hline 40 & $56.6(48.5-64.4)$ & $68.1(66.8-69.4)$ & $54.8(44.2-56.0)$ & $65.2(62.9-67.5)$ \\
\hline
\end{tabular}

\footnotetext{
* Sensitivity; † Specificity
} 
Receiver operator characteristic (ROC) analyses were performed, for both men and women, to define the screening instruments' most adequate cut-off point for sickness absence. For example, a cut-off point of 10 on the screening instrument resulted in a sensitivity score of $41.7 \%$ for women and $38.9 \%$ for men, and a specificity score of $91.3 \%$ for women and $90.6 \%$ for men. The area under the curve was 0,775 for women $(p<0,001)$ and 0,780 for men ( $p<0,001)$ (Figure 1).

\section{Figure 1}

The receiver operator characteristic curves for men (left) and women (right) of the developed screening instrument.
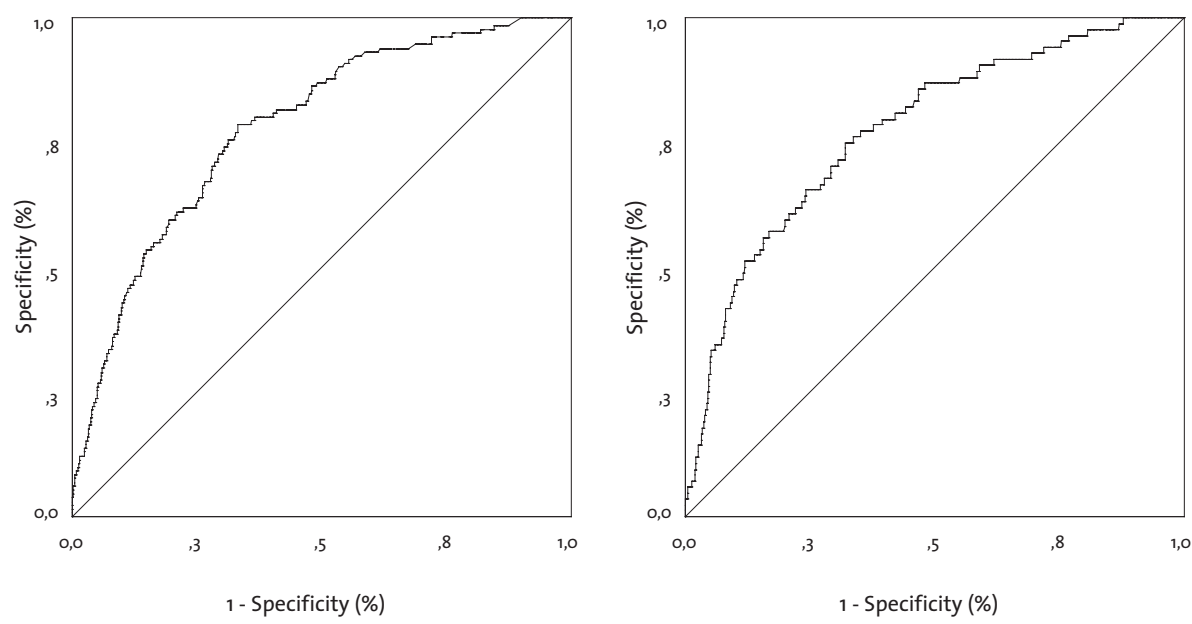

\section{Validation step 1 and 2}

The developed screening instrument was used to predict which employees, in May 1999, were 'at risk' for sickness absence in May 2000. Sum scores were calculated and, by means of the determined cut-off points on the developed screening instrument, sensitivity and specificity scores were estimated. For example, a cut-off point of 10 resulted in a sensitivity score of $10.8 \%$ for women and $17.6 \%$ for men, and a specificity score of $92.8 \%$ for women and $92.4 \%$ for men (Table 2 ). 


\section{Discussion}

\section{General findings}

This study represents the development of a screening instrument for the prediction of sickness absence due to psychosocial health complaints. The selection of a range of predictive factors to screen employees, in order to prevent sickness absence due to psychosocial health complaints, has not been done before. For both men and women, 17 predictive items were extracted from several questionnaires used in the Maastricht Cohort Study, all known for their reliability and unidimensionality. In women, the main results suggest that feeling depressed, having a burnout, being tired, being less interested in work, experiencing an obligatory change in working days, and living alone, were strong predictors of sickness absence due to psychosocial health complaints. In men, statistically significant predictors were having a history of sickness absence, compulsive thinking, being mentally fatigued, finding it hard to relax, missing supervisory attention, and having no hobbies. Sensitivity and specificity assessment, on both the development and the validation of the screening instrument, resulted in rather low sensitivity rates, but high specificity rates for both men and women. We will present methodological features and limitations, and give recommendations for clinicians and policymakers.

\section{Methodological features and limitations}

With respect to the present study, several issues have to be acknowledged. First, information on predictive factors as well as on sickness absence due to psychosocial health complaints is obtained by self-reported measures. Even though the use of objective data is regarded as an ideal starting point, in case of psychosocial health complaints, both self-reported complaints and diagnoses given by medical specialists are rather subjective. A review by Johns states that both subjective and objective absenteeism data are moderately correlated. ${ }^{11}$ The review reports 11 correlations ranging from 0.30 to 0.92 . The conclusion of the review is that self-reports can be considered a moderately valid measure of actual absenteeism. A second point of interest concerns the changeability to which self-reported reasons for sick leave are rather susceptible. Only those employees who explicitly stated that their latest sick leave was due to psychosocial health complaints were included as cases in this study. Since this self-report is not accompanied by a medical diagnosis or objective sickness absence data, the extent of sickness absence due to psychosocial health complaints is not comparable with prevalence measurements on a national level. A third issue 
concerns the time span between the assessment of predictive factors and the followup of sickness absence after one year. The aim of this study was to predict sickness absence in healthy employees, i.e. employees who are not on sick leave and have not diagnosed themselves as suffering from chronic psychosocial health complaints, such as recurring depression. Including these employees creates a heterogeneous study population, which could lead to a misrepresentation of indicators for sickness absence. Therefore, a certain time span is necessary to develop psychosocial health complaints of such a level that an employee is unable to work. A fourth issue concerns the determination of a cut-off point with preferably both high sensitivity and high specificity rates. Unfortunately, no such cut-off point could be found on the developed screening instrument. Nevertheless, the value of an instrument will be determined by its practical usability and efficiency. Specifically, when an expensive preventive intervention is to be implemented after screening of a large group of individuals, a screening instrument with a high specificity rate is preferred, to ensure that the intervention will be directed at the individuals who will particularly benefit from it. For example, a cut-off point of 10 on the developed screening instrument, i.e. specificity scores of $91.3 \%$ for women and $90.6 \%$ for men, restricts the number of false positively classified healthy working employees. Nevertheless, the low sensitivity scores are undeniable and are responsible for the weakness of the instrument, i.e. an amount of false negatively classified employees. However, since the screening instrument is directed at healthy employees, the consequences of not identifying these employees are not very significant. If necessary, they can use the available health care, inside or outside their company, such as consultation with a social worker, general practitioner, or occupational physician. Combination of the developed screening instrument with a more sensitive instrument is a functional possibility for implementation. Finally, to put this instrument into practice, calculation of the sum score on the screening instrument should be easily manageable. Therefore, an electronic version in which a sum score automatically will be calculated is the most obvious solution. 


\section{Recommendations and conclusion}

This study shows that it is possible to identify predictive factors for sickness absence and to develop an instrument for early identification of employees at risk for sickness absence. From a public and preventive medicine perspective, the presence of this screening instrument increases the possibility of implementing interventions directed at the prevention of sickness absence. For instance, employers could use screening to identify and deal with specific psychosocial health complaints, such as fatigue, and consequently influence the absentee rates. Moreover, the same in-company screening could be used to determine which employees are eligible for early treatment or social medical counselling. This is imperative for clinicians and policymakers in order to modify public health consequences on a larger scale. To investigate the effectiveness of the developed screening instrument more adequately, validation of this screening instrument in an additional population is necessitated. Also, implementation possibilities and consequences of falsely classified employees should be examined more thoroughly. 


\section{References}

1 Luz J, Green MS. Sickness absenteeism from work - a critical review of the literature. Public Health Rev 1997; 25(2):89-122.

2 ILO. Mental health in the workplace: Introduction. Geneva: International Labour Office; 2000. Report No.: ILO/OO/37.

3 Schröer C. Verzuim wegens overspanning; een onderzoek naar de aard van overspanning, de hulpverlening en het verzuimbeloop; 1993.

4 Niedhammer I, Bugel I, Goldberg M, Leclerc A, Guéguen A. Psychosocial factors at work and sickness absence in the Gazel cohort: a prospective study. Occup Environ Med 1998;55:735-741.

5 Duijts SFA, Kant IJ, Swaen GMH, Brandt PA van den, Zeegers MPA. A meta-analysis of observational studies identifies predictors of sickness absence. J of Clin Epidemiol 2007; in press.

6 Cooper CL, Dewe P, O’Driscoll M. Employee Assistance Programs. In: Quick JC, Tetrick LE, editors. Handbook of Occupational Health Psychology. Washington: American Psychological Association; 2003.

7 Tetrick LE, Quick JC. Prevention at Work: Public Health in Occupational Settings. In: Ouick JC, Tetrick LE, editors. Handbook of Occupational Health Psychology. Washington: American Psychological Association; 2003.

8 Wallace RB, Doebbeling BN. Maxcy-Rosenau-Last public health \& preventive medicine. 14th ed. Stamford, CT: Appleton \& Lange; 1998.

9 Quick JC. Occupational health psychology: the convergence of health and clinical psychology with public health and preventive medicine in an organizational context. Professional Psychology: research and practice 1999;30(2):123-128.

10 Brug J, Schaalma H, Kok G, Meertens RM, Molen HTvd. Gezondheidsvoorlichting en gedragsverandering. Assen: Van Gorcum; 2000.

11 Kant IJ, Beurskens A, Schröer C, Nijhuis F, Schayck Cv. De Maastrichtse Cohort Studie naar langdurige psychische vermoeidheid in de arbeidssituatie [The Maastricht Cohort Study of prolonged Fatigue at Work]. TBV 2000;8:226-232.

12 Beurskens AJ, Bultmann U, Kant IJ, Vercoulen JH, Bleijenberg G, Swaen GM. Fatigue among working people: validity of a questionnaire measure. Occup Environ Med 2000;57(5):353-7.

13 Swaen GM, Amelsvoort Lv, Bultmann U, Kant IJ. Fatigue as a risk factor for being injured in an occupational accident: results from the Maastricht Cohort Study. Occup Environ Med 2003;60 Suppl 1:i88-92.

14 Kant IJ, Bultmann U, Schroer C, Beurskens A, Amelsvoort Lv, Swaen G. An epidemiological approach to study fatigue in the working population: The maastricht cohort study. Occup Environ Med 2003;60(supl 1):i32-i39. 
15 Vahtera J, Pentti J, Uutela A. The effect of objective job demands on registered sickness absence among British civil servants: the Whitehall II study. Am J Public Health 1996;86:332-340.

16 Smulders PGW, Nijhuis FJN. The Job Demands-Job control model and absence behaviour: results of a 3-year longitudinal study. Work \& Stress 1999;13:115-131.

17 Janssen N, Kant IJ, Swaen GMH, Janssen PPM, Schröer CAP. Fatigue as a predictor of sickness absence: results form the Maastricht Cohort Study on fatigue at work. Occup Environ Med 2003;6o(suppl I):i71-i76.

18 Ware JE, Jr., Sherbourne CD. The MOS 36-item short-form health survey (SF-36). I. Conceptual framework and item selection. Med Care 1992;30(6):473-83.

19 Aaronson NK, Muller M, Cohen PD, Essink-Bot ML, Fekkes M, Sanderman R, et al. Translation, validation, and norming of the Dutch language version of the SF-36 Health Survey in community and chronic disease populations. J Clin Epidemiol 1998;51(11):1055-68. Vercoulen JH, Hommes OR, Swanink CM, Jongen PJ, Fennis JF, Galama JM, et al. The measurement of fatigue in patients with multiple sclerosis. A multidimensional comparison with patients with chronic fatigue syndrome and healthy subjects. Arch. Neurol 1996;53:642-649.

21 Vercoulen JH, Swanink CM, Fennis JF, Galama JM, Meer JWvd, Bleijenberg G. Dimensional assessment of chronic fatigue syndrome. J Psychosom Res. 1994;38:383-392.

22 Schaufeli WB, Dierendonck Dv. UBOS, Utrechtse Burnout Schaal, Handleiding. Lisse: Swets Test Publishers; 2000.

23 Maslach C, Jackson SE. Maslach Burnout Inventory manual. Palo Alto, CA: Consulting Psychologists Press; 1986.

24 Sluiter JK, Beek AJvd, Frings-Dresen MHW. The influence of work characteristics on the need of recovery and experienced health: a study on coach drivers. Ergonomics 1999;42:573-583.

25 Veldhoven Mv, Meijmen T. Het meten van psychosociale arbeidsbelasting met een vragenlijst: de Vragenlijst Beleving en Beoordeling van de Arbeid (VBBA) [Questionnaire on perception and Judgment of Work]. Amsterdam: NIA; 1994.

26 Koeter MWJ, Ormel J. General Health Questionnaire, Handleiding Nederlandse Bewerking [General Health Questionnaire, Manual Dutch Version]. Lisse: Swets \& Zeitlinger; 1991.

27 Goldberg D. Epidemiology of mental disorders in primary care settings. Epidemiological Reviews 1995;17:182-190.

28 Huibers MJ, Bultmann U, KasI SV, Kant IJ, Amelsvoort LGv, Schayck CPv, et al. Predicting the twoyear course of unexplained fatigue and the onset of long-term sickness absence in fatigued employees: results from the Maastricht Cohort Study. J Occup Environ Med 2004;46(10):1041-7.

29 Houtman I. Reliability and Validity of the Dutch version of the Karasek Job Content Questionnaire. In: APA/NIOSH conference on Work, Stress \& Health; 1995; Washington (DC): APA; 1995. 
30 Karasek RA. Job Content Questionnaire and User's Guide. Los Angeles: University of Southern California: Department of Industrial and Systems Engineering.; 1985.

31 Johns G. How often were you absent? A review of the use of self-reported absence data. Journal of Applied Psychology 1994;79:574-591.

32 de Jonge J, Reuvers MM, Houtman IL, Bongers PM, Kompier MA. Linear and nonlinear relations between psychosocial job characteristics, subjective outcomes, and sickness absence: baseline results from SMASH. Study on Musculoskeletal Disorders, Absenteeism, Stress, and Health. J Occup Health Psychol 2000;5(2):256-68.

33 Gaziel HH. Predictors of absenteeism among primary school teachers. Social Psychology of Education 2004;7:421-434.

34 Rentsch JR, Steel RP. Testing the durability of job characteristics as predictors of absenteeism over a six-year period. Personnel psychology 1998;51:165-190.

35 Sagie A. Employee absenteeism, organizational commitment and job satisfaction: another look. Journal of Vocational Behavior 1998;52:156-171.

36 Steel RP, Rentsch JR. Influence of cumulation strategies on the long-range prediction of absenteeism. Academy of Management Journal 1995;38:1616-1634.

37 SPSS. Base 11.0 for Windows User's Guide. In. Chigago: SPSS Inc; 2001. 



\section{4}

\section{ADVANTAGES AND DISADVANTAGES OF AN OBJECTIVE SELECTION PROCESS FOR EARLY INTERVENING IN EMPLOYEES AT RISK FOR SICKNESS ABSENCE}

\footnotetext{
Saskia FA Duijts ${ }^{1}$

IJmert Kant ${ }^{1}$

Gerard MH Swaen ${ }^{1,2}$

1 Department of Epidemiology, Maastricht University, Maastricht, The Netherlands

2 Dow Chemical Terneuzen, Terneuzen, The Netherlands
} 


\section{Abstract}

\section{Background}

It is unclear if objective selection of employees, for an intervention to prevent sickness absence, is more effective than subjective 'personal enlistment'. We hypothesize that objectively selected employees are 'at risk' for sickness absence and eligible to participate in the intervention program.

\section{Methods}

The dispatch of 8603 screening instruments forms the starting point of the objective selection process. Different stages of this process, throughout which employees either dropped out or were excluded, were described and compared with the subjective selection process. Characteristics of ineligible and ultimately selected employees, for a randomized trial, were described and quantified using sickness absence data.

\section{Results}

Overall response rate on the screening instrument was $42.0 \%$. Response bias was found for the parameters sex and age, but not for sickness absence. Sickness absence was higher in the 'at risk' ( $N=212)$ group ( $42 \%)$ compared to the 'not at risk' ( $N=2503)$ group (25\%) (OR 2.17 Cl 1.63-2.89; $\mathrm{p}=0.000$ ). The selection process ended with the successful inclusion of 151 eligible, i.e. $2 \%$ of the approached, employees in the trial.

\section{Conclusions}

The study shows that objective selection of employees for preventive intervening is effective. Despite methodological and practical problems, selected employees are actually those at risk for sickness absence, who will probably benefit more from the intervention program than others. 


\section{INTRODUCTION}

Sickness absence due to psychosocial health complaints, such as fatigue, burnout and work-family conflicts, represents a major concern in Western societies. ${ }^{1}$ In the Netherlands, about one in every three employees seen by their occupational physician are absent from work because of such complaints.2, 3 Reintegration of employees after psychosocial absenteeism causes more difficulties and generally takes longer than return to work following physical problems. Also, the consequences of this type of sickness absence involve enhanced payments and reduced productivity. 4 Thus, successful identification and early intervention with these employees can contribute to the prevention of sickness absence, and should receive profound attention in occupational health practice. Traditionally, intervention programs to reduce psychosocial health complaints, and following sickness absence, are accessible for employees who acknowledge wrestling with these problems. Also, supervisors or personnel departments who notice employees struggling with psychosocial health difficulties support participation in such purposive programs. Both subjective initiatives frequently depend on features such as having certain personality characteristics, holding specific positions or working at particular departments, and are only feasible if financial support from the employer is available and, at best, after repeated sickness absence spells. Overall, work-related intervention programs are initiated when the employee, supervisor or personnel department explicitly summons for assistance, in case of psychosocial health complaints or sickness absence, and if it is within the bounds of possibilities of the company. Though, one could ask oneself if this is the most adequate selection method, when it comes to effectively identifying and preventive intervening. Employees who are aware of an explicit problem and who are able to formulate the underlying issue do not automatically have to be those who benefit most from an intervention program. As well, intervening with those frequently on sick leave does not have to be the timeliest strategy to prevent further sickness absence. Alternatively, intervention programs could be directed at apparently healthy employees, who are objectively selected and identified to be at increased risk for sickness absence due to psychosocial health complaints. These employees may lack insight in their personal situation and may not be able to optimally manage problems that increase their risk on this type of sickness absence. However, certain fundamental prerequisites should be met to make this selection procedure practicable. Specifically, it must be feasible to objectively screen and identify employees at risk for sickness absence, and there must be an effective preventive intervention program. These req- 
uisites involve three essential challenges, i.e. a concise screening instrument for early identification of employees must be available; employees must be willing to be screened for their increased risk for sickness absence and selected employees need to be motivated to participate in a non-requested intervention program. In a foregoing study, an instrument consisting of predictive items for both men and women was developed to screen employees for their risk of sickness absence due to psychosocial health complaints.5,6 With regard to the second and third motivational condition, it is unclear if objective selection is more effective than the traditional subjective selection method of personal enlistment. In this paper, we reported different stages of the objective selection process throughout which employees either dropped out or were excluded, and compared it with the subjective selection process. Also, characteristics of ineligible and ultimately selected employees, for participation in a randomized trial, were described. We hypothesize that these selected employees are actually those at risk for sickness absence, who will consequently benefit more from the preventive intervention program than others. If so, the objective selection process is thought to be effective and successful. 


\section{Methods}

\section{Randomized controlled trial}

The present study is part of a larger randomized trial on the effectiveness of a preventive intervention for employees at risk for sickness absence due to psychosocial health complaints. All employees of participating companies received a screening instrument at their home address. Participating employees received a more extensive baseline questionnaire and were randomized to be included in the trial. Employees allocated to the control group received care as usual, while employees in the intervention group were invited for a preventive coaching program. Follow-up data will be collected until the end of 2006, through self-administered questionnaires. Company records were used to gain insight in duration of sick leave (in days) and frequency of sickness absence (in spells) of each employee. The Medical Ethics Committee of Maastricht University/ Academic Hospital Maastricht approved the study protocol. The design of the trial is presented in Figure 1.

\section{Figure 1}

Design of the trial

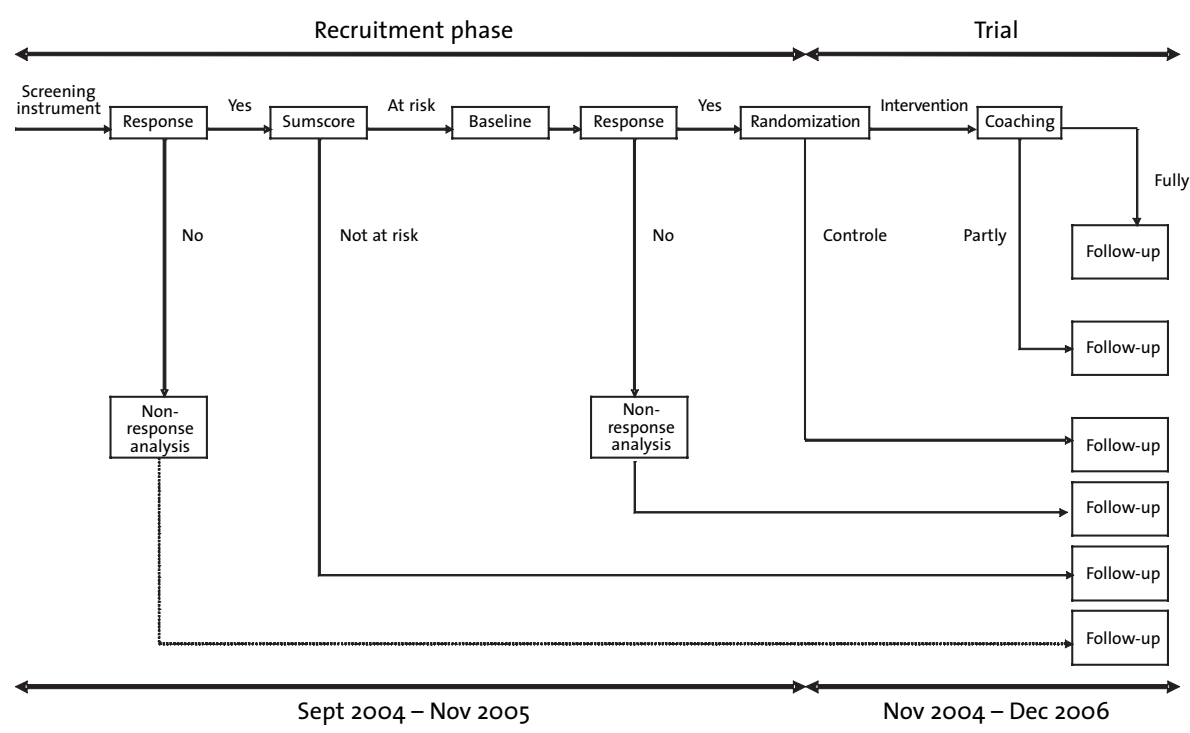




\section{Identification of eligible employees}

Three companies, i.e. two universities and a health care centre, situated in the southeastern part of the Netherlands participated. A total of 8603 employees received an invitational letter, an informative flyer and the screening instrument with informed consent, followed by a reminder two weeks later. The instrument is four pages long with a total of 34 predictive items, 17 for men and 17 for women, completed with a few general demographic items, and exclusion criteria. For both men and women, general health factors, mental health factors, work-related factors, and factors concerning the private situation, were included. Eligibility was assessed through calculation of the individual sum score on each returned screening instrument and verification of the signed informed consent. Employees were 'at risk' for sickness absence if there score was $\leq-3.03$ for men and $\leq-2.39$ for women. Exclusion criteria were 'fully or partially sick leave', 'suffering from chronic psychological problems', 'having more than one work contract' and 'pregnancy or being on maternity leave'.5 When an 'at risk' employee returned the baseline questionnaire, signed the second informed consent, and was allocated to the intervention group, an invitational letter with contact details of a specific coach in the geographic area of the employee was dispatched. Two of the participating companies requested that their selected employees contacted the assigned coach, thereby expectantly increasing commitment of the employee to the entire coaching program. One company preferred the coach to contact the selected employees for the first appointment. Also, two companies requested the preventive coaching program to be offered outside the office, whereas the third company favoured the coaching to occur on the premises. Employees allocated to the control group were free to make use of the care present in their company, such as consultation with a social worker or occupational physician.

\section{Preventive coaching program}

The preventive coaching in question is an existing intervention, which consists of seven to nine one-hour sessions within the course of six months. The intervention has been written down in a coaching protocol. The participating coaches received extensive information on the trial and the protocol. They were experienced and specialized in coaching employees at risk for sickness absence, but had to cope with the objective screening of employees as opposed to the more usual personal enlistment. A consequence of this objective screening is that a small number of employees start the preventive coaching program without (being aware of) an explicit problem. This necessitates a somewhat different approach by the coaches in the first introductory inter- 
view, i.e. the underlying issue still has to be recognized. Personal and coaching objectives are discussed and an overall question is formulated. At the end of this session, the employee has to be committed to attend the whole preventive coaching program. The second session is a three-way consultation, involving the employee, the involved supervisor and the coach. In this session, objectives from the first consultation are communicated to the supervisor and indispensable organizational objectives are added. The third up to and including the eighth session are individual meetings between employee and coach, in which methodologies and instruments of preventive coaching are applied. The program ends with a second three-way consultation, in which gained insights and experiences are discussed with the supervisor and future plans are made. Qualitative information of each session is registered on checklists, and the coach writes out an overall report of the program.

\section{Statistical analyses}

The $\chi^{2}$ statistic was used to compare overall differences between responding and non-responding employees to the screening instrument. By means of the objective sickness absence data from employer's records, we were able to perform nonresponse analyses on this primary outcome measure of the trial. Differences between 'at risk' and 'not at risk' employees, regarding sickness absence, were determined. Subsequently, exclusion criteria were applied and dissimilarities between both groups were tested and described by means of usual descriptive analyze techniques. Within the 'at risk' group, the $\chi^{2}$ statistic was used to detect differences between responding and non-responding employees, but now with respect to the baseline questionnaire. Finally, reasons of employees for non-response on the baseline questionnaire or on the invitation for the preventive coaching program were presented. The analyses were performed using the Statistical Package for Social Sciences (SPSS) version 13.0.7 


\section{Results}

\section{Non-response screening instrument}

Figure 2 presents the flow of employees through the recruitment phase of the trial.

\section{Figure 2}

The flow of employees through the recruitment phase of the trial

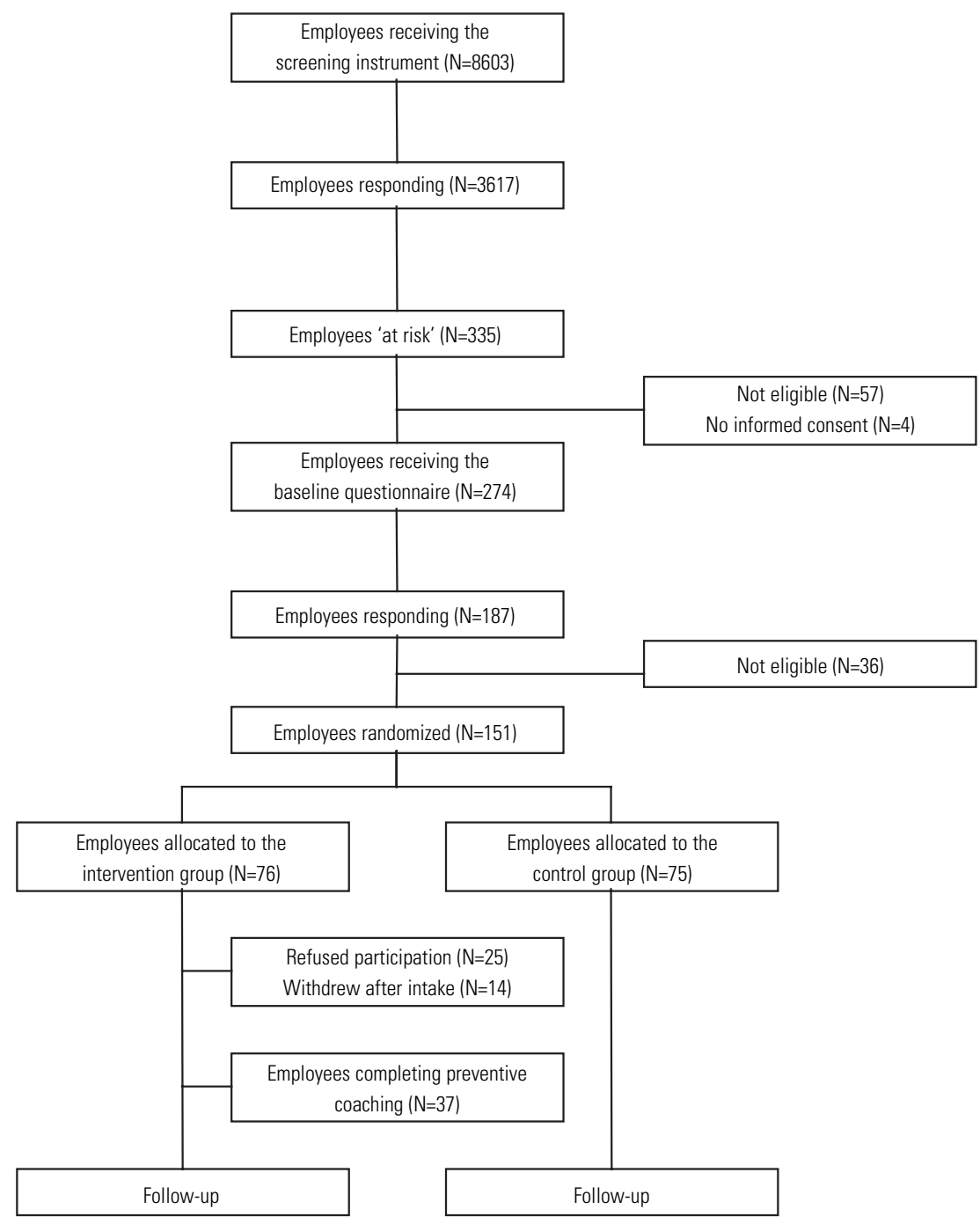


Our database consisted for $58 \%$ of employees from universities and for $42 \%$ of employees working in the health care sector. The overall response rate on the 8603 screening instruments was $42.0 \%$. As shown in Table 1, the percentage men was lower in the respondents than in the non-respondents. The percentage women was approximately the same in both groups. A $X^{2}$ test showed that this difference was significant $(p=0.000)$. Also, response rates of employees in the intermediate age groups (35-44 and 45-54) were higher than outermost age groups (o-35 and 55-64) ( $p=0.000)$. To explore to what extent sickness absence contributes to a possible response bias, we gathered objective sickness absence data from employer's records of two participating companies $(\mathrm{N}=6323)$. The percentage employees on sick leave in the time of the mailing was lower, but not significant, in the respondents group compared to the non-respondents groups $(p=0.609$ ). Furthermore, the percentage employees (excluding the intervention group) that reported sickness absence in the year after the mailing, was higher, but not significant, in the respondents group compared to the non-respondents group $(p=0.676)$. As regards duration of sick leave (days) and frequency of sickness absence (spells), no difference was found between the medians of the respondents and non-respondents $(p=0.468$ and $p=0.708$ respectively) (Table 1 ).

\section{Table 1}

Non-response analyses on the screening instrument and the baseline questionnaire

\begin{tabular}{|c|c|c|c|c|}
\hline \multirow[b]{2}{*}{ Characteristics } & \multicolumn{2}{|c|}{ Screening instrument } & \multicolumn{2}{|c|}{ Baseline questionnaire } \\
\hline & $\begin{array}{l}\text { Response } \\
(\mathrm{N}=3617)\end{array}$ & $\begin{array}{c}\text { Non-response } \\
(\mathrm{N}=4986)\end{array}$ & $\begin{array}{c}\text { Response } \\
(\mathrm{N}=187)\end{array}$ & $\begin{array}{c}\text { Non-response } \\
(\mathrm{N}=87)\end{array}$ \\
\hline Sex & \multicolumn{2}{|c|}{$\chi^{2}=169.04 ; p=0.000$} & \multicolumn{2}{|c|}{$x^{2}=0.00 ; p=0.949$} \\
\hline Men & $1162(34 \%)$ & $2296(66 \%)$ & $35(69 \%)$ & $16(31 \%)$ \\
\hline Women & $2455(48 \%)$ & $2690(52 \%)$ & $152(68 \%)$ & $71(32 \%)$ \\
\hline Age & \multicolumn{2}{|c|}{$x^{2}=71.36 ; p=0.000$} & \multicolumn{2}{|c|}{$X^{2}=4.28 ; p=0.233$} \\
\hline $0-34$ & $1029(36 \%)$ & $1841(64 \%)$ & $40(60 \%)$ & $27(40 \%)$ \\
\hline $35-44$ & $1095(45 \%)$ & $1320(55 \%)$ & $56(67 \%)$ & $28(33 \%)$ \\
\hline $45-54$ & $1077(46 \%)$ & $1262(54 \%)$ & $72(73 \%)$ & $26(27 \%)$ \\
\hline $55-64$ & $416(42 \%)$ & $563(58 \%)$ & $19(76 \%)$ & $6(24 \%)$ \\
\hline Sickness absence* & $\begin{array}{l}\text { Response } \\
(\mathrm{N}=2715)\end{array}$ & $\begin{array}{c}\text { Non-response } \\
(\mathrm{N}=3545)\end{array}$ & $\begin{array}{c}\text { Response } \\
(\mathrm{N}=94)\end{array}$ & $\begin{array}{c}\text { Non-response } \\
(\mathrm{N}=71)\end{array}$ \\
\hline Yes/no & \multicolumn{2}{|c|}{$x^{2}=0.175 ; p=0.676$} & \multicolumn{2}{|c|}{$x^{2}=0.140 ; p=0.708$} \\
\hline Duration (in days) & \multicolumn{2}{|c|}{$p=0.468$} & \multicolumn{2}{|c|}{$p=0.926$} \\
\hline Frequency (in spells) & \multicolumn{2}{|c|}{$p=0.708$} & \multicolumn{2}{|c|}{$p=0.347$} \\
\hline
\end{tabular}

* Sickness absence data of only two companies were available. 


\section{At risk versus not at risk}

From the respondents on the screening instrument $(N=3617), 335$ employees were identified as being 'at risk' for sickness absence due to psychosocial health complaints. 'At risk' employees from two companies providing sickness absence data, excluding the intervention group, $(\mathrm{N}=212)$ were compared to the 'not at risk' employees $(\mathrm{N}=2503)$. The percentage employees that reported sickness absence (one or more times in the last four months) was higher in the 'at risk' group (42\%) compared to the 'not at risk' group (25\%) (OR 2.17 Cl 1.63-2.89; $\mathrm{p}=0.000)$. For the duration of sick leave (days) and frequency of sickness absence (spells), significant differences were found between the 'at risk' and 'not at risk' groups ( $p=0.000$ and $p=0.000$ respectively). Exclusion criteria were applied to all respondents $(N=3617)$ on the screening instrument to explore dissimilarities between the complete 'at risk' group ( $\mathrm{N}=335$; exclusion $18.2 \%$ ) and 'not at risk' group ( $N=3282$; exclusion $16.2 \%$ ), regarding these specific criteria. The percentage of employees fully or partially on sick leave was $17.0 \%$ in the 'at risk' group and $5.3 \%$ in the 'not at risk' group $(p=0.000)$. The percentage of employees reporting to suffer from chronic psychological problems at baseline was $14.0 \%$ in the 'at risk' group and $1.6 \%$ in the 'not at risk' group ( $p=0.000)$. The percentage of employees that had more than one contract was $11.3 \%$ in the 'at risk' group and $8.2 \%$ in the 'not at risk' group ( $p=0.052$ ). Finally, the percentage of employees that was pregnant or on maternity leave was $0.9 \%$ in the 'at risk' group and $1.5 \%$ in the 'not at risk' group $(p=0.382)$.

\section{Non-response baseline questionnaire}

The baseline questionnaire was sent to the remaining 'at risk' employees ( $N=274)$. In accordance with the non-response analyses on the screening instrument, we repeated these analyses to detect differences between responding $(\mathrm{N}=187)$ and nonresponding employees $(\mathrm{N}=87)$ on the baseline questionnaire. As shown in Table 1, the analysis revealed no significant differences between respondents and non-respondents with respect to sex $(p=0.949)$ and age $(p=0.233)$. The percentage of participating employees reporting sickness absence in the year after the baseline questionnaire was sent, was lower in the respondents group compared to the non-respondents group. A $\chi^{2}$ test showed that this difference was not significant $(p=0.708)$. For duration of sick leave (days) and frequency of sickness absence (spells), no difference was found between the respondents and non-respondents. Results for both tests were not significant $(p=0.926$ and $p=0.374$ respectively) (Table 1 ). 


\section{Reasons for non-response}

The main reasons for non-response on the baseline questionnaire $(\mathrm{N}=87)$ were 'personal matters' (61.0\%), such as 'I don't feel like it' (19.1\%) or 'I can deal with these problems myself' (17.1\%); 'issues regarding the preventive coaching program' (39.0\%), such as 'I don't want an invitation for the preventive coaching program' (19.5\%) or 'I don't want my supervisor to participate in the coaching program' (12.2\%); 'organizational matters' (29.3\%), such as 'I am afraid of consequences caused by participation' (12.2\%); and 'other reasons' (31.7\%), such as 'I have lost the questionnaire' (12.2\%). Employees who reported to be on sick leave at the time of the baseline mailing, were excluded from the study $(\mathrm{N}=36)$. As a result, 151 'at risk' employees were left for random allocation to receive the preventive coaching program $(\mathrm{N}=76)$ or 'care as usual' $(\mathrm{N}=75)$. The main reasons for declining the invitation for the preventive coaching program $(\mathrm{N}=25)$ were 'personal matters' (64.3\%), such as 'I can deal with these problems myself' (28.6\%) or 'I don't understand why I received this invitation' (14.3\%); 'issues regarding the preventive coaching program' (35.7\%), such as 'I don't want my supervisor to participate in the coaching program' (14.3\%); and finally, 'organizational matters' (35.7\%), such as 'I am too busy at work to participate in the coaching program' (28.6\%). Eventually, 51 employees entered the preventive coaching program through this objective selection process. 


\section{Discussion}

\section{General findings}

This study describes the objective selection process foregoing a preventive intervention for employees at risk for sickness absence due to psychosocial health complaints. Because of the successive stages and various components in this procedure, such as the response to questionnaires, the determination of being 'at risk' for sickness absence, the multi-stage informed consent and the acceptance of the invitation for the preventive coaching program, the enrolment of eligible employees was a comprehensive task. Keeping Lasagna's Law ${ }^{8}$ in mind, stating that no reliable enrolment estimates can be made, the selection phase of this study started with the dispatch of 8603 screening instruments and ended with the inclusion of 151 employees in the trial. Notwithstanding this seemingly successful recruitment phase, we initially expected a substantially larger number of employees, allocated to the intervention group, to accept the invitation for the coaching program. Nevertheless, the overall selection phase yielded more significant information than anticipated. We will interpret the eligibility of employees throughout the successive stages of the objective selection process, present limitations, and give recommendations for future research and implementation possibilities.

\section{Eligibility of employees}

\section{Non-response}

The screening instrument was mailed to the home addresses of employees of three large companies to identify employees 'at risk' for sickness absence due to psychosocial health complaints. Non-response to mailed questionnaires reduces the effective sample size and can introduce bias. 9 We used our premeditated sample of 150 employees as starting point and estimated the total amount of screening instruments to be dispatched, i.e. a minimum of 8000 . Hereby, we attempted to account for circumstances such as non-response of approximately $50 \%$ on the screening instrument, exclusion of about $20 \%$ of responding employees, estimated prevalence of $10 \%$ 'at risk' employees for sickness absence, non-response of $40 \%$ on the baseline questionnaire and exclusion of about $20 \%$ of responding employees on the baseline questionnaire. These percentages were based on experiences from previous research. 6 Further, bias may be introduced if non-responders differ significantly, particularly regarding sickness absence, from those who do respond. Therefore, it is important to examine the characteristics of responders and non-responders to determine the 
degree to which the sample may be said to be representative of the population. This will permit the generalization to the population, or indicate the degree of caution needed. ${ }^{10}$ Since significant differences were found in sex and age, the results of our upcoming trial have to be corrected for or stratified on these specific characteristics. No difference was found in sickness absence between responding and non-responding employees. Notwithstanding this positive outcome, there is no denying that objective selection has the consequence that many eligible employees at risk for sickness absence can not be included in the preventive intervention, due to their nonresponse on the screening instrument.

\section{Not at risk}

To assure that the intervention will be directed at employees who will particularly benefit from it and to restrict the number of false-positively classified healthy working employees, we preferred a screening instrument with a high specificity. 5 As a result, numerous employees were assigned to the 'not at risk' group, hereby once more reducing the number of employees eligible for randomization. Still, information on these ineligible employees, specifically regarding sickness absence, is extremely useful as it will enable us to externally validate the screening instrument. And, the significant difference in sickness absence between 'at risk' and 'not at risk' employees supports the fact that principally eligible employees were selected through objective selection.

\section{Exclusion}

Exclusion criteria were applied to both 'at risk' and 'not at risk' employees to get an initial impression of the instrument characteristics. The percentage of employees to be excluded from the 'at risk' group turned out to be twice the percentage of employees to be excluded from the 'not at risk' group. The criteria 'being fully or partially on sick leave' and 'suffering from chronic psychological problems at baseline' were the most imperative, statistically significant reasons for this difference. The provisionally presumption can be made that eligible employees, i.e. those at risk for sickness absence, can be reasonably identified using the screening instrument. However, in order to be able to pronounce upon the generalization to the population, external validation of the screening instrument and insight into additional psychometric characteristics of the instrument are indispensable. 


\section{Withdrawal}

All employees eligible for the trial received the baseline questionnaire and a second informed consent. No differences were found in sickness absence between respondents and non respondents on this questionnaire. In order to retain a sufficient number of eligible employees, it was necessary to meet a few conditions. Firstly, a high response rate on the baseline questionnaire was pursued by giving the selected employees comprehensive information on the trial, sending them two reminders and an extra questionnaire in the following month, and by retrieving reasons for nonresponse in case of definite disinterest. Secondly, employees were acquainted with the possible control group allocation and were free to choose 'care as usual' or additional treatment, if necessary. Thirdly, participating companies were free to choose the method of contact between coach and employee and the location of the coaching program, in order to attune the program on their employees and the standards of the company. Finally, the multi-stage informed consent procedure was chosen to thoroughly inform the employees on the consequences of partaking, as preventive coaching implies an intensive commitment. With this, we expected to reduce the number of employees, allocated to the intervention group, declining the invite for the preventive coaching program. Still, a third of the invited employees refused to participate in the preventive coaching program. The main reasons for non-response were related to 'personal matters' and 'issues related to the preventive coaching program' in both non-responders to the baseline questionnaire and non-responders to the coaching program. For example, employees preferred coping with the identified problems by themselves. Probably, employees would be more receptive for support in managing their problems when easy accessible service is continuously available on the premises. Also, employees expressed concern about the participation of their supervisor in the preventive coaching program. Apparently, employees prefer to avoid this confrontation in a three-way consultation. It is plausible that an intervention without such a confrontation is more attractive and, accordingly, has an effect on the number of employees agreeing to randomization. Nevertheless, the spearhead of the preventive coaching program is its reflection to the organization and the input of the supervisor in this matter can not be denied. Eventually, about $2 \%$ of the initially approached employees passed through every described stage of the objective selection process, and entered our trial on the effectiveness of a preventive coaching program for sickness absence. 


\section{Comparison of objective and subjective selection}

Keeping the hypothesis of this study in mind, one can ask oneself if this objective selection process is in fact more effective than the traditional subjective selection method of personal enlistment. Imperative issues, such as non-response, have to be considered when objectively identifying employees to be at risk for sickness absence. Though, such issues are also significant for the subjective route. For instance, the former can be directed at all employees of a company and has the advantage of neutral allocation of the intervention program, specifically for employees who do not let it be known to struggle with psychosocial health complaints. The latter implicitly gives precedence to the employees who monopolize this opportunity by simply asking for participation or informing their supervisor about their problems. Through this, participation in purposive intervention programs is depending on the degree of articulation and personal awareness of the employee. However, this subjective personal enlistment of employees does not imply that they are actually 'at risk' for sickness absence, and by that belong to the target group of the specific intervention program. Therefore, the definition of the intended target group is essential in deciding between objective and subjective procedures. Further, the objective selection method has to contend with non-response on questionnaires and non-commitment to the intervention program. Several employees, who would almost certainly benefit from the intervention, may stay unidentified this way. In contrast, the subjective method starts from the idea that partaking is a self-imposed task, and consequently has the advantage of minimum selective withdrawal. Still, the former is not automatically put at a disadvantage, since requisites of partaking in an intervention program, such as commitment, are probably not unconditionally present in the non-responders. Unpremeditated exclusion of these employees could positively influence the effect of the intervention program. Before putting a selection method into practice, one should determine if preventive or curative intervening is indicative. When the objective of a company is to independently identify employees for the prevention of sickness absence, the only possible selection method is objective identification of eligible employees. 


\section{Conclusion}

This study shows that objective selection to enable preventive intervention is effective and successful. Selected employees are actually those at risk for sickness absence, who will probably benefit more from the preventive intervention program than others. However, methodological problems, such as non-response, are undeniable and the whole process is expensive and time-consuming. Using the subjective method of personal enlistment, the eligibility of employees is not definite, though abovementioned problems are faced to a lesser degree. Thus, before putting a selection method into practice, employees, supervisors or personnel departments should determine which objectives should be given priority, and they should understand the consequences of all stages of the selection process. Interpretation of the presented findings must be seen within the framework of our trial. Nevertheless, our experiences and quantitative information on the effectiveness of the process can prompt researchers to prevent and overcome difficulties mentioned here in future. 


\section{References}

1 Luz J, Green MS. Sickness absenteeism from work - a critical review of the literature. Public Health Rev 1997;25(2):89-122.

2 Schaufeli WB, Kompier MA. Managing job stress in the Netherlands. International Journal of Stress Management 2001;8:15-34.

3 van der Klink JJ, Blonk RW, Schene AH, van Dijk FJ. Reducing long term sickness absence by an activating intervention in adjustment disorders: a cluster randomised controlled design. Occup Environ Med 2003;6o(6):429-37.

4 Schröer C. Verzuim wegens overspanning; een onderzoek naar de aard van overspanning, de hulpverlening en het verzuimbeloop. Universitaire Pers Maastricht: Maastricht; 1993.

5 Duijts SFA, Kant I, Landeweerd JA, Swaen GMH. Prediction of sickness absence: the development of a screening instrument. Occup Environ Med 2006;63:564-596.

6 Kant I, Bultmann U, Schröer C, Beurskens A, Amelsvoort Lv, Swaen G. An epidemiological approach to study fatigue in the working population: The maastricht cohort study. Occup Environ Med 2003;60 (supl 1):i32-i39.

7 SPSS. Base 13.0 for Windows User's Guide. In. Chigago: SPSS Inc.; 2004.

8 Harris EL, Fitzgerald JD. The principles and practices of clinical trials. Edinburgh and London: $\mathrm{E}$ \& S.: Livingstone; 1970 .

9 Armstrong BK, White E, Saracci R. Principles of exposure measurement in epidemiology. Monographs in Epidemiology and Biostatistics 1995;21:31-44.

10 Barclay S, Todd C, Finlay I, Grande G, Wyatt P. Not another questionnaire! Maximizing the response rate, predicting non-response and assessing non-response bias in postal questionnaire studies of GPs. Fam Pract 2002;19(1):105-111. 



\section{PSYCHOMETRIC CHARACTERISTICS AND EXTERNAL VALIDATION OF A SCREENING INSTRUMENT TO IDENTIFY EMPLOYEES AT RISK FOR SICKNESS ABSENCE DUE TO PSYCHOSOCIAL HEALTH COMPLAINTS}

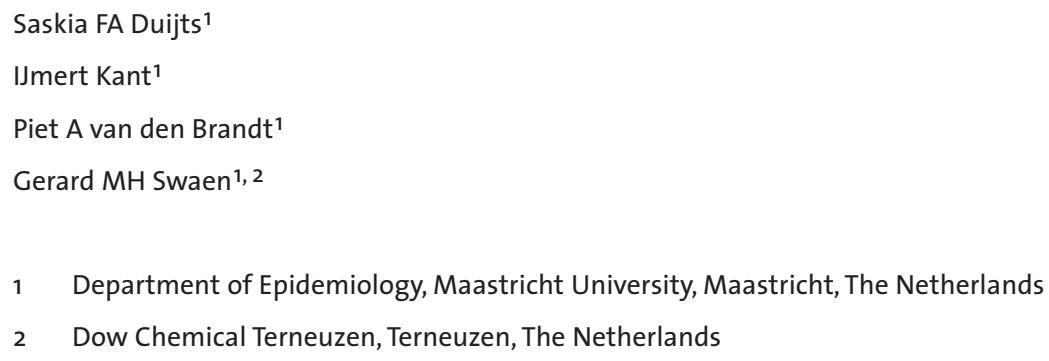




\section{Abstract}

\section{Objectives}

To assess psychometric characteristics and the external validation of a screening instrument for the identification of employees at risk for sickness absence due to psychosocial health complaints.

\section{Methods}

Exploratory factor analysis was applied. Cronbach's alpha coefficient was used to determine internal consistency of the subscales. Sum scores on the screening instrument were correlated to absenteeism data to determine their potential for predicting sickness absence. Predictive value was investigated, using objective sickness absence data as criterion measure. Sensitivity and specificity rates were calculated for the external validation.

\section{Results}

For both men and women, three interpretable factors were found. Sum scores on the instrument did not correlate well with sickness absence. The association between 'being at risk' (yes/no) and sickness absence (yes/no) was OR 3.09 (Cl 1.47-6.47) for men and OR 1.97 ( $\mathrm{Cl}$ 1.44-2.69) for women. Sensitivity scores were rather low, whereas specificity scores were remarkably high.

\section{Conclusions}

The results of this study provide the screening instrument a theoretic and scientific basis. Predictive value is promising, when absence is treated as a dichotomous measure. Sensitivity and specificity were unvarying during the development and validation phases of the instrument. 


\section{INTRODUCTION}

Absence from work due to psychosocial health complaints, such as depression, fatigue, stress or work family conflicts, has considerable negative effects for employees, employers and society. ${ }^{1}$ For the individual, reintegration after psychosocial absenteeism causes more difficulties and generally takes longer than return to work following physical problems. For both employers and society, the consequences of this type of sickness absence involve enhanced payments and reduced productivity. ${ }^{2} \mathrm{~A}$ better and more effective strategy would be early identification of employees at risk for psychosocial sickness absence, and early intervention to prevent sickness absence as much as possible. 3 In order to enable identification of at risk employees, insight in predictive factors for sickness absence is needed. Exploring these factors, the most consistent results are found for demographics, such as age and gender, health and mental health factors, such as fatigue and burnout, and psychosocial work factors, such as job demands and job satisfaction.4 In general, there are two accepted approaches to identify such factors. One is theoretical and uses established scales and concepts to see which ones are predictive. The second approach is empiric and atheoretical, i.e. a large number of candidate items, coming from intact scales as well as other diverse sources, is assembled and then each item is examined for its predictive power. At present, a randomized trial is in progress to determine the effectiveness of a preventive intervention for employees at increased risk for sickness absence due to psychosocial health complaints. For this trial, it is essential to know which employees are at increased risk, so as to affect those who would probably benefit most from preventive intervening. In a preceding study, an instrument consisting of predictive items for both men and women was developed by means of data from the Maastricht Cohort Study on 'Fatigue at Work', to screen employees for their risk of sickness absence. The items in this instrument were identified according to the second approach, i.e. they were derived from various questionnaires, originating from different settings and all known for their reliability and unidimensionality. Furthermore, a prerequisite of this approach, i.e. internal validation, took place in this foregoing study to establish a final set of stable items. However, the confirmed set remained a diffuse enumeration of predictive factors with diverse conceptual content, for which scale characteristics are not representative. 5 Therefore, identification of underlying concepts of the screening instrument is necessary to narrow the variation between the theoretical first and the more statistically driven second approach. Recognizing established concepts from the literature might give the instrument a 
theoretical basis. Also, it is desirable to verify the effectiveness of the instrument in predicting sickness absence, before implementation on a larger scale is attainable. The use of objective sickness absence data as criterion measure is the most efficient device to determine this predictive power. Before any generalization is possible, external validation is essential and clear understanding of sensitivity and specificity rates of the instrument is needed. The objective of the present study is to gain insight in the practical use of the screening instrument by investigating several of its psychometric characteristics and by performing the external validation, using data of employees approached for participation in the randomized trial. 


\section{Methods}

\section{Study population}

Data from the Maastricht Cohort Study on 'Fatigue at Work' were used for the development, internal validation and determination of the cutoff point of the screening instrument. 5 In the course of the randomized trial, employees of three companies situated in the south-eastern part of the Netherlands received the developed instrument at their home address. The responses to the screening instrument were the basis for the identification of 'at risk' employees. These employees received the more extensive baseline questionnaire and were eligible to participate in the trial. Employees allocated to the control group received care as usual, while employees in the intervention group were invited for the preventive intervention. Follow-up data for the trial will be collected until the end of 2006.

One year after the first dispatch of screening instruments, responding employees of two participating companies received a second mailing of instruments, to gather selfreported sickness absence data of those 'at risk' and those 'not at risk' for sickness absence. On behalf of the assessment of psychometric characteristics and the external validation, employees were subdivided into two groups. The first group contains all employees that responded to the first screening instrument $(N=3617)$. Data of these employees were used to examine the structure and internal consistency of the screening instrument. Next, the predictive value was assessed for respondents for whom objective sickness absence data were available for analysis $(\mathrm{N}=2778)$. The second group consists of employees who responded on both screening instruments, with an intervening period of one year, and were employed in participating companies that supplied objective sickness absence data $(N=1736)$. Of these employees, self-reported as well as objective sickness absence data were available. Employees who were randomly allocated to the intervention group in the aforementioned trial were excluded. Data of employees in the second group were used to examine the external validity of the screening instrument. Employees were ineligible for participation if they were fully or partially on sick leave, suffered from chronic psychological problems at baseline, had more than one work contract, were pregnant or on maternity leave at the time the questionnaires were sent out.5 


\section{Screening instrument}

The screening instrument, called the 'Werkwijzer', contains a set of predictive factors, for men and women, associated with sickness absence due to psychosocial health complaints. In women, general health factors, such as physical complaints as a result of repetitive movements, mental health factors, such as burnout, work-related factors, such as experiencing conflicts with colleagues, and factors concerning the private situation, such as living alone, were included in the instrument. In men, general health factors, such as having a history of sickness absence, mental health factors, such as being mentally fatigued, work-related factors, such as lack of supervisor support, and factors concerning the private situation, such as having no hobbies, were added. 5 The screening instrument is four pages long with a total of 40 items and a completion time of approximately 10 minutes. The 34 predictive items, 17 for men and 17 for women, were completed with a few general demographic items, e.g. sex and age, and some exclusion criteria, e.g. items about pregnancy and items concerning current absenteeism. Response options for 22 predictive items were yes/no; two items were scored on a three point scale, six items on a four-point scale, one on a five-point scale and three items on a seven-point frequency scale (Table 1).

\section{Table 1}

Predictive factors of the screening instrument to identify employees at risk for sickness absence

\begin{tabular}{lll}
\hline & Predictive factors men & Predictive factors women \\
\cline { 3 - 3 } 2 & Prior absence & Repetitive movements \\
2 & Hard to relax after working day & Being shy amongst others \\
3 & Feeling exhausted after working day & Being mentally fatigued \\
4 & Trouble concentrating after working day & Tired facing another day \\
5 & Compulsive thinking & Burned out \\
6 & Being mentally fatigued & Being less interested in work \\
7 & Not familiar with responsibilities & Feeling unhappy and depressed \\
8 & Receiving no support from supervisor & Not playing useful part \\
9 & In case of problems at work, go to family doctor & Obligatory change in working days \\
10 & In case of problems at work, go to social worker & Experiencing work as too simple \\
11 & Receive sympathy at work after shocking experience & Having conflicts with colleagues \\
12 & Finding salary of colleagues unreasonable & Experiencing conflicting demands \\
13 & Being unsatisfied with financial situation & Having professional help at home \\
14 & Living together with partner & Having housekeeping help \\
15 & No small jobs in leisure time & Keeping house \\
16 & No hobbies in leisure time & Living alone \\
17 & Following additional education for the job & Not enough time left next to work/ family \\
\hline
\end{tabular}


An overall sum score on the screening instrument was calculated for each individual employee, and was compared to a determined cutoff point on the instrument, i.e. a score of $\leq-3.03$ for men and $\leq-2.39$ for women indicated an increased risk for sickness absence due to psychosocial health complaints. 5

\section{Sickness absence}

Sickness absence data were used to assess both the predictive value and the external validity of the screening instrument. Subjective absence data were gathered by means of the second mailing of screening instruments. Employees were asked to report the frequency of sickness absence in the previous four months, given the six possibilities: (1) never, (2) one time, (3) two times, (4) three times, (5) four times, (6) five times or more. In case of at least one absence report, they were asked to give information about the reason of their latest sick leave. A code was allotted, in accordance with the International Classification of Primary Care (ICPC), to the reasons employees have given for their latest sickness absence. 5 With this, employees who reported sick as a result of psychosocial health complaints could be identified. Objective sickness absence data were gathered by means of absence records of employees from participating companies.

\section{Statistical analyses}

The statistical analyses included descriptive, reliability and validity analyses of the screening instrument. Exploratory factor analysis was used to investigate the structure, i.e. the factor validity, of the predictive items on the instrument for both men and women. Factor analysis is a statistical technique that can be used to analyse intercorrelations among a large number of items while trying to explain these variables in terms of their common underlying dimensions. ${ }^{6}$ Prior to the application of this analysis, a few prerequisites should be met. Bartlett's sphericity test was used to assess the mutual correlation of the items in the screening instrument, for both men and women. In case of non significant test results, i.e. no correlation, the use of factor analysis is irrelevant. The Kaiser-Meyer-Olkin measure of sampling adequacy (MSA) was applied to describe the degree of correlation. MSA adopts values between o and 1. Values larger than 0.80 are excellent, values between 0.50 and 0.80 are questionable, and values below 0.50 are substandard. The number of factors to retain was determined through both Catells's scree plot analysis and the assessment of eigenvalues. A breakdown between the factors with relatively large eigenvalues and those with smaller eigenvalues was explored. The resulting factors were subjected to 
oblique (Oblimin) rotation as mutual correlation of the observed dimensions of the screening instrument was possible. Items failing to show salient loadings on any of the factors $(<0.40)$ and items with substantial cross-loadings $(\leq 0.40)$ were removed. Each factor should be comprised of at least three items.7 A forced two factor analysis was carried out on the removed items. After establishing the structure of the instrument, internal consistency reliability of the identified scales was assessed by the Cronbach's alpha coefficient. Predictive value was investigated, using objective sickness absence data as criterion measure. The hypothesis was that an increase in sum score on the instrument is accompanied by an increase in absence duration or absence frequency. Finally, the external validity of the screening instrument was assessed by means of both subjective and objective sickness absence data from employees. Sensitivity and specificity rates were presented for different cutoff points on the instrument. All analyses were performed using the Statistical Package for Social Sciences (SPSS) version 13.0.8 


\section{REsULts}

Exploratory factor analysis was performed on 17 predictive items for men and 17 predictive items for women ( $\mathrm{N}=3617$ ). Bartlett's sphericity test was significant for both men $(p=0.000)$ and women $(p=0.000)$, and MSA resulted in 0.75 and 0.78 respectively. Catell's scree plot applied to the data of men shows a distinct break before factor three, suggesting that only the first two factors were meaningful enough to be retained. The scree test for women showed a similar plot, indicating that the factor structure for women was best described by two factors as well (Figure 1).

\section{Figure 1}

Scree plot of eigenvalues for men and women
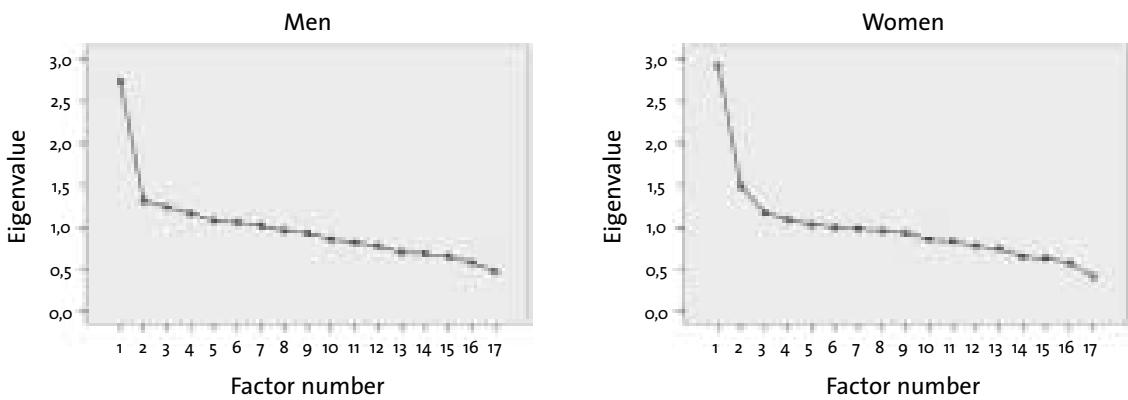

In men, the first factor accounted for $16 \%$ of the variance among respondents and consisted of five mental health related items $(2,3,4,5,6)$ (Table 1). Three of these items were retrieved from a questionnaire, measuring the degree to which employees are able to recover from fatigue and stress at work. 9 The fourth item explored if employees had suffered from fatigue complaints in the preceding four months and, if so, whether they felt if the cause of these complaints was psychological. The fifth and last item that loaded on this factor was retrieved from a questionnaire measuring anxious mood. ${ }^{10}$ The incorporated item 'compulsive thinking' turned out to be a strong predictor of sickness absence. The second factor explained $8 \%$ of the variance and captured four items, all pertained to social support $(7,8,11,14)$. The first item was retrieved from the Dutch questionnaire on the Perception and Judgment of Work, by which data on organizational characteristics such as commitment, job demands and role ambiguity were gathered.11, 12 Being in a state of uncertainty as regards everyday work responsibilities can increase the risk of sickness absence due to psychosocial 
health complaints. The second item that loaded on this factor is related to the concept of 'supervisor support', i.e. receiving no thought from the supervisor. The third and fourth item loaded negatively on this factor. Both items were associated with being empathically surrounded by people at work or at home. A third factor, retrieved from the forced two factor solution, accounted for $17 \%$ of the variance and consisted of three mainly health related items $(1,9,13)$. Two items that loaded on this third factor were evidently related to health, and described 'prior periods of absenteeism' and 'visits to one's family doctor'. The third item was 'being satisfied with one's financial situation'. An explanation for the classification of this last item within the supplemented factor could be that social deprivation and economical uncertainty generally affects people's well being negatively. The fourth factor explained $14 \%$ of the variance, but merely consisted of two items, both concerning leisure activities, i.e. items 15 and 16 (Table 1). Examination of the factor loadings showed three items with loadings less then 0.40 on all factors, i.e. items 10, 12 and 17. Both the two items included in the fourth factor and the three items with substandard loadings were excluded from further reliability analyses. Internal consistency as measured by Cronbach's alpha was $0.70,0.08$ and -0.03 for factor I, II and III respectively (Table 2).

\section{Table 2}

Two factor solution and forced one factor supplement in men

\begin{tabular}{|c|c|c|c|}
\hline Items & Factor 1 & Factor 2 & Factor $3^{*}$ \\
\hline Prior absence & .39 & .18 & .68 \\
\hline Hard to relax after working day & .74 & -.07 & - \\
\hline Feeling exhausted after working day & .63 & -.15 & - \\
\hline Trouble concentrating after working day & .69 & -.04 & - \\
\hline Compulsive thinking & .63 & -.09 & - \\
\hline Being mentally fatigued & .64 & -.08 & - \\
\hline Not familiar with responsibilities & -.21 & .55 & - \\
\hline Receiving no support from supervisor & -.17 & .69 & - \\
\hline In case of problems at work, go to family doctor & .30 & .01 & .69 \\
\hline Receive sympathy at work after shocking experience & .07 & -.41 & - \\
\hline Being unsatisfied with financial situation & -.25 & .15 & -.48 \\
\hline Living together with partner & -.08 & -.44 & - \\
\hline
\end{tabular}

* Third factor retrieved from forced two factor solution on remaining items 
In women, the first factor accounted for $17 \%$ of the variance among respondents and consisted of six mental health related items $(3,4,5,6,7,17)$ (Table 1 ). Three of these items were retrieved from a burnout questionnaire, with the subscales 'exhaustion', 'distance' and 'competence'.13, 14 Two predictive items were from the 'exhaustion' subscale and one from the 'distance' subscale. The fourth item explored if employees had suffered from fatigue complaints in the preceding four months and, if so, whether they felt if the cause of these complaints was psychological. The fifth item that loaded on this factor was retrieved from a questionnaire measuring psychological distress (GHO-12).15, 16 The incorporated item 'feeling unhappy and depressed' turned out to be a strong predictor of sickness absence. The sixth and last item describes the shortness of leisure time, next to work and family. The second factor explained $9 \%$ of the variance and yielded three items, indicating sociodemographic characteristics (14, $15,16)$. The included items regarded living conditions and domestic activities. A third factor, retrieved from the forced two factor solution, accounted for $16 \%$ of the variance and consisted of three work related items $(1,10,11)$. The items that loaded on this third factor were related to work, and described 'repetitive movements', 'conflicts with colleagues' and 'experiencing the work as too simple'. The fourth factor explained $13 \%$ of the variance, but consisted of just two items, both concerning autonomy at work, i.e. items 8 and 9 (Table 1). Assessment of the factor loadings showed three items with loadings less then 0.40 on all factors, i.e. items 2, 12 and 13 . Both the two items included in the fourth factor and the three items with substandard loadings were excluded from further reliability analyses. Internal consistency as measured by Cronbach's alpha was $0.72,-0.29$ and 0.19 for factor I, II and III respectively (Table 3). 


\section{Table 3}

Two factor solution and forced one factor supplement in women

\begin{tabular}{|c|c|c|c|}
\hline Items & Factor 1 & Factor 2 & Factor $3^{*}$ \\
\hline Repetitive movements & .23 & .17 & .46 \\
\hline Being mentally fatigued & .65 & .03 & - \\
\hline Tired facing another day & .75 & .08 & - \\
\hline Burned out & .75 & .01 & - \\
\hline Being less interested in work & .56 & .03 & - \\
\hline Feeling unhappy and depressed & .66 & .12 & - \\
\hline Experiencing work as too simple & .21 & .15 & .57 \\
\hline Having conflicts with colleagues & .30 & .04 & .56 \\
\hline Having housekeeping help & .07 & -.45 & - \\
\hline Keeping house & -.02 & -.76 & - \\
\hline Living alone & .11 & .74 & - \\
\hline Not enough time left next to work/ family & -.44 & .23 & - \\
\hline
\end{tabular}

* Third factor retrieved from forced two factor solution on remaining items

Employees who were randomly allocated to the intervention group in the aforementioned trial were excluded $(N=63)$. Sum scores of both men and women on the screening instrument were correlated to absenteeism data, to determine how powerful they are in predicting sickness absence. In men, the correlation between the sum score on the screening instrument and absence duration (in days) and absence frequency (number of spells) were both 0.21 ( $p=0.000$ ). Since there was no clear linear relation between sum scores and absenteeism, binary logistic regression was used to determine the association between 'being at risk' (yes/no) and sickness absence (yes/no) in the following year (OR $3.09 \mathrm{Cl}$ 1.47-6.47). In women, the correlation between the sum score on the screening instrument and absence duration (in days) and absence frequency (number of spells) were both 0.14 ( $p=0.000$ ). Again, there was no clear linear relation between sum scores and absenteeism. Therefore, binary logistic regression was used to determine the association between "being at risk' (yes/no) and sickness absence (yes/no) in the following year (OR $1.97 \mathrm{Cl}$ 1.442.69). 
The external validity of the screening instrument was tested, using data of employees who responded on two screening instruments $(N=1736)$. The ability of the screening instrument to identify employees with or without self-reported sickness absence due to psychosocial health complaints, at one year follow-up, was assessed by calculating sensitivity and specificity, and their corresponding confidence intervals, of different cutoff points. A cutoff point of 10 on the screening instrument resulted in a sensitivity score of $13.0 \%$ for women and $50.0 \%$ for men and a specificity score of $95.5 \%$ for women and $96.6 \%$ for men (Table 4 ). The cutoff points were determined using data from the development of the screening instrument. 5 Beside the original external validation of the screening instrument, i.e. its feasibility to predict sickness absence due to psychosocial health complaints, the instrument might also be predictive for overall sickness absence. Sensitivity and specificity were calculated, using objective sickness absence data from participating companies. Now, a cutoff point of 10 on the screening instrument resulted in a sensitivity of $8.0 \%$ for women and $11.8 \%$ for men and a specificity of $96.3 \%$ for women and $98.0 \%$ for men (Table 4 ).

\section{Table 4}

External validation of the screening instrument: cutoff points (CP), sensitivity and specificity (\%) and corresponding confidence intervals (CI)

\begin{tabular}{|c|c|c|c|c|c|}
\hline \multicolumn{6}{|c|}{ Self-reported sickness absence due to psychosocial health complaints } \\
\hline \multicolumn{3}{|c|}{ Men } & \multicolumn{3}{|c|}{ Women } \\
\hline $\mathrm{CP}$ & $\mathrm{Se}^{*}(\mathrm{Cl})$ & Spt (Cl) & $\mathrm{CP}$ & $\mathrm{Se}^{*}(\mathrm{Cl})$ & $\mathrm{Spt}(\mathrm{Cl})$ \\
\hline $5(-2.59)$ & $0(0-80.0)$ & $99.0(96.8-99.7)$ & $5(-1.94)$ & $4.3(0-24.0)$ & $97.5(96.3-98.3)$ \\
\hline $10(-3.03)$ & $50.0(2.7-97.3)$ & $96.6(93.7-98.3)$ & $10(-2.39)$ & $13.0(3.4-34.7)$ & $95.5(94.1-96.6)$ \\
\hline $20(-3.51)$ & $50.0(2.7-97.3)$ & $90.3(86.2-93.3)$ & $20(-2.89)$ & $34.8(17.2-57.2)$ & $86.9(84.8-88.9)$ \\
\hline $30(-3.85)$ & $50.0(2.7-97.3)$ & $81.6(78.7-87.5)$ & $30(-3.22)$ & $52.2(31.1-72.6)$ & $76.2(73.6-78.7)$ \\
\hline $40(-4.14)$ & $50.0(2.7-97.3)$ & $75.8(70.5-80.5)$ & $40(-3.49)$ & $65.2(42.8-82.8)$ & $65.8(62.9-68.6)$ \\
\hline \multicolumn{6}{|c|}{ Objective sickness absence from company records } \\
\hline \multicolumn{3}{|c|}{ Men } & \multicolumn{3}{|c|}{ Women } \\
\hline $\mathrm{CP}$ & $\mathrm{Se}^{*}(\mathrm{CI})$ & $\mathrm{Spt}(\mathrm{Cl})$ & $\mathrm{CP}$ & $\mathrm{Se}^{*}(\mathrm{Cl})$ & $\mathrm{Spt}(\mathrm{Cl})$ \\
\hline $5(-2.59)$ & $3.9(0-14.6)$ & $99.6(97.4-99.9)$ & $5(-1.94)$ & $3.8(2.0-7.1)$ & $97.8(96.5-98.6)$ \\
\hline $10(-3.03)$ & $11.8(4.9-24.6)$ & $98.0(95.1-99.3)$ & $10(-2.39)$ & $8.0(5.1-12.2)$ & $96.3(94.8-97.4)$ \\
\hline $20(-3.51)$ & $23.5(13.2-37.8)$ & $92.8(88.6-95.5)$ & $20(-2.89)$ & $17.6(13.3-22.8)$ & $87.7(85.3-89.8)$ \\
\hline $30(-3.85)$ & $31.4(19.5-46.0)$ & $86.3(81.3-90.2)$ & $30(-3.22)$ & $33.2(27.6-39.3)$ & $78.3(75.4-80.9)$ \\
\hline $40(-4.14)$ & $41.2(27.9-55.8)$ & $79.1(73.4-84.4)$ & $40(-3.49)$ & $42.0(38.0-48.2)$ & $67.4(64.1-70.4)$ \\
\hline
\end{tabular}

\footnotetext{
* Sensitivity; † Specificity
} 


\section{Discussion}

In this study, the psychometric characteristics and the external validation of a recently developed screening instrument were explored. To implement preventive interventions for sickness absence, it is imperative to determine which employees are at increased risk for sickness absence and by that eligible for preventive interventions. An objective screening instrument is a feasible alternative to subjective assessment of employees, and it can efficiently be used in an early stage to determine which employees will benefit most from preventive intervening. In order to enable implementation of the screening instrument on a larger scale, theoretic underpinning and an overview of features of the instrument are needed. We will discuss the characteristics of the instrument, present limitations of this study and give recommendations for future research.

For the development of the instrument, a pure empirical approach was used to identify predictive factors for sickness absence. Since the resulting set of items was a diffuse enumeration of factors with diverse conceptual content, representative scale characteristics are essential to support this statistically driven approach. For this purpose, the structure of the instrument was explored by means of exploratory factor analysis. In men, five items loaded high on a factor which was labeled 'mental health' and four items loaded on 'social support'. In women, six items loaded high on the factor 'mental health' and three items loaded on 'sociodemographic'. In both men and women, the third factor contained remaining items that did not load on a specific factor in the initial analysis. Notwithstanding the identification of a second and a third factor in both groups, the internal consistency reliability of these scales was negligible. Thus, factor analysis only revealed a comprehensible structure of variables related to the dimension 'mental health'. Analogous to the literature, mental health related complaints are identified as a main cause for sickness absence. Although the remaining individual factors did not significantly merge into an overall construct, they are independently predictive for sickness absence.

In order for the instrument to be a usable screening device for sickness absence, it should have predictive value. Dichotomized sickness absence data and the reasons of sick leave were used for the development of the screening instrument. Accordingly, the present form of the instrument is suitable to predict who is 'not at risk' or 'at risk' for sickness absence due to psychosocial health complaints. The results from the 
logistic regression analyses support this assumption. However, the ability of the instrument to predict the duration or the frequency of sick leave was indefinite. Hence, correlations were calculated between the sum scores of responding employees on the screening instrument and their objective sickness absence data, retrieved from company records. The hypothesis was that an increase in the sum score on the instrument correlated with an increase in absence duration and absence frequency in the following year. However, acceptable correlations could not be obtained. Since no definite linear relation was found between these measures, little value could be attached to these results. One could state that the extent to which the screening instrument predicts sickness absence is promising, if it is intended for the dichotomous outcome measure sickness absence. The correlations or absence duration and absence frequency were statistically significant, but not convincing.

After the evaluation of the predictive value, sickness absence data at one year followup were used to assess the external validity of the screening instrument. This is of great importance, since an atheoretical approach was used in the development of the instrument. Potential cutoff points on the developed screening instrument were applied to both the self-reported and objective absenteeism data of employees in the current study for the calculation of sensitivity and specificity rates. To affect those who would probably benefit most from preventive intervening, one could prefer a screening instrument with high specificity. However, the low sensitivity scores that were found in the external validation are undeniable and responsible for the weakness of the instrument, i.e. a substantial number of false-negatively classified employees. Yet, the consequences of not identifying a number of employees are not extremely severe, since the screening instrument is directed at healthy employees. If necessary, they can use the available health care, inside or outside their company, such as consultation with a social worker, general practitioner or occupational physician. Still, the combination of a more sensitive instrument with this specific screening instrument is a functional possibility for future implementation. 5 


\section{Limitations}

Although we have made an accurate examination of psychometric characteristics of the screening instrument, there still remain aspects that merit discussion. The characteristics were tested to provide the instrument a theoretic and scientific basis, and to gain insight in its practical use. Questionnaire reduction and modification of the screening instrument, through deletion of items, were not objectives of this study. Moreover, factor analysis was applied to detect the conceptual structure of the instrument, to compare these with previous research and to enable the investigation of scale characteristics. Though, the identification of unambiguous factors was less successful then expected. Keeping the predictive value of the individual items in the instrument in mind, one could ask oneself if barely revealing comprehensible constructs is a prohibited objective. Sickness absence is a multivariate phenomenon, of which the occurrence and course is likely to be explained by a range of factors. The structure and content of the screening instrument, i.e. a diffuse enumeration of predictive factors from different sources, is a representation of this variety and at the same time an underpinning of not identifying obvious clusters. Also, a reason for results not being as clear and unambiguous as expected could be that different factors are associated with different measures of absence. Nevertheless, more structure in the screening instrument could have resulted in higher internal consistency reliability. On closer consideration, factor analysis implicates a few choices that may contribute to the current results. That is, limiting values for significant loadings, cross-loadings and the minimum items within a factor were, rather arbitrarily, determined beforehand. As regards the number of items in a factor, identification of the same number of underlying dimensions as the number of items in the instrument is meaningless. Though, some items formed a factor by itself but were still removed from the analysis, since they did not load sufficiently on other identified constructs. Consequently, numerous underlying dimensions stay unrevealed. Further, the expected correlation between sum scores on the screening instrument and sickness absence failed to materialize, whereas the dichotomous comparison between 'at risk' and 'not at risk' employees and being absent from work (yes/no) yielded noteworthy associations. 'Correlation' assumes that there is a linear relationship between the two sets of numbers. If not, it will give false and misleading readings that substantially underestimate the relationship. Since dichotomized sickness absence data were used for the development of the screening instrument, the present form of the instrument is explicitly suitable to predict who is 'not at risk' or 'at risk' for sickness absence due to psychosocial health complaints. As regards implementation possibilities, the instrument should merely be applied for this latter pur- 
pose. As regards the external validation of the instrument, both self-reported and objective sickness absence data were used to identify employees at increased risk for sickness absence and to determine the sensitivity and specificity rates of the instrument. Results for sensitivity were not noteworthy, but the findings for specificity were remarkably high. More important, both sensitivity and specificity were unvarying during the development and validation phases of the instrument. And, no immense differences in rates were found when using self-reported or objective sickness absence data. These results suppress the view that self-reports can not be considered a valid measure of absenteeism.

\section{Recommendations and conclusion}

To conclude, the results of this study provide a theoretical and scientific basis for the recently developed screening instrument for the prediction of sickness absence due to psychosocial health complaints. An objective of the current study was to identify the underlying conceptual structure of the instrument to narrow the variation between the theoretical and the pure empirical atheoretical approach of identification of predictive factors for sickness absence. Rather unexpectedly, these constructs could not successively be found. After consideration, factor analysis proved to be quite valuable since the findings are a concrete underpinning of the multifactor concept that sickness absence is. Numerous factors are predictive of sickness absence, and they can be summarized in several significant concepts. However, the combination of individual predictors of sickness absence in a concise screening instrument does not have to reflect these facts. Notwithstanding, the comprehensible structure of variables related to the dimension 'mental health' is reflected in both men and women. This result corresponds with previous research on sickness absence due to psychosocial health complaints. For the additional factors, the low internal consistency is the consequential manifestation of a parcel of individual predictive factors. Still, the screening instrument is capable of identifying employees at risk for sickness absence due to psychosocial health complaints. The increased risks for both men and women, and the constant rates for sensitivity and specificity support this ability. With this, opportunities for a more preventive approach to sickness absence become feasible for employees, employers and the society. Future research is needed to assess the effectiveness of such preventive measurements and interventions. Also, psychometric adaptation is needed to improve the properties of the screening instrument and to simplify the implementation on a larger scale. 


\section{References}

1 Luz J, Green MS. Sickness absenteeism from work - a critical review of the literature. Public Health Rev 1997;25(2):89-122.

Borritz M, Rugulies R, Christensen KB, Villadsen E, Kristensen TS. Burnout as a predictor of selfreported sickness absence among human service workers: prospective findings from three year follow up of the PUMA study. Occup Environ Med 2006;63(2):98-106.

3 Schröer C. Verzuim wegens overspanning; een onderzoek naar de aard van overspanning, de hulpverlening en het verzuimbeloop.; 1993.

4 Duijts SFA, Kant I, Swaen GMH, Brandt PAvd, Zeegers MPA. A meta-analysis of observational studies identifies predictors of sickness absence. J of Clin Epidemiol 2007; in press.

5 Duijts SFA, Kant I, Landeweerd JA, Swaen GMH. Prediction of sickness absence: the development of a screening instrument. Occup and Environ Med 2006;63:564-569.

6 Hair JF, Anderson RE, Tatham RL, Black WC. Multivariate data analysis. 5 ed. New Yersey: Prentice Hall; 1998.

7 Streiner DL. Figuring out factors: the use and misuse of factor analysis. Can J Psychiatry 1994;39(3):135-40.

8 SPSS. Base 13.0 for Windows User's Guide. In. Chigago: SPSS Inc; 2004.

9 Veldhoven Mv, Meijman TF. Het meten van psychosociale arbeidsbelasting met een vragenlijst: de Vragenlijst Beleving en Beoordeling van de Arbeid (VBBA) (Questionnaire on psychosocial job demands and job stress). 1994.

10 Huibers MJ, Bultmann U, KasI SV, Kant I, van Amelsvoort LG, van Schayck CP, et al. Predicting the two-year course of unexplained fatigue and the onset of long-term sickness absence in fatigued employees: results from the Maastricht Cohort Study. J Occup Environ Med 2004;46(10):1041-7.

11 Sluiter JK, Beek AJvd, Frings-Dresen MHW. The influence of work characteristics on the need of recovery and experienced health: a study on coach drivers. Ergonomics 1999;42:573-583.

12 Veldhoven Mv, Meijman T. Het meten van psychosociale arbeidsbelasting met een vragenlijst: de Vragenlijst Beleving en Beoordeling van de Arbeid (VBBA) [Questionnaire on perception and Judgment of Work]. Amsterdam: NIA; 1994.

13 Maslach C, Jackson SE. Maslach Burnout Inventory manual. Palo Alto, CA: Consulting Psychologists Press; 1986.

14 Schaufeli WB, Dierendonck Dv. UBOS, Utrechtse Burnout Schaal, Handleiding. Lisse: Swets Test Publishers; 2000.

15 Koeter MWJ, Ormel J. General Health Questionnaire, Handleiding Nederlandse Bewerking [General Health Questionnaire, Manual Dutch Version]. Lisse: Swets \& Zeitlinger; 1991. 
16 Goldberg D. Epidemiology of mental disorders in primary care settings. Epidemiological Reviews 1995;17:182-190. 

THE COMPATIBILITY BETWEEN CHARACTERISTICS OF EMPLOYEES AT RISK FOR SICKNESS ABSENCE AND COMPONENTS OF A PREVENTIVE COACHING INTERVENTION

Saskia FA Duijts ${ }^{1}$

IJmert Kant ${ }^{1}$

Piet A van den Brandt 1

Gerard MH Swaen ${ }^{1,2}$

1 Department of Epidemiology, Maastricht University, Maastricht, The Netherlands

2 Dow Chemical Terneuzen, Terneuzen, The Netherlands 


\section{Abstract}

\section{Objective}

To assess the compatibility between characteristics of employees 'at risk' for sickness absence and components of a preventive coaching intervention.

\section{Methods}

Data from baseline questionnaires of the 'at risk' study population of a randomized trial, and of two reference groups of the Maastricht Cohort Study were used to compare (mental) health and work related characteristics. Details of the intervention were described. Similarities between characteristics of the study population and components of the coaching intervention were discussed.

\section{Results}

Substantial differences between characteristics of the 'at risk' study population and the 'not at risk' reference group were found, which were all addressed during the coaching intervention. The contrast with the 'sick leave' reference group was less obvious. The 'at risk' study population could be indicated as the most beneficial population for this preventive intervention.

\section{Conclusions}

The results show that preventive coaching is an appropriate intervention for employees 'at risk' for sickness absence. 


\section{INTRODUCTION}

Psychosocial health complaints, such as depression, fatigue, stress or work-family conflicts, place an enormous burden on society and are a leading cause of sickness absence in the world. ${ }^{1}$ A substantial number of employees are home on sick leave at any time, and it is estimated that $32 \%$ of these sick leaves can be attributed to psychosocial complaints. ${ }^{2}$ Once on sick leave due to these complaints, employees may encounter difficulties to reintegrate. A better and more effective strategy would be early identification of employees at risk for sickness absence, and early intervention to prevent sickness absence as much as possible. 3 Over the past 20 years, the number of interventions in workplace settings to affect sickness absence has continued to grow. 4 Most of these interventions have a curative character, i.e. they are aimed at reintegration of employees already on sick leave. However, there are also interventions with a more preventive approach, aimed at for example reducing stress at work or improving overall physical activity, in order to reduce the risk for future sick leave. 5 With respect to the target population for preventive interventions, there is little consensus on the characteristics of these employees. To our knowledge, the assessment of compatibility between features of a particular study population and components of a preventive intervention has not been done before. Currently, a randomized trial is in progress to determine the effectiveness of a preventive coaching intervention for employees 'at risk' for sickness absence due to psychosocial health complaints. For this trial, it is essential to identify early which employees are at increased risk, so as to include those who would probably benefit most from preventive coaching. An objective instrument (in Dutch: 'Werkwijzer'), developed with data from the Maastricht Cohort Study on 'Fatigue at Work', was used to screen employees for their risk of sickness absence due to psychosocial health complaints. ${ }^{6}$ Employees who were identified to be 'at risk' were selected to participate in the trial and a sample was invited for the preventive coaching intervention. The current study was designed to assess the appropriateness of preventive coaching as an early intervention for an 'at risk' study population. To clarify this association, clear understanding of features of 'at risk' employees, with regard to health, mental health and work related concepts, was gained. Also, details of the preventive coaching intervention, its approach, structure and protocol, and recurring problems and objectives were described. Further, characteristics of two reference groups were inventoried to enable a comparison between these groups and the 'at risk' study population. The degree to which this preventive coaching intervention suits the characteristics of employees 'at risk' for sickness absence, in contrast with the reference groups, is discussed. 


\section{Methods}

\section{Study population}

Employees of three companies situated in the south-eastern part of the Netherlands received the screening instrument 'Werkwijzer' at their home address. The responses to this screening instrument were the basis for the identification of 'at risk' employees. ${ }^{6}$ These employees received a more extensive baseline questionnaire and were invited to participate in the randomized trial. A more detailed description of the design of the trial is given elsewhere.7 For the current study, data from the baseline questionnaire on the 'at risk' study population were used.

\section{Reference groups}

The screening instrument for the identification of employees 'at risk' for sickness absence was developed using data from the Maastricht Cohort Study on 'Fatigue at Work'. The instrument was applied to the data of this study to identify employees 'not at risk' for sickness absence $(\mathrm{N}=5484)$ and employees 'on sick leave' $(\mathrm{N}=764)$, as only baseline characteristics of the 'at risk' employees in the randomized trial were available. Baseline data of both groups were used in the current study.

\section{Measures}

The baseline questionnaires from the randomized trial and the Maastricht Cohort Study included items on health, mental health and work related concepts. General health was assessed with one item from the Short Form Health Survey (SF-36) ${ }^{8}$ and with a Dutch version of the 12 item General Health Questionnaire (GHO-12).9, 10 Anxious mood was assessed with four items: shyness, excessive worrying, compulsive behavior and compulsive thinking. ${ }^{11}$ Burnout was assessed with two subscales of the Dutch version of the Maslach Burnout Inventory-General Survey (MBI-GS) 12, 13: exhaustion (five items) and professional efficacy (six items). Fatigue was assessed with the 20 item self-reported Checklist Individual Strength (CIS).14, 15 The CIS covers several aspects of fatigue, such as severity (eight items), concentration (five items), motivation (four items) and physical activity (three items). Work related characteristics were assessed with five subscales of a validated Dutch version of the Job Content

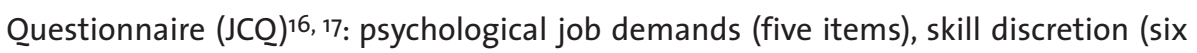
items), decision authority (three items), co-worker social support (four items), and supervisor social support (four items). Additional data on perception of work, such as 'job security', 'commitment', 'role ambiguity', and information on 'need for recovery' 
were gathered with the Dutch Questionnaire on the Perception and Judgment of Work (VBBA). ${ }^{18,19}$ Participants were also asked to indicate whether they experienced conflicts with colleagues or conflicts with supervisors.

\section{The preventive coaching intervention}

The preventive coaching in question is an existing intervention, which consists of seven to nine one-hour sessions within the course of six months. The intervention has been written down in a coaching protocol. The participating coaches received extensive information on the trial and the protocol. A checklist was specifically developed to make an inventory of the main features of each session and the problems that were addressed. The coach completed a checklist after each coaching session. The first session was an introductory interview. Main goal of this session was to discuss practicable personal and coaching objectives and to formulate an overall problem. When phrasing this problem, several issues were examined, e.g. why is it a problem; for whom is it a problem; what causes the problem; and is it possible to solve the problem? At the end of this first session, the employee had to be committed to attend the whole preventive coaching intervention. The second session was a three-way consultation, involving the employee, the related supervisor and the coach. Before the start of the trial, all supervisors of the participating companies were informed about the screening, the coaching and their potential role in this intervention. When an employee completed the introductory session and declared to be committed to the whole program, the related supervisor received an informative letter in which an invitation for partaking in the three-way consultation was extended and the significance of this input was explained. In this first three-way consultation, the main objective was setting up a plan in which the coaching intervention was geared to the involved employee. After completing the coaching intervention, this plan could be used as a prompt for both employee and employer to adhere to, when additional issues arise. The next four to six sessions were individual meetings between employee and coach. Underlying behavioural characteristics of the employee were identified, objectives for the session were determined, and methodologies and instruments related to preventive coaching were applied to initiate behavioural changes. The program ended with a second three-way consultation, in which the coach, the related supervisor and the employee reassembled to evaluate the overall coaching program. Gained insights and experiences were discussed and future plans were made to support the continuation of the initiated alterations in the workplace setting. Meetings to exchange experiences between coaches were organized every two months throughout the trial, under the supervision of the responsible researcher (SD). 


\section{Analyses}

Descriptive analyses were used to compare the characteristics of the 'at risk' study population with the two reference groups. Identical concepts in the baseline questionnaires of the randomized trial and the Maastricht Cohort Study were inventoried, and response options were dichotomized. For each population, responses on the various items of the included concepts were explored and summary percentages for the aggregated response categories were calculated. As regards preventive coaching, information on the adherence to the structure and protocol of the intervention was gathered by means of checklists. Both conceptual issues, such as the possibility of defining a coaching problem, and organizational issues, such as the willingness of the supervisor to participate, were inventoried. Further, the identified problems and behavioural characteristics of employees, objectives and used coaching instruments were assessed. Concepts within the range of defined problems were identified. Similarities between characteristics of the study population and the components of the coaching program were described. 


\section{RESULTS}

\section{Characteristics of study population and reference groups}

To indicate the appropriateness of the preventive coaching intervention, characteristics of the 'at risk' study population $(\mathrm{N}=151)$, and the reference groups 'not at risk' $(\mathrm{N}=5484)$ and 'on sick leave' ( $\mathrm{N}=764)$ were compared (Table 1a and 16$)$.

\section{Table 1a}

Comparison of the 'at risk' study population with two reference groups on (mental) health related characteristics

\begin{tabular}{|c|c|c|c|}
\hline Employee characteristics & $\begin{array}{c}\text { Reference group * } \\
\text { 'not at risk' } \\
(\mathrm{N}=5484)\end{array}$ & $\begin{array}{c}\text { Study population † } \\
\text { 'at risk' } \\
(\mathrm{N}=151)\end{array}$ & $\begin{array}{c}\text { Reference group } \ddagger \\
\text { 'sick leave' } \\
(\mathrm{N}=764)\end{array}$ \\
\hline (Mental) health related characteristics & Yes $(\%)$ & Yes $(\%)$ & Yes $(\%)$ \\
\hline General health is (very) good & 91.8 & 81.4 & 52.7 \\
\hline Lost much sleep & 15.3 & 40.4 & 44.7 \\
\hline Under stress & 29.3 & 51.0 & 48.7 \\
\hline Able to concentrate & 88.3 & 67.5 & 49.4 \\
\hline Playing useful part & 90.5 & 74.8 & 55.5 \\
\hline Face up to problems & 95.2 & 90.7 & 72.1 \\
\hline Capable of making decisions & 94.7 & 83.5 & 69.3 \\
\hline Could not overcome difficulties & 89.5 & 64.8 & 56.8 \\
\hline Feeling reasonably happy & 88.2 & 56.3 & 52.2 \\
\hline Enjoy normal activities & 85.5 & 66.2 & 57.0 \\
\hline Feeling unhappy and depressed & 13.8 & 57.6 & 47.7 \\
\hline Losing confidence in self & 6.2 & 21.2 & 34.3 \\
\hline Thinking of self as worthless & 4.0 & 10.6 & 27.9 \\
\hline Being shy amongst others & 5.0 & 5.3 & 9.1 \\
\hline Extremely worried & 7.3 & 15.3 & 20.5 \\
\hline Compulsive behaviour & 5.6 & 6.0 & 18.6 \\
\hline Compulsive thinking & 10.5 & 20.5 & 31.6 \\
\hline Burnout & Yes (\%) & Yes $(\%)$ & Yes $(\%)$ \\
\hline Mentally exhausted & 29.3 & 39.1 & 44.0 \\
\hline Able to handle problems & 92.7 & 91.3 & 79.5 \\
\hline Whole day work is a burden & 12.7 & 27.8 & 43.9 \\
\hline Positive contribution to organisation & 87.4 & 74.2 & 71.2 \\
\hline Burned out by work & 12.9 & 31.8 & 41.1 \\
\hline Doing a good job at work & 98.0 & 96.1 & 97.1 \\
\hline Empty feeling at the end of work day & 23.9 & 44.4 & 50.1 \\
\hline Happy when finishing something at work & 91.2 & 64.9 & 77.8 \\
\hline Tired facing another day & 13.4 & 38.5 & 42.3 \\
\hline Accomplished valuable goals & 67.3 & 70.1 & 47.9 \\
\hline Self confident at work & 85.8 & 70.8 & 72.8 \\
\hline
\end{tabular}


Table 1a continued

\begin{tabular}{|c|c|c|c|}
\hline Employee characteristics & $\begin{array}{l}\text { Reference group * } \\
\text { 'not at risk' } \\
(\mathrm{N}=5484)\end{array}$ & $\begin{array}{c}\text { Study population } \dagger \\
\text { 'at risk' } \\
(\mathrm{N}=151)\end{array}$ & $\begin{array}{c}\text { Reference group } \\
\text { 'sick leave' } \\
(\mathrm{N}=764)\end{array}$ \\
\hline Fatigue & Yes $(\%)$ & Yes $(\%)$ & Yes (\%) \\
\hline I feel fit & 74.7 & 59.6 & 28.9 \\
\hline I feel very active & 70.9 & 59.6 & 31.7 \\
\hline Thinking requires effort & 15.8 & 24.5 & 30.5 \\
\hline Physically I feel exhausted & 17.5 & 50.4 & 46.7 \\
\hline I feel like doing all kind of nice things & 73.7 & 69.6 & 50.1 \\
\hline I feel tired & 28.6 & 60.2 & 55.0 \\
\hline I do quite a lot within a day & 79.8 & 79.5 & 55.6 \\
\hline When I am doing something, I can concentrate very well & 85.9 & 73.4 & 58.5 \\
\hline I feel weak & 13.4 & 33.8 & 40.2 \\
\hline I don't do much during the day & 8.5 & 21.2 & 26.8 \\
\hline I can concentrate well & 84.4 & 75.5 & 53.6 \\
\hline I feel rested & 57.9 & 35.0 & 25.8 \\
\hline I have trouble concentrating & 15.5 & 28.5 & 36.3 \\
\hline Physically I am in a bad condition & 17.3 & 42.4 & 52.1 \\
\hline I am full of plans & 73.0 & 68.9 & 52.2 \\
\hline I am tired very quickly & 19.0 & 53.0 & 54.1 \\
\hline I have a low output & 8.9 & 16.5 & 30.6 \\
\hline I feel no desire to do anything & 15.4 & 32.5 & 39.0 \\
\hline My thoughts easily wander & 20.6 & 42.3 & 42.6 \\
\hline Physically I feel in a good shape & 61.7 & 43.1 & 24.9 \\
\hline
\end{tabular}

* The 'not at risk' group is identified by applying the screening instrument on data of the Maastricht Cohort Study; † The study population is identified in the randomized trial; ‡ The 'sick leave' group is identified in the Maastricht Cohort Study.

Identical concepts in the baseline questionnaires of the randomized trial and the Maastricht Cohort Study were 'general health', 'burnout', 'fatigue', 'work content', 'perception of work' and 'need for recovery'. Employees 'at risk' for sickness absence reported worse general health than employees 'not at risk' for sickness absence. Additionally, general health of employees 'on sick leave' was classified 'bad' by almost half of these subjects. There are considerable differences between the three populations as regards the scores on the General Health Questionnaire, e.g. 50\% of the employees 'at risk' and 'on sick leave' are feeling stressed, in comparison with about $30 \%$ of the employees 'not at risk' for sickness absence, and more than half of the employees 'at risk' and 'on sick leave' are unhappy and depressed compared to barely $14 \%$ of the employees 'not at risk'. Regarding 'burnout' and 'fatigue', there is a recognizable trend between the 'not at risk', 'at risk' and the 'sick leave' populations. For example, almost $13 \%$ of the 'not at risk' population indicates that a whole day of work is a burden, as opposed to $30 \%$ of the 'at risk' population and nearly $45 \%$ of the 
employees 'on sick leave'. Also, $28 \%$ of the 'not at risk' group reveals to feel tired, as opposed to $60 \%$ of the 'at risk' group and $55 \%$ of the employees 'on sick leave' (Table 1a).

Regarding the work related characteristics, substantial differences between the three groups are present as well. For example, both the 'at risk' population and the employees 'on sick leave' reported to have less supervisor support than the employees 'not at risk' for sickness absence. Also, more conflicts with their superior and colleagues are indicated by the 'at risk' and 'sick leave' population. Further, the 'at risk' employees indicate to have indefinite responsibilities and to have more troubles recovering after work than the 'not at risk' population (Table 1b).

\section{Table 1b}

Comparison of the 'at risk' study population with two reference groups on work related characteristics

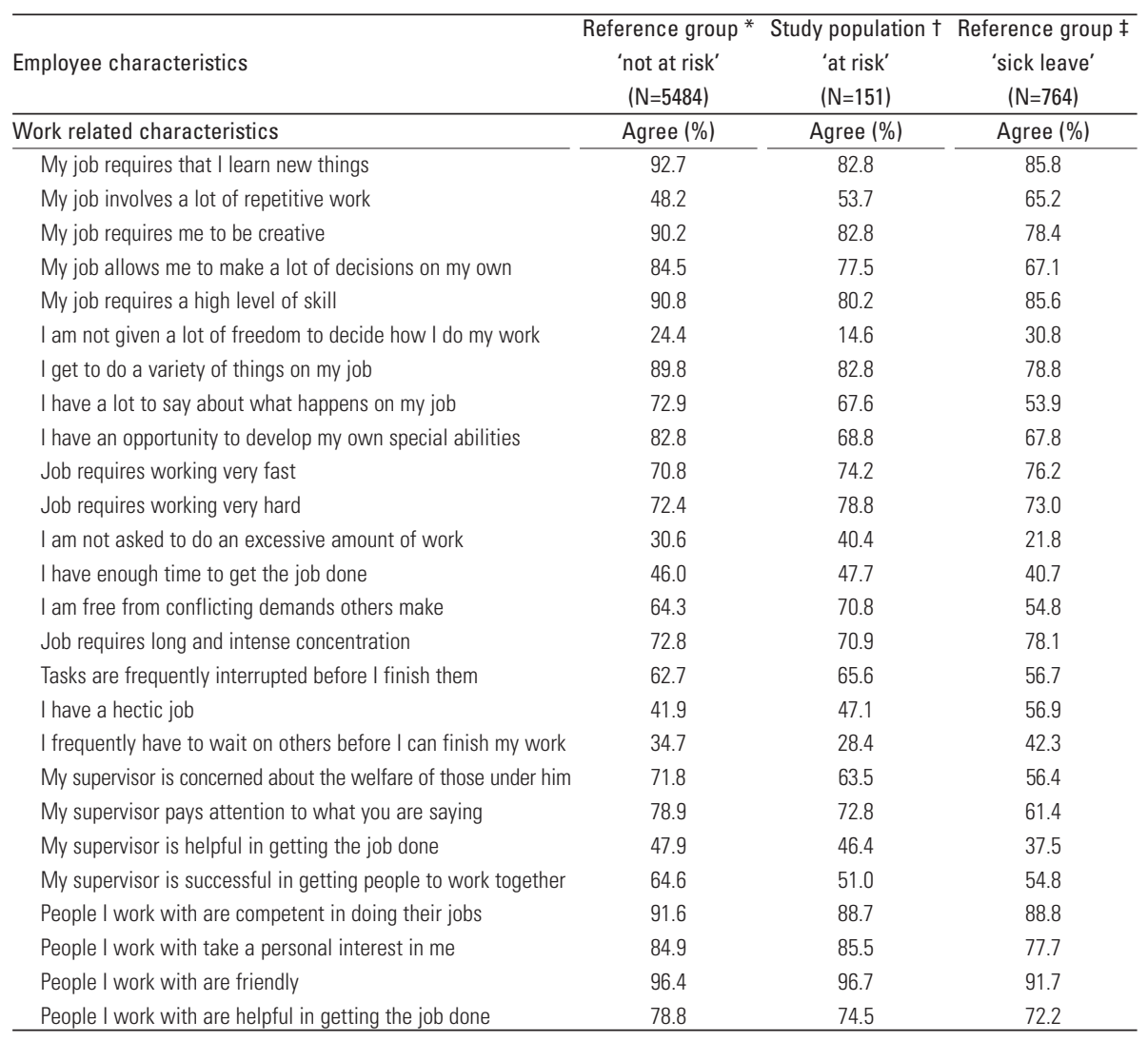




\section{Table 1b continued}

\begin{tabular}{|c|c|c|c|}
\hline Employee characteristics & $\begin{array}{c}\text { Reference group * } \\
\text { 'not at risk' } \\
(\mathrm{N}=5484)\end{array}$ & $\begin{array}{c}\text { Study population } † \\
\text { 'at risk' } \\
(\mathrm{N}=151)\end{array}$ & $\begin{array}{c}\text { Reference group } \ddagger \\
\text { 'sick leave' } \\
(\mathrm{N}=764)\end{array}$ \\
\hline Perception of work & Yes $(\%)$ & Yes (\%) & Yes $(\%)$ \\
\hline Enough career possibilities & 57.5 & 38.4 & 41.1 \\
\hline Committed to the organisation & 85.8 & 58.9 & 73.8 \\
\hline Committed to stay for a few years & 45.1 & 78.1 & 45.0 \\
\hline Conflicts with colleagues & 6.6 & 11.9 & 11.5 \\
\hline Conflicts with supervisor & 8.3 & 15.9 & 19.2 \\
\hline Responsibilities are clear & 85.3 & 73.5 & 83.0 \\
\hline Job specification is clear & 75.7 & 74.8 & 76.2 \\
\hline Need for recovery & Yes (\%) & Yes $(\%)$ & Yes $(\%)$ \\
\hline I find it hard to relax at the end of a working day & 20.1 & 49.0 & 47.3 \\
\hline At the end of a working day I am really feeling worn-out & 33.3 & 62.3 & 62.2 \\
\hline My job causes me to feel rather exhausted at the end of a day & 36.8 & 62.3 & 59.4 \\
\hline Generally speaking, I am still feeling fresh after supper & 57.4 & 31.8 & 29.8 \\
\hline Generally speaking, I am able to relax only on a second day off & 28.4 & 58.3 & 52.5 \\
\hline I have trouble concentrating in the hours off after a working day & 17.6 & 43.0 & 40.6 \\
\hline I find it hard to show interest in other people after work & 27.0 & 42.4 & 43.2 \\
\hline Generally, it takes me over an hour to feel recovered after work & 37.6 & 62.3 & 60.9 \\
\hline When I get home, people should leave me alone for some time & 41.7 & 58.3 & 60.3 \\
\hline After a working day, I am too tired to start other activities & 31.0 & 62.3 & 58.0 \\
\hline During the last part of the working day, I can't optimally perform & 16.3 & 26.5 & 38.4 \\
\hline
\end{tabular}

* The 'not at risk' group is identified by applying the screening instrument on data of the Maastricht Cohort Study; † The study population is identified in the randomized trial. $¥$ The 'sick leave' group is identified in the Maastricht Cohort Study.

\section{Information from the checklists}

Details on conceptual and organizational issues of the coaching protocol are described in Table 2. Of the 76 employees in the intervention group, 51 employees agreed to start the program. Of these, 14 were not committed to continue after the first session, and 37 completed the whole coaching program. Only with regard to the first session, details are given on both the early dropouts and those who completed the whole intervention (Table 2). 
Table 2

Details on conceptual and organizational issues of the preventive coaching protocol

\begin{tabular}{|c|c|c|}
\hline & Whole program & Early dropouts \\
\hline Number of employees & 37 & 14 \\
\hline Mean number of sessions & 8.5 & 1 \\
\hline First session & $\mathrm{N}(\%)$ & $\mathrm{N}(\%)$ \\
\hline Employee's particulars inventoried & $37(100)$ & $14(100)$ \\
\hline Details related supervisor inventoried & $37(100)$ & $3(21)$ \\
\hline Employee surprised by invitation & $6(16)$ & $4(29)$ \\
\hline Significant coaching problem existed beforehand & $14(38)$ & $0(0)$ \\
\hline Answers on screening instrument resulted in defining problem & $37(100)$ & $5(36)$ \\
\hline Significance of coaching intervention was recognized & $37(100)$ & $4(29)$ \\
\hline Coaching objectives were clear & $37(100)$ & $7(50)$ \\
\hline Acquainted with participation of related supervisor & $37(100)$ & $14(100)$ \\
\hline Committed to attend the whole coaching intervention & $37(100)$ & $0(0)$ \\
\hline Second session (first three way consultation) & Whole program & \\
\hline Related supervisor is motivated to participate & $34(92)$ & \\
\hline Supervisor is surprised that this specific employee is invited & $7(19)$ & \\
\hline Experiences from first session are communicated to supervisor & $37(100)$ & \\
\hline Personal and organizational objectives were geared to one another & $33(89)$ & \\
\hline Consensus on the main coaching problem exists & $37(100)$ & \\
\hline Division of roles between the three partakers was elucidated & $33(89)$ & \\
\hline Agreements upon future communication were made & $33(89)$ & \\
\hline A overall plan for the coaching intervention was made & $33(89)$ & \\
\hline Individual sessions & Mean of 6 sessions & \\
\hline Main coaching problems and subordinate issues were explored & $32(86)$ & \\
\hline Behavioural characteristics of the employee were identified & $25(68)$ & \\
\hline Objectives for the session were determined & $28(76)$ & \\
\hline Methodologies and instruments related to coaching were applied & $37(100)$ & \\
\hline Objective for individual session achieved (yes-in part-no) & $12(33)-16(43)-9(24)$ & \\
\hline Last session (second three way consultation) & Whole program & \\
\hline Gained insights and experiences were discussed & $23(62)$ & \\
\hline Future plans for continuation were made & $23(62)$ & \\
\hline
\end{tabular}

Next to the details on the coaching protocol, information on the defined problems, behavioural characteristics of the employees, objectives and applied coaching instruments was gathered. The most frequently reported problems by the employees can roughly be classified into three concepts, i.e. work related problems, personal issues and the combination of both. Regarding the work related category, too much workload, insufficient social support or feedback, indefinite responsibilities, and poor communication at work were important problems. As regards the personal issues, low self-esteem, low personal efficacy, disability to concentrate, feeling depressed or fatigued were points of interest. As far as the combination of both categories, an imbalance between workload and capacity, poor combination of personal and organizational objectives and uncertainties upon functioning were significant issues. 
Subsequent to the determination of the main coaching problem, behavioural characteristics of the employee, linked to this problem, were inventoried. Frequently recurring features were uncertainty, inflexibility, vulnerability, restlessness, apathy, instability in emotions, nervousness and perfectionism. For each individual session, the coach and employee formulated a coaching objective to pursue in that specific meeting. When the objective was not achieved directly, various sessions were spend accomplishing the issue. Regarding the coaching problem 'too much workload', principal objectives were e.g. indicating limits, establishing priorities and coping. 'Insufficient social support and feedback' was tackled with e.g. taking initiative, improving communication and coping with negative criticism. As regards 'indefinite responsibilities', imperative objectives were e.g. requesting clarity and adhering to ones job specification, and 'poor communication at work' was handled with e.g. gaining insight in the cause of the problem, extending sincerity, coping with conflicts, promoting interactions and exchanging ideas. Coaching objectives for problems in the personal field were e.g. increasing self-awareness, appreciating personal capacities and qualities, avoiding distraction, improving structure, learning to make choices and time-management. With regard to the combination of work related problems and personal issues, objectives were e.g. recovering the energy balance, being aware of the personal position in the organization, asking for feedback and generating stability in the combination of work and family. Finally, the coaches registered information on the checklists about the applied coaching instruments. Useful instruments during the coaching intervention were e.g. self-analysis, exploring role patterns, time-management, role-playing, career planning, analysing the personal life line and relaxation exercises. 


\section{Discussion}

\section{Appropriateness of preventive coaching}

This study presents a qualitative analysis of preventive coaching and it describes the appropriateness of this intervention for employees 'at risk' for sickness absence. Preventive coaching is described as an approach to enhance wellbeing and performance in personal life and work domains, and to improve functioning, achieve goals, and manage stress in non-clinical populations. The underlying principle of the intervention is to assist the individual, by enforcing strengths and reducing weaknesses, to gain a better understanding of underlying behaviour and to manage changes. The coach is not responsible for supplying solutions, but attempts to improve internal reflection. Since preventive coaching is directed at apparently healthy employees, who are not on sick leave, the coaching problems can be interpreted as relatively mild. Accordingly, coaching can be seen as a rather 'healthy' intervention. Further, the involvement of the related supervisor in the coaching program, and the fact that the coaching problems are mainly work-related or a combination of work and personal related issues, demonstrates the occupational nature of this intervention.

The preventive coaching intervention was offered to a specific non-clinical, but 'at risk', study population. Employees were identified as being 'at risk' for sickness absence if they scored above the cut-off point on the developed screening instrument. This instrument consists of predictive items for sickness absence, for both men and women, mostly related to health, mental health and work related characteristics. Being 'at risk' for sickness absence implied that the employee in question was not on sick leave, but responded positively on several predictive items such as 'having conflicts at work', 'being tired', 'having a burnout', 'having a lack of supervisor support', and 'having troubles concentrating'. Herewith, the 'at risk' employees can be considered as rather healthy subjects with relatively mild work or personal related problems. On the strength of this description, one could say that the 'at risk' study population and the preventive coaching intervention were quite compatible.

\section{Comparison with reference groups}

To enable a broad assessment of the 'at risk' study population and both reference groups, concepts from baseline questionnaires of the randomized trial and the Maastricht Cohort Study were explored. When comparing the characteristics of the employees 'at risk' for sickness absence with those 'not at risk' for sickness absence, the 
health and mental health related concepts are reported more negatively by the former group. The differences in percentages of numerous characteristics, such as 'losing confidence in self', 'capable of making decisions', 'able to concentrate', 'feeling unhappy and depressed' and 'feeling tired', completely validated defined coaching problems, such as low self-esteem, low personal efficacy, disability to concentrate, feeling depressed or fatigued. Further, differences in percentages of work related characteristics, such as 'working very fast and hard', 'attention from supervisor', 'clear responsibilities' and 'conflicts at work', supported formulated coaching problems, such as too much workload, insufficient social support, indefinite responsibilities, and poor communication at work. Overall, hardly any differences in characteristics between 'at risk' and 'not at risk' employees were recognized that were not subject of discussion in the preventive coaching intervention.

The contrast between employees 'at risk' for sickness absence and employees 'on sick leave' was less obvious, i.e. the percentages of the latter group were equivalent or even worse than those of the former. Notwithstanding the main difference between these two groups, i.e. presence at work, the resemblances were significant. This supports the idea that the characteristics of the 'at risk' employees are potential aspects to deal with, through interventions, in the workplace setting. And, it confirms the appropriateness of coaching as an early intervention in 'at risk' employees to prevent sickness absence.

\section{Recommendations and conclusions}

The results of this study show that preventive coaching is an appropriate intervention for employees 'at risk' for sickness absence. That is, the characteristics of these employees are compatible with the components of the intervention. Differences in numerous (mental) health and work related characteristics, between the 'at risk' study population and employees from the reference groups, completely corresponded with defined coaching problems of the participating employees. Assessing the compatibility between features of the study population and components of the intervention contributes to the knowledge on suitability of preventive interventions in the occupational health field. For both employers and policymakers, this non-clinical approach provides leads to manage work and personal related problems of employees, to enhance their general wellbeing and to prevent sick leave. 


\section{References}

1 Luz J, Green MS. Sickness absenteeism from work - a critical review of the literature. Public Health Rev 1997;25(2):89-122.

2 ILO. Mental health in the workplace: Introduction. Geneva: International Labour Office; 2000. Report No.: Report No.: ILO/OO/37.

3 Schröer C. Verzuim wegens overspanning; een onderzoek naar de aard van overspanning, de hulpverlening en het verzuimbeloop.; 1993.

4 Mercer WM. National Worksite Health Promotion Survey. Northbrook: Association for Worksite Health Promotion, US Department of Health and Human Services; 1999.

5 Wilson MG. A comprehensive review of the effects of worksite health promotion on healthrelated outcomes: an update. Am J Health Promot 1996;11(2):107-8.

6 Duijts SFA, Kant I, Landeweerd JA, Swaen GMH. Prediction of sickness absence: the development of a screening instrument. Occup and Environ Med 2006;63:564-569.

7 Duijts SFA, Kant I, Swaen GMH. Advantages and disadvantages of an objective selection process to enable preventive intervening in employees at risk for sickness absence. BMC Public Health 2007; 7 (67).

8 Ware JE, Jr., Sherbourne CD. The MOS 36-item short-form health survey (SF-36). I. Conceptual framework and item selection. Med Care 1992;30(6):473-83.

9 Koeter MWJ, Ormel J. General Health Questionnaire, Handleiding Nederlandse Bewerking [General Health Questionnaire, Manual Dutch Version]. Lisse: Swets \& Zeitlinger; 1991.

10 Goldberg D. Epidemiology of mental disorders in primary care settings. Epidemiological Reviews 1995;17:182-190.

11 Huibers MJ, Bultmann U, KasI SV, Kant I, van Amelsvoort LG, van Schayck CP, et al. Predicting the two-year course of unexplained fatigue and the onset of long-term sickness absence in fatigued employees: results from the Maastricht Cohort Study. J Occup Environ Med 2004;46(10):1041-7.

12 Maslach C, Jackson SE. Maslach Burnout Inventory manual. Palo Alto, CA: Consulting Psychologists Press; 1986.

13 Schaufeli WB, Dierendonck Dv. UBOS, Utrechtse Burnout Schaal, Handleiding. Lisse: Swets Test Publishers; 2000.

14 Vercoulen JH, Swanink CM, Fennis JF, Galama JM, Meer JWvd, Bleijenberg G. Dimensional assessment of chronic fatigue syndrome. J Psychosom Res. 1994;38:383-392.

15 Vercoulen JH, Hommes OR, Swanink CM, Jongen PJ, Fennis JF, Galama JM, et al. The measurement of fatigue in patients with multiple sclerosis. A multidimensional comparison with patients with chronic fatigue syndrome and healthy subjects. Arch. Neurol 1996;53:642-649. 
16 Karasek RA. Job Content Questionnaire and User's Guide. Los Angeles: University of Southern California: Department of Industrial and Systems Engineering.; 1985.

17 Houtman I. Reliability and Validity of the Dutch version of the Karasek Job Content Questionnaire. In: APA/NIOSH conference on Work, Stress \& Health; 1995; Washington (DC): APA; 1995.

18 Sluiter JK, Beek AJvd, Frings-Dresen MHW. The influence of work characteristics on the need of recovery and experienced health: a study on coach drivers. Ergonomics 1999;42:573-583.

19 Veldhoven Mv, Meijmen T. Het meten van psychosociale arbeidsbelasting met een vragenlijst: de Vragenlijst Beleving en Beoordeling van de Arbeid (VBBA) [Questionnaire on perception and Judgment of Work]. Amsterdam: NIA; 1994. 


\title{
7
}

\author{
EFFECTIVENESS OF A PREVENTIVE COACHING \\ INTERVENTION FOR EMPLOYEES AT RISK FOR SICKNESS \\ ABSENCE DUE TO PSYCHOSOCIAL HEALTH COMPLAINTS: \\ RESULTS OF A RANDOMIZED CONTROLLED TRIAL
}

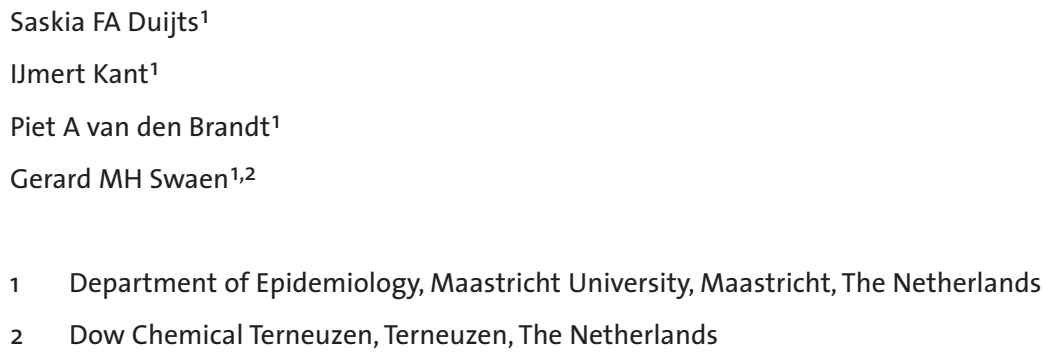




\section{Abstract}

\section{Objectives}

To assess the effectiveness of a preventive coaching intervention on sickness absence due to psychosocial health complaints and on general wellbeing of employees.

\section{Methods}

The study was carried out in three large companies in the Netherlands. Employees $(\mathrm{N}=151)$ at risk for sickness absence were identified, by means of a screening instrument, and randomized. The intervention group $(\mathrm{N}=76)$ received the preventive coaching program; the control group $(\mathrm{N}=75)$ received usual care. Self-administered questionnaires were sent to employees at six ( $\left.\mathrm{T}_{1}\right)$ and twelve $\left(\mathrm{T}_{2}\right)$ months follow-up, and subjective and objective sickness absence data were gathered. Primary outcome measure of the trial is sickness absence; secondary outcome measures are self-rated health, psychological distress, anxious mood, coping, psychological work characteristics, need for recovery, fatigue and burnout.

\section{Results}

The results showed no effect of coaching on self-reported sickness absence due to psychosocial health complaints. Based on objective data, a $14 \%$ reduction in sickness absence duration was achieved in the intervention group as compared to the control group (15.6 vs. 18.1 days). Employees who participated in the coaching, reported statistically significant and clinically relevant improved health, declined psychological distress, less burnout, less need for recovery, and an increased satisfaction with life. Adverse significant effects were found for job insecurity and training possibilities.

\section{Conclusions}

This study shows that the coaching intervention has an effect on both objective duration of sick leave and general wellbeing of employees. For implementation of the preventive strategy further research is warranted. 


\section{INTRODUCTION}

Sickness absence due to psychosocial health complaints represents a major concern in the Western world. ${ }^{1}$ As many as one in ten workers suffers from depression, fatigue, stress or work family conflicts, and about one third of all sick leaves can be attributed to such psychosocial complaints. ${ }^{2}$ Once on sick leave due to these complaints, employees may encounter difficulties to reintegrate. From an occupational health care perspective, a better and more effective strategy might be early identification of employees at risk for sickness absence, and early intervention to prevent sickness absence as much as possible. 3 First, it is essential to know which employees are at increased risk, so as to affect those who would probably benefit most from preventive intervening. And second, there must be an appropriate intervention program that suits the characteristics of these identified 'at risk' employees. In a previous study, an instrument consisting of predictive items for both men and women, called the 'Werkwijzer', was developed by means of data from the Maastricht Cohort Study on 'Fatigue at Work', to screen employees for their risk of sickness absence.4 The characteristics of this screening instrument were explored and it proved to be effective in the prediction of who is 'not at risk' or 'at risk' for sickness absence due to psychosocial health complaints.5, 6 For the second prerequisite, a preventive coaching intervention was examined. Most of the interventions in workplace settings have a rather curative character, i.e. they are aimed at reintegration of employees already on sick leave. However, there are also interventions with a more preventive approach, aimed at for example reducing stress at work or improving overall physical activity, in order to reduce the risk for future sick leave.7 Preventive coaching appeared to be a promising intervention to affect sickness absence due to psychosocial health complaints, i.e. the compatibility of the characteristics of identified 'at risk' employees and the components of this preventive coaching intervention were explored and the intervention demonstrated its appropriateness to manage work and personal related problems of employees. ${ }^{8}$ In the current randomized controlled trial, the preventive coaching intervention was compared with usual care in a Dutch population of 'at risk' employees to assess its effect on sickness absence due to psychosocial health complaints. We hypothesized that delivering this intervention to employees at risk for sickness absence would reduce future sick leave due to psychosocial health complaints and increase their general wellbeing. 


\section{Methods}

\section{Design and study population}

To study our hypothesis, a randomized controlled trial was conducted. Employees of three companies, being part of the health care sector and the educational sector, participated ( $\mathrm{N}=8603)$. They received the screening instrument, specifically developed for the present study, at their home address. The development and the internal and external validation of the screening instrument have been described in detail elsewhere.4, 5 An overall sum score on the screening instrument was calculated for each responding employee, and was compared to the cutoff point on the instrument. Identified 'at risk' employees who signed the informed consent received an extensive baseline questionnaire (To). Randomization was achieved by means of computerized block allocation (size of four), carried out by the principal investigator (SD), and took place after completion of this baseline questionnaire and after verification of a second informed consent that was added to this questionnaire. Employees allocated to the control group ( $\mathrm{N}=75$ ) were free to make use of the usual care present in their company, such as consultation with a social worker or occupational physician. Employees in the intervention group $(\mathrm{N}=76)$ received an invitational letter for the preventive coaching program. Researchers and coaches were not blind to the group allocation. During the follow-up period, self-administered questionnaires were sent to the randomized employees at six ( $\left.\mathrm{T}_{1}\right)$ and twelve $\left(\mathrm{T}_{2}\right)$ months after randomization and sickness absence data were collected through both these questionnaires and linkage to company sickness absence records. Employees were ineligible for participation if they were fully or partially on sick leave while completing the screening instrument, suffered from chronic psychological problems at baseline, had more than one work contract, were pregnant or on maternity leave at the time the questionnaires were sent out. Primary outcome measure of the trial is self-reported sickness absence due to psychosocial health complaints; secondary outcome measures are self-rated health, psychological distress, anxious mood, coping, psychological work characteristics, need for recovery, fatigue, burnout and several sociodemographic and organizational characteristics. The Medical Ethics Committee of Maastricht University/ Academic Hospital Maastricht approved the study protocol.

\section{The preventive coaching intervention}

Employees in the intervention group were offered seven to nine one-hour sessions of preventive coaching within the course of six months. The intervention was written 
out in a coaching protocol. A checklist was developed to inventory the main features of each session and the problems that were addressed. The coach completed several checklists, depending on the number of sessions, and a final report. The first session was an introductory interview. The main goal was to discuss practicable personal and coaching objectives and to formulate an overall problem. When phrasing this problem, several issues were examined, e.g. why is it a problem; for whom is it a problem; what causes the problem; and is it possible to solve the problem? At the end of this first session, the employee had to be committed to attend the whole intervention. The second session was a three-way consultation, involving the employee, the related supervisor and the coach. In this session, objectives and the formulated coaching problem were communicated to the supervisor and indispensable organizational objectives were added. The main objective was setting up a plan in which the coaching intervention was geared to the involved employee. The next four to six sessions were individual meetings, in which the employee and the coach further explored the main coaching problem and subordinate issues. Underlying behavioral characteristics of the employee were identified, objectives for the session were determined, and methodologies and instruments related to preventive coaching were applied to initiate behavioral changes. The program ended with a second three-way consultation. The coach, the related supervisor and the employee reassembled to evaluate the overall coaching program. Gained insights and experiences were discussed and future plans were made to support the continuation of the initiated alterations in the workplace setting. A qualitative analysis of the preventive coaching intervention was described in detail elsewhere. ${ }^{8}$

\section{Primary outcome measure}

Primary outcome of the trial was the occurrence of sickness absence due to psychosocial health complaints (no/ yes). Subjective absence data were gathered by means of questionnaires at 12 months follow-up (T2). Employees were asked to report the frequency of sickness absence in the previous four months, given the six possibilities: (1) never, (2) one time, (3) two times, (4) three times, (5) four times, (6) five times or more. In case of at least one absence report, they were asked to give information about the reason of most recent sick leave. A code has been allotted, in accordance with the International Classification of Primary Care (ICPC), to the reasons employees have given for their latest sickness absence.4 Employees who reported sick due to psychosocial health complaints, including both the psychological and social cluster of the ICPC, could be identified. Since bias can occur in these self-reported diagnostic 
labels, i.e. employees prefer to attribute their absence to flu than to psychosocial complaints, objective sickness absence data were gathered as well, by means of absence records of employees from participating companies. Sickness absence (no/ yes), duration of sick leave (in days) and frequency of sick leave (in spells) were assessed (1) from baseline to eight months follow-up, (2) from eight to twelve months follow-up, i.e. in line with the subjective absence data, and (3) in the whole year after baseline. 9

\section{Secondary outcome measures}

Data on secondary outcome measures were gathered by means of self-administered questionnaires at six ( $\left.\mathrm{T}_{1}\right)$ and twelve months ( $\left.\mathrm{T}_{2}\right)$ follow-up, and included self-rated health, psychological distress, anxious mood, coping, psychological work characteristics, need for recovery, fatigue, burnout and several sociodemographic and organizational characteristics, such as work-family matters, commitment, job satisfaction and job security. Self-rated health was assessed with one item from the Short Form Health Survey (SF-36) ${ }^{10}$, a widely used measure of general health status. ${ }^{11}$ This item was scored on a five point scale ( $1=$ excellent health, 2 = very good health, $3=$ good health, $4=$ moderate health, 5 = bad health). Psychological distress was assessed with a Dutch version of the 12 item General Health Questionnaire (GHO-12). ${ }^{12,} 13$ The GHO-12 was developed as a screening instrument for detecting minor psychiatric disorders and contains items such as 'unhappy and depressed' and 'losing confidence in self'. A higher score on this four point scale indicates a higher level of psychological distress. Anxious mood was assessed with four items on anxiety: shyness, excessive worrying, compulsive behavior and compulsive thinking. A higher sum score indicates a higher level of anxious mood. ${ }^{14}$ Coping was measured with the Utrecht Coping List (UCL). ${ }^{15}$ The UCL has 47 statements covering seven coping strategies, such as active problem solving, seeking social support and depressive reaction, and is scored on a four-point scale ( 1 = never or seldom, 2 = sometimes, 3 = often, 4 = very often). Psychosocial work characteristics were measured with five subscales of a validated Dutch version of the Job Content Questionnaire (JCQ) ${ }^{16,17}$ : psychological job demands (five items), skill discretion (six items), decision authority (three items), co-worker social support (four items), and supervisor social support (four items). The response options for each item varied on a four point scale from 'strongly disagree' to 'strongly agree'. Need for recovery was measured with a scale, derived from the Dutch Questionnaire on the Perception and Judgment of Work (VBBA). ${ }^{18,} 19$ The scale contains 11 dichotomous items, concerning the recuperation period after one day of work, for example 'it is dif- 
ficult for me to relax at the end of a work day'. Higher scores on this scale indicate more complaints, i.e. a higher need for recovery. Fatigue was assessed with the 20 item self-reported Checklist Individual Strength (CIS). ${ }^{20,} 21$ The CIS covers several aspects of fatigue, such as severity (eight items), concentration (five items), motivation (four items) and physical activity (three items). The response on each item is scored on a seven point Likert scale ( $1=$ yes, that is true to $7=$ no, that is not true). Higher scores on these subscales indicate a higher degree of fatigue, more concentration problems, reduced motivation, or a lower level of physical activity. Burnout was assessed with two subscales of the Dutch version of the Maslach Burnout Inventory-General Survey (MBI-GS) 22, 23: exhaustion (five items) and professional efficacy (six items). All items are scored on a seven point frequency scale, ranging from o (never) to 6 (daily). High scores of exhaustion and low scores on professional efficacy are indicative for burnout. Additional data on organizational characteristics, such as 'role ambiguity', 'job security', 'commitment' and 'conflicts', were gathered with the Dutch Questionnaire on the Perception and Judgment of Work (VBBA). ${ }^{18,} 19$ Finally, cointerventions, such as treatment by a general practitioner, occupational physician, psychologist or specialist, were measured by self-report during the whole follow-up period.

\section{Statistical analyses}

To detect a clinically significant difference of $15 \%$ between the intervention and control group on self-reported sickness absence, at a two-sided significance level of $5 \%$ and a power of 90\%, 75 employees per group were needed. These estimates and calculations derive from data of the Maastricht Cohort Study on 'Fatigue at Work', a prospective study in which over 12.000 employees were followed for three years. ${ }^{24}$ The data were analyzed according to the intention-to-treat principle, based on the groups as randomized. Also, a per-protocol analysis, excluding all employees who were not committed to the whole coaching intervention, was performed. For both procedures, differences in baseline characteristics were tested with t-tests for independent samples (continuous data) and $X^{2}$ tests (dichotomous data). Differences scores on continuous outcomes (both To-T1 and To-T2) were used in the analysis. To estimate the effectiveness of the intervention, both linear regression (for continuous data) and logistic regression (for dichotomous data) were used. Because the distribution of the duration of sick leave (in days) and frequency of sick leave (in spells) were skewed to the left like a Poisson distribution, Poisson regression analyses were used to test differences in sickness absence (days and spells) between employees in the 
intervention and the control group. Analyses were performed using the Statistical Package for Social Sciences (SPSS) version $13.0^{25}$ and the Stata statistical software package (StataCorp, College Station, TX). ${ }^{26}$ 


\section{Results}

Figure 1 presents the flow of employees through the trial. Recruitment started in September 2004 and was completed in November 2005.

\section{Figure 1}

The flow of employees through the recruitment phase of the trial

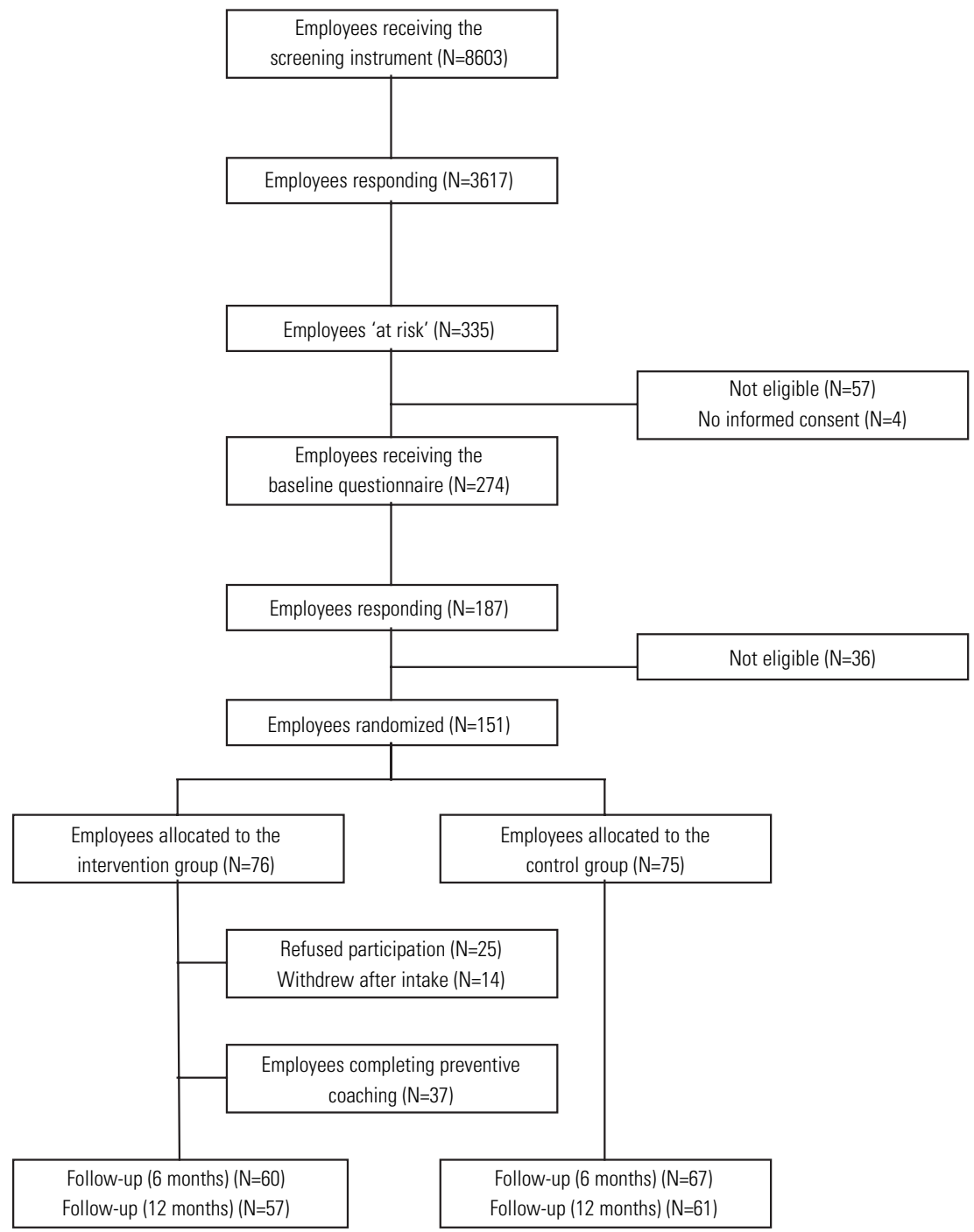


The screening instrument was sent to the home addresses of 8603 employees. From the respondents on the instrument ( $N=3617 ; 42 \%), 335$ employees were identified as being 'at risk' for sickness absence due to psychosocial health complaints. After application of the exclusion criteria, the baseline questionnaire was sent to the remaining 'at risk' employees ( $N=274)$. Of the responding employees $(N=187 ; 68 \%), 151$ were eligible for inclusion in the trial and randomized: 76 to the preventive coaching group and 75 to the control group. After six months of follow-up, self reported data on secondary outcome measures were available for 127 employees (withdrawal rate $15.9 \%$; 16 from the intervention and 8 from the control group). After twelve months of follow-up, self-reported sickness absence data and data on secondary outcome measures were available for 118 employees (withdrawal rate 21.9\%: 19 from the intervention and 14 from the control group). Objective sickness absence data at twelve months follow-up were available for all 151 randomized employees. Table 1 demonstrates that there were no differences in baseline demographic characteristics and outcome measures between the intervention and the control group. Also, no difference in co-interventions existed (Table 1).

Of the 76 employees, allocated to the intervention group, 25 refused coaching instantaneously. Reasons for not accepting the invitation were described elsewhere. ${ }^{6}$ of the remaining 51 employees who agreed to participate in the preventive coaching program, 37 employees (72.5\%) completed the intervention according to protocol (Figure 1). 
Table 1

Baseline characteristics of employees

\begin{tabular}{|c|c|c|c|}
\hline Characteristics * & $\begin{array}{l}\text { Intervention } \\
(\mathrm{N}=76)\end{array}$ & $\begin{array}{l}\text { Control } \\
(\mathrm{N}=75)\end{array}$ & $\begin{array}{l}\text { t-test }(95 \% \mathrm{Cl}) \text { or } \\
\text { odds ratio }(95 \% \mathrm{CI}) \ddagger\end{array}$ \\
\hline Sex, number (\%); m/f & $15 / 61(20 / 80)$ & $12 / 63(16 / 84)$ & 1.29 (0.56 to 2.98) \\
\hline Age (years) & $43.0(9.8)$ & $42.6(9.7)$ & 0.789 (-3.571 to 2.718$)$ \\
\hline Self-rated health, SF-36 ( $1=$ excellent to $5=$ bad) & $2.97(0.75)$ & $3.03(0.59)$ & $0.630(-0.164$ to 0.270$)$ \\
\hline Psychological distress, GHQ-12 (scale 12-48) & $25.70(5.9)$ & $25.99(6.2)$ & $0.767(-1.653$ to 2.237$)$ \\
\hline Anxious mood, (scale 4-16) & $7.04(1.6)$ & $7.29(1.9)$ & $0.420(-0.327$ to 0.781$)$ \\
\hline Total fatigue, CIS (scale 20-140) & $69.75(19.7)$ & $69.27(20.8)$ & $0.886(-6.979$ to 6.034$)$ \\
\hline Burnout Exhaustion, MBI-GS (scale 0-6) & $2.32(1.13)$ & $2.18(1.19)$ & $0.443(-5.181$ to 0.228$)$ \\
\hline Health complaints, number $(\%) \dagger$ & $30(39)$ & $25(33)$ & 1.30 (0.67 to 2.53$)$ \\
\hline Skill discretion, JCQ (scale 12-48) & $35.70(5.9)$ & $34.48(7.0)$ & 0.246 (-3.286 to 0.849$)$ \\
\hline Decision authority, JCO (scale 12-48) & $31.00(4.1)$ & $29.92(4.4)$ & $0.118(-2.440$ to 0.278$)$ \\
\hline Job demands, JCQ (scale 12-48) & $31.88(5.3)$ & $31.61(4.6)$ & $0.741(-1.854$ to 1.322$)$ \\
\hline Decision latitude, JCQ (scale 24-96) & $66.70(8.6)$ & $64.40(9.5)$ & $0.121(-5.212$ to 0.613$)$ \\
\hline Job strain, JCQ (>1 indicates job strain) & $0.97(0.2)$ & $1.00(0.2)$ & $0.353(-0.036$ to 0.100$)$ \\
\hline Coworker social support, JCQ (scale 4-16) & $9.99(1.4)$ & $9.85(1.5)$ & $0.553(-0.609$ to 0.327$)$ \\
\hline Supervisor soc support, JCQ (scale 4-16) & $10.64(1.6)$ & $10.70(1.6)$ & $0.799(-0.438$ to 0.567$)$ \\
\hline Need for recovery, VBBA (>0.54 indicates high NFR) & $0.51(0.3)$ & $0.50(0.3)$ & $0.768(-0.097$ to 0.072$)$ \\
\hline Responsibilities clear, number $(\%) \dagger$ & $53(70)$ & $57(76)$ & 0.76 (0.37 to 1.57 ) \\
\hline Role ambiguity, number (\%) † & $52(68)$ & $60(80)$ & $0.57(0.27$ to 1.20$)$ \\
\hline Job insecurity, number $(\%) \dagger$ & $19(25)$ & $20(27)$ & $0.92(0.44$ to 1.90$)$ \\
\hline Commitment, number $(\%) \dagger$ & $65(86)$ & $65(87)$ & 0.91 (0.36 to 2.29) \\
\hline Training possibilities, number (\%) † & $51(67)$ & $58(77)$ & 0.57 (0.28 to 1.19$)$ \\
\hline Active problem solving, UCL (scale 7-28) & $18.71(3.4)$ & $18.76(3.7)$ & $0.930(-1.094$ to 1.195$)$ \\
\hline Palliative responses, UCL (scale 8-32) & $18.50(3.1)$ & $17.60(3.0)$ & $0.072(-1.882$ to 0.083$)$ \\
\hline Avoidance and passive expectancy, UCL (scale 8-32) & $15.39(3.4)$ & $15.14(2.8)$ & $0.616(-1.258$ to 0.748$)$ \\
\hline Seeking social support, UCL (scale 6-24) & $15.31(7.8)$ & $14.61(3.3)$ & $0.233(-1.836$ to 0.450$)$ \\
\hline Depressive reaction, UCL (scale 7-28) & $12.26(3.5)$ & $12.12(3.3)$ & $0.802(-1.237$ to 0.957$)$ \\
\hline Expressing emotions, UCL (scale 3-12) & $6.50(1.5)$ & $6.53(1.5)$ & $0.890(-0.444$ to 0.510$)$ \\
\hline Comforting cognitions, UCL (scale 5-20) & $12.47(2.5)$ & $12.01(2.4)$ & $0.260(-1.246$ to 0.339$)$ \\
\hline Combination work-family, number (\%) † & $67(88)$ & $71(95)$ & 0.42 (0.12 to 1.43 ) \\
\hline Enough leisure time, number $(\%) \dagger$ & $47(62)$ & $48(64)$ & 0.82 (0.43 to 1.58$)$ \\
\hline Satisfied with life, number (\%) † & $43(57)$ & $47(63)$ & 0.47 (0.38 to 1.43$)$ \\
\hline
\end{tabular}

* Data are mean values (SD) unless stated otherwise; † Measured as dichotomous variable (no/yes) with $\mathrm{N}(\%)$ indicating 'yes'; ‡ t-test $(95 \% \mathrm{Cl})$ in case of continuous variable and odds ratio $(95 \% \mathrm{Cl})$ in case of dichotomous variable.

\section{Effects of coaching compared to usual care on sickness absence}

Table 2 presents the results of the intention-to-treat and the per-protocol analyses for both subjective sickness absence due to psychosocial health complaints and objective sickness absence (no/ yes; in days; in spells). There were no significant differences in both analyses between the coaching and the control group on self-reported sickness absence due to psychosocial health complaints. Objective sickness absence was measured in the months during the intervention, i.e. from baseline to eight months 
follow-up, in the same months in which subjective sickness absence was measured, i.e. from eight to twelve months after baseline, and in the whole year after baseline. In the first follow-up period, the coaching group had a statistically significant smaller amount of absence days, in both the intention-to-treat and the per-protocol analyses, compared to the control group. In both the second follow-up period, i.e. from eight to twelve months after baseline, and the third follow-up period, i.e. the whole year after baseline, the results of the intention-to-treat analysis show that the coaching group had a statistically significant smaller number of sickness absence days. For these follow-up periods, the per-protocol analyses showed no significant differences (Table 2).

\section{Table 2}

Primary outcome measures

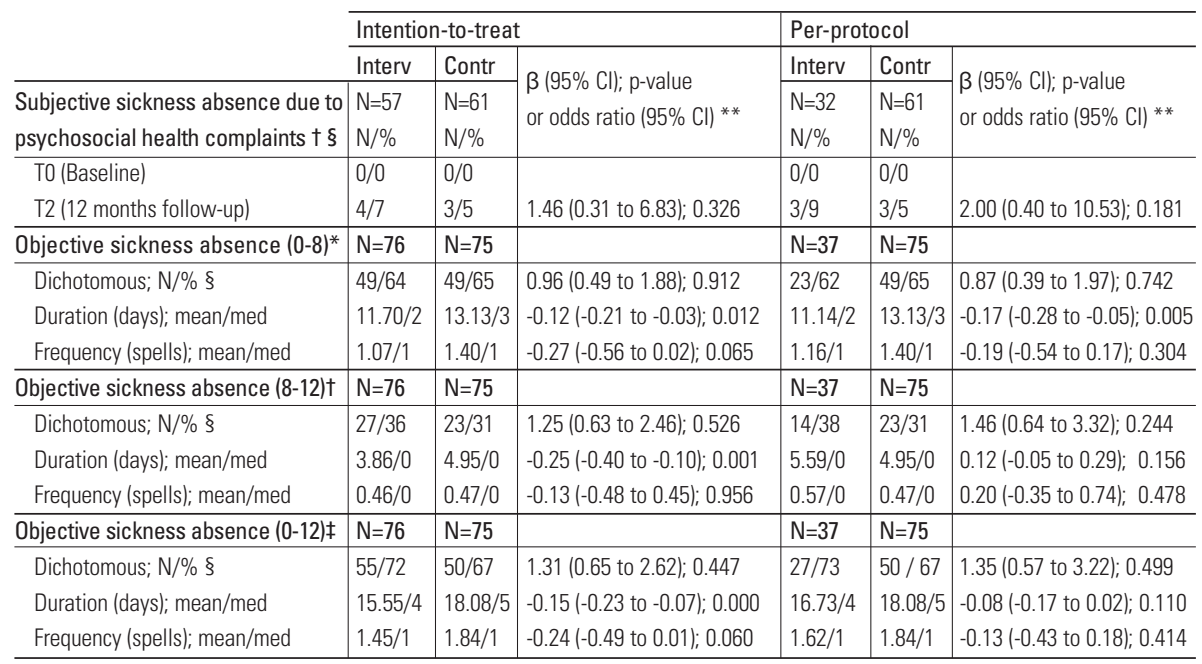

\footnotetext{
* Measured from baseline till 8 months after baseline; † Measured from 8 to 12 months after baseline; ¥ Measured from baseline till 12 months after baseline; § Measured as dichotomous variable (no/ yes) with N / \% indicating 'yes'; * $\beta$ (95\% Cl) in case of continuous variable and odds ratio $(95 \% \mathrm{Cl})$ in case of dichotomous variable.
} 


\section{Effects of coaching on (mental) health, coping and personal factors}

In Table 3, the effect of coaching on (mental) health, coping and personal related outcomes, such as self-rated health, psychological distress, fatigue, the combination of work and family, and satisfaction with life, is presented. The results show that the coaching group had a statistically significant improved self-rated health compared to the control group, between baseline and one year follow-up, in both the intention-totreat and the per-protocol analyses. Psychological distress decreased significantly in the coaching group between baseline and six months follow-up, as shown by the intention-to-treat analyses, and in both follow-up periods as shown by the per-protocol analyses. Burnout, i.e. only data for the subscale exhaustion were shown, decreased significantly in the coaching group between baseline and one year followup, in both the intention-to-treat and the per-protocol analyses. Anxious mood, fatigue, i.e. only data for total fatigue were shown, and health complaints showed no significant differences. With regard to coping, a significant effect of coaching on two strategies, i.e. depressive reaction and expressing emotions, was found in the per-protocol analyses between baseline and twelve months follow-up. Coping with problems, through these strategies, declined in employees who participated in the coaching. Employees in the coaching group were statistically significant more satisfied with their lives in both follow-up periods as regards the intention-to-treat analyses, and between baseline and six months follow-up, in the per-protocol analyses. Results of several not significant coping strategies and personal factors are not shown (Table 3). 
Table 3

(Mental) health, coping and personal related secondary outcomes

\begin{tabular}{|c|c|c|c|c|c|c|c|}
\hline & & \multicolumn{3}{|c|}{ Intention to treat } & \multicolumn{2}{|c|}{ Per protocol } & \multirow[b]{2}{*}{$\begin{array}{l}\text { Diff in diff score (t0-tx) and } \\
95 \% \mathrm{Cl} ; \mathrm{p} \text {-value }\end{array}$} \\
\hline \multicolumn{2}{|l|}{ Outcome * } & $\overline{\text { Interv }}$ & Contr & $\begin{array}{l}\text { Diff in diff score (t0-tx) and } \\
95 \% \mathrm{Cl} ; \mathrm{p} \text {-value }\end{array}$ & $\overline{\text { Interv }}$ & Contr & \\
\hline Self-rated health (SF-36), & T0 & 2.97 & 3.03 & & 3.05 & 3.03 & \\
\hline \multirow[t]{4}{*}{ Scale 1-5; excellent-bad } & $\mathrm{T} 1$ & 2.82 & 3.00 & & 2.85 & 3.00 & \\
\hline & $\mathrm{T} 2$ & 2.68 & 3.05 & & 2.81 & 3.05 & \\
\hline & TO-T1 & 0.23 & 0.03 & $-0.20(-0.43$ to 0.02$) ; 0.074$ & 0.24 & 0.03 & $-0.21(-0.47$ to 0.05$) ; 0.117$ \\
\hline & TO-T2 & 0.37 & -0.02 & $-0.39(-0.66$ to -0.11$) ; 0.007$ & 0.34 & -0.02 & $-0.36(-0.67$ to -0.05$) ; 0.023$ \\
\hline Psychological distress & TO & 25.70 & 26.99 & & 25.62 & 25.99 & \\
\hline \multirow[t]{4}{*}{ (GHQ-12), Scale 12-48 } & $\mathrm{T} 1$ & 23.00 & 26.19 & & 22.82 & 26.19 & \\
\hline & T2 & 22.61 & 25.42 & & 22.31 & 25.42 & \\
\hline & T0-T1 & 2.58 & -0.21 & $-2.80(-5.12$ to -.47$) ; 0.019$ & 3.06 & -0.21 & $-3.27(-5.91$ to -0.63$) ; 0.016$ \\
\hline & T0-T2 & 2.75 & 0.52 & $-2.24(-4.90$ to .42$) ; 0.098$ & 3.56 & 0.52 & $-3.05(-6.08$ to -0.01$) ; 0.049$ \\
\hline Anxious mood, & $\overline{\mathrm{TO}}$ & 7.04 & 7.29 & & 7.16 & 7.29 & \\
\hline \multirow[t]{4}{*}{ Scale 4-16 } & $\mathrm{T} 1$ & 6.80 & 7.15 & & 7.09 & 7.15 & \\
\hline & T2 & 6.87 & 7.40 & & 7.20 & 7.40 & \\
\hline & T0-T1 & 0.10 & 0.06 & $-0.04(-0.48$ to 0.40$) ; 0.851$ & 0.18 & 0.06 & $-0.12(-0.64$ to 0.40$) ; 0.656$ \\
\hline & TO-T2 & 0.04 & -0.36 & $-0.41(-0.92$ to 0.11$) ; 0.120$ & 0.08 & -0.36 & $-0.48(-1.09$ to 0.13$) ; 0.120$ \\
\hline Total fatigue (CIS), & T0 & 69.75 & 69.27 & & 69.28 & 69.27 & \\
\hline \multirow[t]{4}{*}{ Scale $20-140$} & $\mathrm{~T} 1$ & 64.11 & 69.05 & & 71.06 & 69.05 & \\
\hline & T2 & 62.99 & 69.76 & & 68.15 & 69.76 & \\
\hline & TO-T1 & 5.64 & 0.40 & -5.24 (-11.18 to 0.69$) ; 0.083$ & 3.43 & 0.40 & $-3.03(-10.05$ to 3.98$) ; 0.393$ \\
\hline & TO-T2 & 5.90 & -0.16 & $-6.06(-13.0$ to 0.92$) ; 0.088$ & 4.72 & -0.16 & $-4.88(-12.94$ to 3.17$) ; 0.232$ \\
\hline Burnout Exhaustion & T0 & 2.32 & 2.18 & & 2.44 & 2.18 & \\
\hline \multirow[t]{4}{*}{ (MBI-GS), Scale 0-6 } & $\mathrm{T} 1$ & 2.01 & 2.07 & & 2.08 & 2.07 & \\
\hline & T2 & 1.90 & 2.20 & & 2.06 & 2.20 & \\
\hline & TO-T1 & 0.34 & 0.15 & $-0.19(-0.48$ to 0.10$) ; 0.191$ & 0.38 & 0.15 & $-0.24(-0.59$ to 0.11$) ; 0.181$ \\
\hline & TO-T2 & 0.47 & -0.03 & $-0.51(-0.83$ to -0.18$) ; 0.003$ & 0.56 & -0.03 & $-0.59(-0.97$ to -0.22$) ; 0.002$ \\
\hline \multirow{3}{*}{$\begin{array}{l}\text { Health complaints } \dagger \\
(\mathrm{N} / \%)\end{array}$} & TO & $\overline{30 / 39}$ & $25 / 33$ & & $\overline{16 / 43}$ & $\overline{25 / 33}$ & \\
\hline & $\mathrm{T} 1$ & $16 / 27$ & $27 / 40$ & $13 \%$ (0 to 30$) ; 0.107$ & $10 / 29$ & $27 / 40$ & $11 \%(-9$ to 31$) ; 0.285$ \\
\hline & T2 & $16 / 28$ & $26 / 43$ & $15 \%$ (0 to 32 ); 0.101 & $10 / 31$ & $26 / 43$ & $11 \%(-10$ to 33$) ; 0.287$ \\
\hline
\end{tabular}




\section{Table 3 continued}

\begin{tabular}{|c|c|c|c|c|c|c|c|}
\hline \multirow[b]{2}{*}{ Outcome ${ }^{*}$} & & \multicolumn{2}{|c|}{ Intention to treat } & \multirow[b]{2}{*}{$\begin{array}{l}\text { Diff in diff score (t0-tx) and } \\
95 \% \mathrm{Cl} ; \mathrm{p} \text {-value }\end{array}$} & \multicolumn{2}{|c|}{ Per protocol } & \multirow[b]{2}{*}{$\begin{array}{l}\text { Diff in diff score (t0-tx) and } \\
95 \% \mathrm{Cl} ; \mathrm{p} \text {-value }\end{array}$} \\
\hline & & Interv & Contr & & $\overline{\text { Interv }}$ & Contr & \\
\hline Depressive reaction & TO & 12.26 & 12.12 & & $\overline{12.43}$ & 12.12 & \\
\hline \multirow[t]{4}{*}{ (UCL), Scale 8-32 } & $\mathrm{T} 1$ & 11.93 & 11.89 & & 12.11 & 11.89 & \\
\hline & T2 & 11.40 & 12.38 & & 12.09 & 12.38 & \\
\hline & T0-T1 & 0.47 & 0.20 & $-0.19(-1.07$ to 0.70$) ; 0.681$ & 0.63 & 0.20 & $-0.43(-1.53$ to 0.68$) ; 0.443$ \\
\hline & TO-T2 & 0.84 & -0.59 & $-0.26(-1.07$ to 0.55$) ; 0.530$ & 0.66 & -0.59 & $-1.25(-2.49$ to -0.01$) ; 0.048$ \\
\hline Expressing emotions & TO & 6.50 & 6.53 & & 6.41 & 6.53 & \\
\hline \multirow[t]{4}{*}{ (UCL), Scale 3-12 } & $\mathrm{T} 1$ & 6.39 & 6.66 & & 6.27 & 6.66 & \\
\hline & $\mathrm{T} 2$ & 6.35 & 6.89 & & 6.07 & 6.89 & \\
\hline & T0-T1 & 0.18 & -0.12 & $-0.31(-0.84$ to 0.23$) ; 0.259$ & 0.14 & -0.12 & $-0.27(-0.93$ to 0.40$) ; 0.426$ \\
\hline & TO-T2 & 0.10 & -0.33 & $-0.43(-0.89$ to 0.025$) ; 0.063$ & 0.28 & -0.33 & $-0.60(-1.14$ to -0.06$) ; 0.029$ \\
\hline Comforting cognitions & TO & 12.47 & 12.01 & & 12.24 & 12.01 & \\
\hline \multirow[t]{4}{*}{ (UCL), Scale 5-15 } & $\mathrm{T} 1$ & 12.35 & 11.92 & & 12.26 & 11.92 & \\
\hline & $\mathrm{T} 2$ & 12.86 & 11.95 & & 12.41 & 11.95 & \\
\hline & T0-T1 & 0.32 & 0.22 & $-0.11(-0.84$ to 0.63$) ; 0.774$ & 0.09 & 0.22 & $0.13(-0.77$ to 1.03$) ; 0.777$ \\
\hline & TO-T2 & -0.22 & 0.28 & $0.50(-0.24$ to 1.24$) ; 0.183$ & -0.22 & 0.28 & $0.50(-0.34$ to 1.34$) ; 0.240$ \\
\hline Combi work-family $\dagger$ & TO & $\overline{67 / 88}$ & $71 / 95$ & & $\overline{31 / 84}$ & $\overline{71 / 95}$ & \\
\hline \multirow[t]{2}{*}{$(\mathrm{N} / \%)$} & $\mathrm{T} 1$ & 52 / 87 & $59 / 88$ & $1 \%(-10$ to 13$) ; 0.813$ & $30 / 88$ & $59 / 88$ & $0 \%(-14$ to 14$) ; 0.979$ \\
\hline & $\mathrm{T} 2$ & $51 / 89$ & $57 / 93$ & $4 \%(-6$ to 14$) ; 0.443$ & $29 / 91$ & $57 / 93$ & $3 \%(-9$ to 14$) ; 0.626$ \\
\hline Enough leisure time $\dagger$ & TO & $\overline{47 / 62}$ & $48 / 64$ & & $\overline{21 / 57}$ & $\overline{48 / 64}$ & \\
\hline \multirow[t]{2}{*}{$(\mathrm{N} / \%)$} & $\mathrm{T} 1$ & $41 / 68$ & $45 / 67$ & $-1 \%(-18$ to 15$) ; 0.888$ & $23 / 68$ & $45 / 67$ & $1 \%(-20$ to 19$) ; 0.961$ \\
\hline & $\mathrm{T} 2$ & 38 / 67 & $39 / 64$ & $-3 \%(-20$ to 15$) ; 0.755$ & $20 / 63$ & $39 / 64$ & $1 \%(-20$ to 23$) ; 0.891$ \\
\hline \multirow{3}{*}{$\begin{array}{l}\text { Satisfied with life } \dagger \\
(N / \%)\end{array}$} & TO & $\overline{43 / 57}$ & $47 / 63$ & & $\overline{21 / 57}$ & $\overline{47 / 63}$ & \\
\hline & $\mathrm{T} 1$ & $47 / 78$ & $39 / 58$ & $-20 \%(-36$ to -4$) ; 0.017$ & $28 / 82$ & $39 / 58$ & $-24 \%$ (-44 to 5$) ; 0.019$ \\
\hline & $\mathrm{T} 2$ & $40 / 70$ & $41 / 67$ & $-3 \%(-20$ to 14$) ; 0.005$ & $22 / 69$ & $41 / 67$ & $-2 \%(-22$ to 19$) ; 0.880$ \\
\hline
\end{tabular}

* Data are mean values unless stated otherwise; † Measured as dichotomous variable (no/ yes) with $\mathrm{N} / \%$ indicating 'yes 


\section{Effects of coaching on psychosocial work characteristics}

In Table 4, the effect of coaching on psychosocial work related outcomes, such as job demands, social support, need for recovery, job insecurity and commitment, is presented. The results show almost no statistically significant effects. However, need for recovery declined significantly in the coaching group between baseline and six months follow-up and between baseline and twelve months follow-up, as shown by the per-protocol analyses. Contradictory effects were found in the effect of coaching on job insecurity and training possibilities. Employees in the coaching group reported a statistically significant increase in job insecurity between baseline and twelve months follow-up, in the intention-to-treat analyses. And, a statistically significant difference in the intention-to-treat analyses was found between baseline and six months follow-up as regards training possibilities, in favor of the control group. Results on several not significant psychosocial work characteristics, such as fairness, career possibilities and conflicts, are not shown (Table 4). 


\section{- RESULTS OF RANDOMIZED CONTROLLED TRIAL -}

Table 4

Psychosocial work related secondary outcomes

\begin{tabular}{|c|c|c|c|c|c|c|c|}
\hline & & \multicolumn{3}{|c|}{ Intention to treat } & \multicolumn{2}{|c|}{ Per protocol } & \multirow[b]{2}{*}{$\begin{array}{l}\text { Diff in diff score (t0-tx) and } \\
95 \% \mathrm{Cl} ; \mathrm{p} \text {-value }\end{array}$} \\
\hline \multicolumn{2}{|l|}{ Outcome * } & Interv & Contr & $\begin{array}{l}\text { Diff in diff score (t0-tx) and } \\
95 \% \mathrm{Cl} ; \mathrm{p} \text {-value }\end{array}$ & Interv & Contr & \\
\hline Job demands & TO & 31.88 & 31.61 & & 32.57 & 31.61 & \\
\hline \multirow[t]{4}{*}{ (JCQ), Scale 12-48 } & $\mathrm{T} 1$ & 33.07 & 31.44 & & 32.51 & 31.44 & \\
\hline & T2 & 32.86 & 32.27 & & 32.28 & 32.27 & \\
\hline & T0-T1 & -0.51 & 0.23 & $0.74(-0.77$ to 2.24$) ; 0.336$ & 0.20 & 0.23 & $0.03(-1.78$ to 1.84$) ; 0.974$ \\
\hline & T0-T2 & $\underline{-0.11}$ & $\underline{-0.70}$ & -0.59 (-2.33 to 1.15$) ; 0.504$ & 0.59 & -0.70 & $-1.29(-3.29$ to 0.70$) ; 0.201$ \\
\hline Coworker social support & T0 & 9.99 & 9.85 & & 10.00 & 9.85 & \\
\hline \multirow[t]{4}{*}{ (JCQ), Scale 4-12 } & $\mathrm{T} 1$ & 10.38 & 10.24 & & 10.58 & 10.24 & \\
\hline & $\mathrm{T} 2$ & 10.03 & 9.96 & & 10.41 & 9.96 & \\
\hline & T0-T1 & -0.46 & -0.48 & $-0.02(-0.55$ to 0.52$) ; 0.951$ & -0.61 & -0.48 & $0.13(-0.50$ to 0.76$) ; 0.680$ \\
\hline & T0-T2 & -0.14 & -0.08 & 0.05 (-0.53 to 0.63$) ; 0.855$ & -0.44 & -0.08 & $0.36(-0.32$ to 1.04$) ; 0.295$ \\
\hline Supervisor soc support & TO & 10.64 & 10.70 & & 10.59 & 10.70 & \\
\hline \multirow[t]{4}{*}{ (JCQ), Scale 4-12 } & $\mathrm{T} 1$ & 10.82 & 10.76 & & 10.80 & 10.76 & \\
\hline & $\mathrm{T} 2$ & 10.63 & 10.58 & & 10.94 & 10.58 & \\
\hline & T0-T1 & -0.19 & -0.10 & $-0.02(-0.55$ to 0.52$) ; 0.951$ & -0.12 & -0.10 & $0.02(-0.70$ to 0.74$) ; 0.951$ \\
\hline & T0-T2 & 0.13 & 0.25 & $0.05(-0.53$ to 0.63$) ; 0.855$ & -0.20 & 0.25 & $0.45(-0.39$ to 1.29$) ; 0.293$ \\
\hline Need for recovery & TO & 0.51 & 0.50 & & 0.52 & 0.50 & \\
\hline \multirow[t]{4}{*}{ (VBBA), Scale 0-1 } & $\mathrm{T} 1$ & 0.42 & 0.51 & & 0.41 & 0.51 & \\
\hline & $\mathrm{T} 2$ & 0.40 & 0.52 & & 0.44 & 0.52 & \\
\hline & T0-T1 & 0.09 & -0.01 & $0.08(-0.90$ to 1.05$) ; 0.877$ & 0.11 & -0.01 & $-0.12(-0.20$ to -0.03$) ; 0.008$ \\
\hline & T0-T2 & 0.11 & -0.03 & $0.18(-0.93$ to 1.28$) ; 0.755$ & 0.11 & -0.03 & $-0.13(-0.25$ to -0.02$) ; 0.019$ \\
\hline \multirow{3}{*}{$\begin{array}{l}\text { Responsibilities clear } \uparrow \\
\text { (N / \%) }\end{array}$} & TO & $53 / 69$ & $57 / 76$ & & $28 / 37$ & $57 / 76$ & \\
\hline & $\mathrm{T} 1$ & $52 / 87$ & $52 / 78$ & $-10 \%(-23$ to 0$) ; 0.190$ & $29 / 85$ & $52 / 78$ & $-7 \%(-24$ to 9$) ; 0.363$ \\
\hline & $\mathrm{T} 2$ & $45 / 79$ & $51 / 84$ & $5 \%$ (-10 to 19$) ; 0.517$ & $26 / 81$ & $51 / 84$ & $3 \%(-14$ to 19$) ; 0.775$ \\
\hline Role ambiguity $\dagger$ & T0 & $52 / 68$ & $60 / 91$ & & $30 / 81$ & $60 / 80$ & \\
\hline \multirow[t]{2}{*}{$(\mathrm{N} / \%)$} & $\mathrm{T} 1$ & $44 / 73$ & $48 / 72$ & $-1 \%(-18$ to 14$) ; 0.831$ & $24 / 71$ & $48 / 72$ & $1 \%$ (-18 to 20$) ; 0.912$ \\
\hline & $\underline{\mathrm{T} 2}$ & $42 / 74$ & $52 / 85$ & $11 \%(-3$ to 26$) ; 0.123$ & $24 / 75$ & $52 / 85$ & $10 \%(-6$ to 27$) ; 0.229$ \\
\hline Job insecurity ${ }^{\dagger}$ & TO & $19 / 25$ & $20 / 27$ & & $9 / 24$ & $20 / 27$ & \\
\hline \multirow[t]{2}{*}{ (N / \%) } & $\mathrm{T} 1$ & $21 / 35$ & $19 / 28$ & $-7 \%(-23$ to 10$) ; 0.422$ & $14 / 41$ & 19 / 28 & $-13 \%(-32$ to 7$) ; 0.197$ \\
\hline & $\mathrm{T} 2$ & $24 / 42$ & $14 / 23$ & $-19 \%(-36$ to -2$) ; 0.028$ & $12 / 38$ & $14 / 23$ & $-15 \%(-34$ to 5$) ; 0.141$ \\
\hline Commitment $†$ & TO & 65 / 86 & 65 / 87 & & 32 / 86 & 65 / 87 & \\
\hline \multirow[t]{2}{*}{ (N / \%) } & $\mathrm{T} 1$ & $54 / 90$ & 59 / 88 & $-2 \%(-13$ to 9$) ; 0.728$ & $30 / 88$ & 59 / 88 & $0 \%(-14$ to 14$) ; 0.979$ \\
\hline & T2 & 47 / 82 & $54 / 89$ & $7 \%(-7$ to 19$) ; 0.351$ & $26 / 81$ & $54 / 89$ & $8 \%$ (-8 to 22$) ; 0.341$ \\
\hline \multirow{3}{*}{$\begin{array}{l}\text { Training possibilities } † \\
(\mathrm{~N} / \%)\end{array}$} & TO & $51 / 67$ & $58 / 77$ & & $24 / 65$ & $58 / 77$ & \\
\hline & $\mathrm{T} 1$ & 37 / 62 & $53 / 79$ & $17 \%$ (2 to 33 ); 0.033 & $21 / 62$ & $53 / 79$ & $17 \%(-1$ to 36$) ; 0.066$ \\
\hline & $\mathrm{T} 2$ & $44 / 77$ & $45 / 74$ & $-3 \%(-19$ to 12$) ; 0.666$ & $25 / 78$ & $45 / 74$ & $-4 \%(-23$ to 15$) ; 0.644$ \\
\hline
\end{tabular}

* Data are mean values unless stated otherwise; † Measured as dichotomous variable (no/ yes) with $\mathrm{N} / \%$ indicating 'yes' 


\section{Discussion}

\section{General findings}

This paper describes the effect of a preventive coaching intervention, for employees 'at risk' for sickness absence due to psychosocial health complaints, on sick leave and general wellbeing. The intervention was compared with usual care over a 12-month follow-up period. No effect on the primary outcome 'self-reported sickness absence due to psychosocial health complaints' was found. However, the results showed statistically significant effects with regard to objectively measured duration of sick leave in favor of the coaching group. With regard to general wellbeing, most effects were found in the category of (mental) health related outcomes. Employees, who participated in the coaching, reported significantly improved health, declined psychological distress, less burnout, less need for recovery, less depressive and emotional reactions and an increased satisfaction with life, compared to the employees in the control group. For job insecurity and training possibilities, adverse effects were found. We will describe previous research, interpret the outcomes, present methodological considerations, and give recommendations for future research and implementation possibilities.

\section{Previous research}

To our knowledge, this was the first study of preventive coaching on sickness absence due to psychosocial health complaints. The remarkable growth of coaching to date has not, so far, been matched by a similar growth in the research literature that underpins it. Most of the interventions in workplace settings have a rather curative character, i.e. they are aimed at reintegration of employees already on sick leave, e.g. Hlobil et al. 27 Also, many studies investigated the effectiveness of interventions to prevent long-term absenteeism is sick-listed employees, e.g. Brouwers et al. ${ }^{28}$ In addition, there are interventions with a more preventive approach, aimed at for example reducing stress at work or improving overall physical activity, in order to reduce the risk for future sick leave, e.g. Cooper 29, 30 and Bernaards et al.30 However, no study investigated the effect of a coaching intervention in employees 'at risk' for sickness absence due to psychosocial health complaints, which was the primary focus of this study. 


\section{Interpretation of outcomes}

The present randomized controlled trial was conducted from the assumption that early identification of employees at risk for sickness absence, and early intervention to prevent sickness absence would probably be a better and more effective strategy than the more common curative interventions in workplace settings. In spite of a successful identification process, employees did not mention psychosocial health complaints, e.g. fatigue or work-family conflicts, as the main reason for their sick leaves. Moreover, an underestimation of the effect might be present because of potential bias in the self-reported diagnoses. Herewith, the effect of coaching on the primary outcome measure 'sickness absence due to psychosocial health complaints' could not be confirmed. In accordance with self-reported occurrence of sickness absence, no effect could be found for objective, dichotomously measured sickness absence. In contrast, the employees who participated in the coaching intervention seemed to be registered as 'being on sick leave' a little more, but not significantly, than the employees in the control group. Still, the coaching intervention demonstrated to have an effect on objectively measured duration of sick leave, despite the fact that the employees were 'at risk' for subjective sickness absence due to psychosocial health complaints, as determined by the screening instrument. In the intention-to-treat analyses, the difference in total number of days of sick leave in the various follow-up periods was not large, but the results were significant. An employee in the coaching group was on average 2.5 days less absent from work in the whole year after baseline than an employee in the control group. So, a reduction in sickness absence of almost $14 \%$ is found, above what can be achieved by usual care. It is important to realize that this advantage is gained in a group of apparently healthy employees, and in companies with mean sickness duration in that same year of 14 days. Further, the coaching intervention also demonstrated to have an effect on objectively measured frequency of sick leave in employees who participated in the coaching. The difference in absence spells between the intervention and the control group was almost 0.4 , when measured over the entire follow-up period. However, this result was not significant.

As expected, the preventive coaching intervention showed its effects on several (mental) health, work and personal related factors. This expectation followed the results of a previous study, in which components of the intervention and characteristics of the employees 'at risk' for sickness absence were compared. These turned out to be highly compatible. Specifically, preventive coaching is directed at apparently healthy employees, who are not on sick leave, and whose problems can be interpreted as rel- 
atively mild. Since coaching is an occupational related and assisting intervention, anticipated problems of employees, i.e. mainly (mental) health and work-related problems, could be effectively dealt with. For example, statistically significant and clinically relevant effects were found for self-reported health, psychological distress, burnout, need for recovery, and satisfaction with life. These concepts were important points of interest during the intervention, i.e. the main problems the employees in the coaching group defined. Additionally, significant improvements in favor of the coaching group were present in these outcome measures. With regards to their clinical relevancy, substantial differences were found between intervention and control group and in the follow-up of these measures next to the confirmed statistical significance. Also, adverse effects were found for job insecurity and training possibilities. A possible explanation is the impact of the prediction of who's at risk on the involved employees, which can be rather stigmatizing. Distress about potential consequences of this identification can incite the employees to assess these concepts differently, e.g. being at risk for sickness absence can cause job insecurity in the employees participating in the coaching.

\section{Methodological considerations}

Despite the innovative character of the present study, one could question the specificity of the study. Predominantly, the prevention of sickness absence due to psychosocial health complaints was subject of research. Yet, the effectiveness of the preventive coaching intervention on the intended outcome measure was difficult to assess, since employees scarcely reported psychosocial health complaints as the reason for absence. Since this complexity was taken into account when developing the study, objectively measured sickness absence and related secondary outcomes were included in the protocol. Still, a larger difference in duration or frequency of sick leave would probably have been found, if employees 'at risk' were identified based on overall sickness absence, and subsequently were invited for participation in the trial. Also, a withdrawal rate of $\mathbf{2 1 . 9 \%}$ was found at twelve months follow-up. Since the objective sickness absence data were retrieved from company absence records, i.e. data on all 151 randomized employees were available, there were no consequences for the strength of the study. As regards the subjective sickness absence data and data on secondary outcome measures, the loss-to-follow-up could have affected the results of the study. However, the 37 employees who were committed to the coaching, all completed the intervention. Further, the study was carried out in three large companies, being part of two different sectors, i.e. the health care sector and the educational sec- 
tor. Consequently, it remains uncertain whether the results can be easily generalized to various types and sizes of companies. Next to this generalization matter, it is essential to consider the time frame of the prediction of sickness absence, and the follow-up in sick leave. This study started with the dispatch of screening instruments in a time period with low absenteeism rates. Consequently, the achievable advantage in sickness absence is probably lower than what can be gained in previous years, when absenteeism was higher. Also, the follow-up in sick leave was exactly one year after randomization. Directly after randomization, an invitation for the coaching program was sent to the employee, contact between the employee and the assigned coach was realized and an appointment for the first meeting was made. Overall, it took several weeks before the introductory interview was held. In addition, the whole coaching program comprised about six months. So, at eight months follow-up, it was known for certain that the intervention was completed. Various follow-up periods were included in the analyses of sickness absence, to gain insight in sick leave during the intervention, after the intervention and in the whole year after baseline. The follow-up period was artificially cut-off at exactly twelve months post-randomization As a consequence, the time span necessary to develop complaints of such a level that an apparently health employee is unable to work, was rather short. And, long-term sickness absence was probably just partially included. Finally, the results should be weighted against the costs of the coaching intervention, if implementation in daily practice is considered. To be exact, the benefit in duration of sick leave and in improved wellbeing of employees in the coaching group has to be compared with the fixed sum of 1500 euros to be paid for a fulfilled coaching program.

\section{Conclusions}

This study shows that the intervention coaching has an effect on the duration and frequency of objectively measured sickness absence. Also, employees, who participated in the coaching, reported significantly improved health, declined psychological distress, less burnout, less need for recovery, less depressive and emotional reactions and an increased satisfaction with life, compared to the employees in the control group. Still, the identification of eligible employees and the realization of the invention are time-consuming and rather expensive. Thus, employers and policymakers have to weight the effects against the costs of the intervention, if implementation in daily practice is considered. 


\section{References}

1 Luz J, Green MS. Sickness absenteeism from work - a critical review of the literature. Public Health Rev 1997;25(2):89-122.

ILO. Mental health in the workplace: Introduction. Geneva: International Labor Office; 2000. Report No.: Report No.: ILO/Oo/37.

3 Schröer C. Verzuim wegens overspanning; een onderzoek naar de aard van overspanning, de hulpverlening en het verzuimbeloop.; 1993.

4 Duijts SFA, Kant I, Landeweerd JA, Swaen GMH. Prediction of sickness absence: the development of a screening instrument. Occup and Environ Med 2006;63:564-569.

Duijts SFA, Kant I, van den Brandt PA, Swaen GMH. Psychometric characteristics and external validation of a screening instrument to identify employees at risk for sickness absence due to psychosocial health complaints. Submitted. 2007.

6 Duijts SFA, Kant I, Swaen GMH. Advantages and disadvantages of an objective selection process to enable preventive intervening in employees at risk for sickness absence. BMC Public Health 2007; 7 (67).

7 Wilson MG. A comprehensive review of the effects of worksite health promotion on healthrelated outcomes: an update. Am J Health Promot 1996;11(2):107-8.

8 Duijts SFA, Kant I, van den Brandt PA, Swaen GMH. The compatibility between characteristics of employees at risk for sickness absence and components of a preventive coaching intervention. Int J of Evid Bas Coach \& Ment 2007; 5 (1): 19-29.

9 Hensing G, Alexanderson K, Allebeck P, Bjurulf P. How to measure sickness absence? Literature review and suggestion of five basic measures. Scand J Soc Med 1998;26(2):133-44.

10 Ware JE, Jr., Sherbourne CD. The MOS 36-item short-form health survey (SF-36). I. Conceptual framework and item selection. Med Care 1992;30(6):473-83.

11 Aaronson NK, Muller M, Cohen PD, Essink-Bot ML, Fekkes M, Sanderman R, et al. Translation, validation, and norming of the Dutch language version of the SF-36 Health Survey in community and chronic disease populations. J Clin Epidemiol 1998;51(11):1055-68.

12 Koeter MWJ, Ormel J. General Health Questionnaire, Handleiding Nederlandse Bewerking [General Health Questionnaire, Manual Dutch Version]. Lisse: Swets \& Zeitlinger; 1991.

13 Goldberg D. Epidemiology of mental disorders in primary care settings. Epidemiological Reviews 1995;17:182-190.

14 Huibers MJ, Bultmann U, KasI SV, Kant I, van Amelsvoort LG, van Schayck CP, et al. Predicting the two-year course of unexplained fatigue and the onset of long-term sickness absence in fatigued employees: results from the Maastricht Cohort Study. J Occup Environ Med 2004;46(10):1041-7. 
15 Schreurs PJG, Van De Willige G, Brosschot JF, Grau G. De Utrechtse Copinglijst: UCL. Handleiding. 2 ed. Lisse; 1993.

16 Houtman I. Reliability and Validity of the Dutch version of the Karasek Job Content Questionnaire. In: APA/NIOSH conference on Work, Stress \& Health; 1995; Washington (DC): APA; 1995.

17 Karasek RA. Job Content Questionnaire and User's Guide. Los Angeles: University of Southern California: Department of Industrial and Systems Engineering.; 1985.

18 Sluiter JK, Beek AJvd, Frings-Dresen MHW. The influence of work characteristics on the need of recovery and experienced health: a study on coach drivers. Ergonomics 1999;42:573-583.

19 Veldhoven Mv, Meijmen T. Het meten van psychosociale arbeidsbelasting met een vragenlijst: de Vragenlijst Beleving en Beoordeling van de Arbeid (VBBA) [Questionnaire on perception and Judgment of Work]. Amsterdam: NIA; 1994.

20 Vercoulen JH, Swanink CM, Fennis JF, Galama JM, Meer JWvd, Bleijenberg G. Dimensional assessment of chronic fatigue syndrome. J Psychosom Res. 1994;38:383-392.

21 Vercoulen JH, Hommes OR, Swanink CM, Jongen PJ, Fennis JF, Galama JM, et al. The measurement of fatigue in patients with multiple sclerosis. A multidimensional comparison with patients with chronic fatigue syndrome and healthy subjects. Arch. Neur 1996;53:642-649.

22 Schaufeli WB, Dierendonck Dv. UBOS, Utrechtse Burnout Schaal, Handleiding. Lisse: Swets Test Publishers; 2000.

23 Maslach C, Jackson SE. Maslach Burnout Inventory manual. Palo Alto, CA: Consulting Psychologists Press; 1986.

24 Kant I, Bultmann U, Schröer C, Beurskens A, Amelsvoort Lv, Swaen G. An epidemiological approach to study fatigue in the working population: The maastricht cohort study. Occup Environ Med 2003;60 (supl 1):i32-i39.

25 SPSS. Base 13.0 for Windows User's Guide. In. Chigago: SPSS Inc; 2004.

26 Stata. Stata Statistical Software: Release 9.0. In: College station, TX: Stata Corporation; 2005.

27 Hlobil H, Staal JB, Twisk J, Koke A, Ariens G, Smid T, et al. The effects of a graded activity intervention for low back pain in occupational health on sick leave, functional status and pain: 12month results of a randomized controlled trial. J Occup Rehabil 2005;15(4):569-80.

28 Brouwers EP, Tiemens BG, Terluin B, Verhaak PF. Effectiveness of an intervention to reduce sickness absence in patients with emotional distress or minor mental disorders: a randomized controlled effectiveness trial. Gen Hosp Psychiatry 2006;28(3):223-9.

29 Cooper CL. The changing nature of work: workplace stress and strategies to deal with it. Med Lav 2006;97(2):132-6.

30 Bernaards CM, Jans MP, van den Heuvel SG, Hendriksen IJ, Houtman IL, Bongers PM. Can strenuous leisure time physical activity prevent psychological complaints in a working population? Occup Environ Med 2006;63(1):10-6. 

8

EPILOGUE 

In this Epilogue, some of the major findings described in the previous chapters of this thesis will be reflected. The research themes and study objectives presented in the Introduction (Chapter 1 ) are the basic principle of this chapter. Prediction of sickness absence due to psychosocial health complaints is the first concept to be reviewed on its main findings and methodological considerations. In addition, these issues are described and discussed on behalf of the second concept, the effectiveness of early intervening in employees at risk for sickness absence due to psychosocial health complaints. At the end, the chapter addresses overall implications for occupational health practice, and recommendations for further research are given.

\section{Prediction of sickness absence due to psychosocial health complaints}

\section{Main findings}

Probably the most important finding of the first part of the thesis, described in chapter 2 to 5 , is that is it possible to reasonably identify which, apparently healthy, employees are at increased risk for sickness absence due to psychosocial health complaints. This prediction was done by means of an objective screening instrument, called the 'Werkwijzer'. Prior to the development of this instrument, an overview of predictive factors was generated and presented in the second chapter of this thesis, the meta-analysis. The results of this study indicated that predictors such as experiencing psychosomatic complaints, using medication, having a burnout, and having low job control, were statistically significant predictive for the occurrence of sickness absence. Since several independent studies were quantified in this meta-analysis, and the included studies not often explicitly described sickness absence due to psychosocial health complaints as the main outcome measure, the data of the Maastricht Cohort Study on 'Fatigue at Work' were additionally used to identify predictive factors. ${ }^{1}$ In this study, identified predictive items for women were for example feeling depressed, having a burnout, and being less interested in work. For men, predictive items for sickness absence due to psychosocial health complaints were for example compulsive thinking, being mentally fatigued, and lack of supervisor support. The identified items in the Maastricht Cohort Study were combined in the screening instrument, of which the development and internal validation were described in chapter 3. A score above the cutoff point on this instrument indicated a threefold risk for men and a twofold risk for women on sickness absence due to psychosocial health complaints, compared to men and women scoring below the cutoff point. A large pro- 
portion of employees dropped out throughout the objective selection process, illustrated in chapter 4 . The specified number of employees to be randomized was achieved, but many eligible employees could not be included in the preventive intervention, due to the high non-response on the screening instrument or the baseline questionnaire, or due to declining the invitation for the intervention program. Notwithstanding methodological problems, the costs and comprehensiveness of the objective process, the selected employees are actually those at increased risk for sickness absence, and consequently may benefit from the preventive intervention program more than others. Further, the constancy of sensitivity and specificity rates, found when exploring the psychometric characteristics and the external validation of the screening instrument in chapter 5 , supported the applicability of the instrument. Still, the low sensitivity of the instrument resulted in detecting only a small percentage of employees at risk for sickness absence. With these main findings of chapter 2 to 5 , the research objective related to the development of the screening instrument and the assessment of its basic measures was met. Also, insight in the willingness of employees to be screened and in their motivation to participate is gained.

\section{Methodological considerations}

The present study was based on the assumption that prediction of employees at high risk for sickness absence and early intervention would be a promising strategy in the management of psychosocial sickness absence. This idea is not completely innovative, since parts of this hypothesis were already explored in previous studies. Several studies demonstrated the association between work related factors and psychological ill health2,3, and psychological factors and sickness absence4. In line with these studies, Michie et al (2003) presented the association between work related factors and psychological ill health and sickness absence in a literature review. Significant factors in this review were for example work overload, lack of control over work, and poor social support. Also, successful interventions that improve psychological health and levels of sickness absence, mostly training and organizational approaches, were described. 5 However, since most included studies in the review were cross-sectional, and only concerned work related factors, causal relations on various predictive items and psychosocial sickness absence could not be found. Moreover, a recent prospective study by Roelen et al (2006) evaluated various predictive factors for sickness absence at one year follow-up. The aim of the study was to elucidate whether a self-completed questionnaire, consisting of predictive factors, could identify employees at future risk for sickness absence. Workers who reported multiple health complaints, especial- 
ly concentration problems, nervous complaints or coping problems, were at increased risk for sickness absence. Though, the main outcome measure in this study was allcauses sickness absence, rather than psychosocial sickness absence. ${ }^{6}$

Since reintegration of employees on psychosocial sick leave generally takes more time and is associated with more difficulties than return to work following physical problems, the research theme of this thesis was prediction and early intervening in employees at risk for sickness absence due to psychosocial health complaints.

Numerous preceding studies explored all-causes sickness absence, in which underlying diagnoses for sickness absence were not taken into account. In some studies, such as those based on the Whitehall II-study, the information on underlying medical reasons was actually recorded, but not used in the published articles.7, 8 In the metaanalysis, presented in this thesis, the partition of psychosocial complaints from allcauses sickness absence was a complex process, of which the success could not be guaranteed. 9 However, with the omission of studies on predictors of sickness absence due to specific, explicitly reported somatic complaints, the homogeneity of the remaining set of studies in the meta-analysis improved. Also, an overall framework of existing research on the subject, up to now, emerged. The purpose of identifying such predictive factors is to enable screening of employees with a higher probability of developing a particular outcome. ${ }^{10}$ Since it was not possible to account for factors simultaneously in the meta-analysis, data of the Maastricht Cohort Study were used. This cohort study enabled analysis of predictive factors for sickness absence due to psychosocial health complaints on an individual level, and herewith contained unique data for the development of the actual screening instrument. ${ }^{11}$ Also, and more important, the objective of the thesis was to predict and early intervene in employees at high risk for sickness absence due to psychosocial health complaints. In the Maastricht Cohort Study reasons for sickness absence were identified and reported and consequently could be explored. ${ }^{1}$

The Maastricht Cohort Study on 'Fatigue at Work' was a prospective study on a sample of 12,140 workers, employed by 45 different organizations. The cohort study started in May 1998 and covered a period of three years, in which the participants received several self-administered questionnaires, and in which both self-reported and objective sickness absence data from company records were gathered. ${ }^{1}$ Employees who reported that their latest sick leave was due to psychosocial health complaints, i.e. 
complaints belonging to the psychological or social cluster of the International Classification of Primary Care, ${ }^{12}$ were identified and predictive factors for this type of self-reported sickness absence were detected for both men and women. A difficulty of these self-reported absence reasons was that they were not accompanied by a medical diagnosis. Still, the self-reported psychosocial absence data of employees were highly compatible with their available objective absence data.1, 13 In addition, this assumption was supported by previous research on the comparison of selfreported sickness absence with absences recorded in employers' registers. ${ }^{14}$ Thus, the Maastricht Cohort Study was considered an optimal set of data for the identification of predictive factors for sickness absence due to psychosocial health complaints.

After merging the identified factors for both men and women in the screening instrument, it was necessary to establish a cutoff point on the instrument, based on the best possible sensitivity and specificity rates. 15 However, the premeditated combination of high sensitivity and high specificity rates could not be accomplished. A perfect method of screening would be $100 \%$ accurate, i.e. all employees it predicted to go on sick leave would do so and vice versa. In practice, no screening method ever approaches this entirely correct prediction, or even comes close. Because of the multifactorial influences on sickness absence and the large variation in individual behavior, there is always some error. ${ }^{16}$ Hence, the practical usability of the instrument and subsequently the applicability of the intervention were decisive factors in the determination of the cutoff point. To be sure that the intervention was predominantly directed at employees who would benefit most from it, i.e. the preventive coaching program was a rather expensive intervention, high specificity of the screening instrument was preferred. With this, employees who scored below the cutoff point were almost certainly not at risk for sickness absence due to psychosocial health complaints. Nevertheless, low sensitivity scores were present and responsible for the weakness of the instrument, i.e. an amount of false negatively classified employees. The consequences of not identifying these employees were not severe, since the screening instrument was directed at healthy employees. If necessary, they can use the available health care, inside or outside their company, such as consultation with a social worker, general practitioner, or occupational physician.

With the identification of employees at risk, it was necessary to retain them for the participation in the early intervention program, and during the whole course of the study. ${ }^{17}$ Instead of personal enlistment for this intervention, an objective process was 
used to select the eligible employees. The underlying thought for this was that employees who are aware of their being at high risk and who are able to formulate the underlying issue do not automatically have to be those who benefit most from an intervention program. They may be able to eventually handle their situation. Also, supervisors or personnel officers who notice employees struggling with psychosocial health difficulties do not have to make the correct choice in their selection of employees. These subjective methods implicitly give precedence to the employees who profit from this opportunity by simply asking for participation or informing their supervisor about their problems. And, observing supervisors can put employees forward of whom they personally think participating in the intervention is essential for their performance and satisfaction. Through this, participation in purposive intervention programs is depending on the degree of articulation and personal awareness of the employee or supervisor. ${ }^{18}$ Conversely, objective selection can be directed at all employees of a company and has the advantage of neutral allocation of the intervention program. Still, this method had to deal with non-response on questionnaires and non-commitment to the intervention program, through which many eligible employees at risk for sickness absence could not be selected for the preventive intervention.

To gain insight in the characteristics of the unintentional omitted eligible and the ineligible employees, both self-reported and objective sickness absence data were gathered and used for the external validation of the screening instrument. ${ }^{13}$ At the same time, other psychometric features of the instrument were explored. For the development of the instrument, a pure statistical, instead of theoretical, approach was used to identify predictive factors for sickness absence. Since the resulting set of items was a diffuse enumeration of factors with diverse conceptual content, representative scale characteristics were essential to support this approach. Using factor analysis in a scale, which is put together from items coming from different sources, was probably not an obvious method. However, identification of underlying concepts of the screening instrument in the present study was necessary to improve alignment between the theoretical and the more statistically driven approach in the development of the instrument. The results of these analyses were not entirely in favor of the questionnaire, but evidently gave more insight in the practical use of the instrument. For example, a comprehensible structure of variables related to the dimension 'mental health' was found in the exploratory factor analysis. Analogous to the literature, this dimension was identified as a main cause for sickness absence. ${ }^{19}$ 
The remaining individual factors did not significantly merge into an overall construct. Yet, these factors were independently predictive for sickness absence, ${ }^{11}$ and represented the multifariousness of the concept sickness absence.

With regard to the predictive value of the instrument, the hypothesis was that an increase in the sum score correlated with an increase in absence duration and absence frequency in the following year. However, acceptable correlations could not be obtained. The screening instrument was originally developed to predict the occurrence of sickness absence due to psychosocial health complaints, instead of absence duration or absence frequency. Still, different absence measures were considered, since the effect of the intervention on objectively measured occurrence, duration and frequency of sickness absence was assessed. With regard to the external validation of the instrument, both self-reported and objective sickness absence data were used to validate employees at risk for sickness absence, and to determine the sensitivity and specificity rates of the instrument. Results for sensitivity were not noteworthy, but the findings for specificity were remarkably high. And, sensitivity and specificity rates were quite unvarying during the development, the internal validation and the external validation of the instrument, which is not often seen in these measures. ${ }^{20}$ The characteristics and the described methodological considerations should be kept in mind when using the instrument, and applying an objective selection process of employees, in daily occupational health practice.

\section{Early intervention to prevent sickness absence due to psychosocial health com-} PLAINTS

\section{Main findings}

Significant findings of the second part of this thesis, described in chapter 6 and 7, are that coaching can be regarded as an appropriate intervention for employees at risk for sickness absence due to psychosocial health complaints. Components of coaching were compatible with characteristics of these employees. ${ }^{21}$ And, and more important, this intervention has a statistically significant effect on several psychosocial health complaints and on objectively measured duration of sick leave. ${ }^{22}$ To explore the appropriateness of the intervention, characteristics of the at risk study population $(\mathrm{N}=151)$ were compared to a sample of not at risk employees and a group of employees on sick leave. When comparing the at risk employees with the not at risk refer- 
ence group, health and mental health related concepts were reported more negatively by the former group. That is, differences in characteristics, such as 'losing confidence in self' and 'feeling unhappy and depressed', corresponded with coaching objectives, which at risk employees defined in the intervention, such as increasing self-esteem, reducing depressed feelings. Also, differences in work related characteristics, such as 'working very fast and hard' and 'receiving no attention from supervisor', supported formulated objectives by at risk employees, such as minimizing workload, and increasing social support. The contrast between employees at risk for sickness absence and employees on sick leave was less obvious, i.e. characteristics of the latter were equivalent or worse than those of the former. This supported the idea that the characteristics of at risk employees are potential aspects to deal with, through the preventive coaching intervention, in the workplace setting. ${ }^{21}$

Furthermore, randomized employees did not mention psychosocial health complaints, e.g. fatigue, burnout or work-family conflicts, as the main reason for their sick leaves. Herewith, the hypothesized effect of coaching on the primary outcome measure 'sickness absence due to psychosocial health complaints' could not be confirmed. Still, the coaching intervention demonstrated to have an effect on objectively measured duration of sick leave. And, employees who participated in the coaching reported significantly improved health, declined psychological distress, less burnout, less need for recovery, less depressive and emotional reactions and an increased satisfaction with life.22 With these main findings of chapter 6 and 7, the research objective related to the effectiveness of early intervention in employees at risk for sickness absence due to psychosocial health complaints is answered. Also, insight in the compatibility of features of the intervention and characteristics of the study population is gained.

\section{Methodological considerations}

The coaching intervention under study existed and was applied for several years in employees with different complaints, to support their health and wellbeing. ${ }^{23}$ The alternative of applying this coaching intervention in a preventive manner was considered, but up to now not fully explored. The exchange of ideas between the involved researchers and the partner in this project, Capability, resulted in this preventive approach of counseling. The structure of the coaching intervention was slightly adjusted to achieve more uniformity in performance. This modified intervention has been written down in a coaching protocol. The organization Capability 
selected experienced coaches, who received extensive information on the trial and the protocol. A checklist was specifically developed to inventory the main features of each session and the problems that were addressed. Also, the compliance of the coaches to the protocol was inventoried by these checklists. ${ }^{21}$

Instead of this specific preventive coaching intervention, other strategies might be appropriate to employ when confronted with a non-clinical, but at high risk, study population. Counseling or a psychotherapy consult could have positive effects on sickness absence and on several (mental) health related problems. A recent study by McLeod et al (2003) stated that after counseling, work-related symptoms returned to normal in more than half of all clients and sickness absence was reduced by over $25 \% .{ }^{24}$ Also, cognitive-behavioral approaches and relaxation techniques have proved to be effective in improving perceived quality of life, or reducing stress-related complaints. ${ }^{25}$ Still, some of these interventions might probably be too therapeutically for rather healthy employees, with relatively mild work or personal related problems. Also, the work-relatedness of problems of the involved employees is not explicitly considered in the more clinical interventions, compared to coaching, in which the related supervisor takes a central place. On the other hand, a difficulty in the preventive coaching intervention is that the conceptual structure and applied methodologies and instruments have not as much uniformity as can be expected from more clinical interventions. Also, it is rather difficult to explicate exactly what parts of the coaching intervention initiated specific results. The preventive coaching intervention supported the employees at risk for sickness absence in managing changes, understanding underlying behavior and balancing strengths and weaknesses, by unraveling their difficulties effectively through increasing problem-solving skills. ${ }^{21,} 26$ Yet, this intervention can not be presented as the ultimate solution for psychosocial sickness absence. Other promising interventions could probably produce similar results.

Next to the more qualitative and conceptual data evaluation on the coaching intervention, quantitative data on sickness absence and wellbeing related concepts were gathered, by means of questionnaires and linkage to company records, to assess the effectiveness of this intervention.22 Following the development of the screening instrument to identify employees at risk for sickness absence due to psychosocial health complaints, the effectiveness of the preventive coaching intervention on primarily psychosocial sickness absence was explored. Since no medical diagnoses were available in the objective sickness absence data from participating companies, sub- 
jective data on sickness absence and the reasons for sick leaves were gathered by means of self-administered questionnaires. Despite the accurate information on the occurrence of sick leaves, employees scarcely reported psychosocial health complaints as the reason for these absences. Ursin (1997) stated that the most frequently reported subjective health complaints, causing sickness absence, are musculoskeletal pain. ${ }^{27}$ Moreover, participating employees in the trial were more likely to report the flu or headache as the main cause for their absence than a conflict at work, fatigue or work-family problems. This complexity was taken into account when developing the study. Therefore, objective sickness absence data were additionally used to assess the effect of the preventive coaching intervention on overall sickness absence.

The results on duration of sick leave and frequency of sick leave were not exceptional, though, the coaching group had a statistically significant less amount of absence days in the year after randomization. Still, the clinical relevance of these results should be considered. This study started with the dispatch of screening instruments in a time period with low and decreasing absenteeism rates (5.3\% in 2002 to $4.0 \%$ in 2005), 28 probably induced by new Dutch legislation in 2002, ${ }^{29}$ which mandated employers to exploit a more stringent sickness absence policy. Consequently, the achievable advantage in sickness absence was probably lower than what could have been gained in previous years, when absenteeism rates were higher. Also, the follow-up period was artificially cut off at exactly twelve months post-randomization. As a consequence, the time span necessary to develop complaints of such a level that an apparently health employee is unable to work, was rather short. And, long-term sickness absence was probably just partially included. With regard to the secondary outcome measures, several effects of the coaching intervention were found. Specifically, points of interest during the intervention, i.e. the main problems employees defined, were the outcome measures in which significant improvements in favor of the coaching group were present. For example, psychological distress, fatigue and dissatisfaction with life were frequently defined problems. ${ }^{21}$ Subsequently, the results showed that the coaching intervention had significant effects on these concepts. Still, absolute certainty that the intervention in question caused these effects, instead of the attention the employees received for their exposed problems, can not be given. Nonetheless, the results should be weighted against the costs of the coaching intervention, if implementation in daily practice is considered. To be exact, the benefit in duration of sick leave and in improved wellbeing of employees in the coaching group has to compete with the fixed sum of 1500 euros to be paid for a fulfilled coaching program. 


\section{Implications for occupational health practice}

Keeping the main findings and methodological considerations described in this chapter in mind, one could ask oneself if the application of a screening instrument, an objective selection process to identify employees at risk for sickness absence due to psychosocial health complaints, and an early intervention program to prevent sickness absence and to improve general wellbeing, are appropriate methods to implement in daily occupational health practice. The findings in this study clearly show that psychosocial health complaints are common problems in the working population. For the individual, reintegration after psychosocial absenteeism causes more difficulties and generally takes longer than return to work following physical problems. For both employers and society, the consequences of this type of sickness absence involve enhanced payments and reduced productivity. 30 Consequently, prediction of at risk employees and early intervention could certainly be suitable methods. Still, do the findings of this thesis underscore this hypothesis?

Irrespective of the information presented in this thesis, it must be emphasized that prediction and early intervention in employees at risk for sickness absence is a difficult and comprehensive process. Companies should be prepared to expose their employees to an overall screening process to identify an at risk group of employees. In the current study, numerous companies were approached to participate. Most of them embraced the idea of prediction and early intervention to prevent sickness absence due to psychosocial health complaints and improve wellbeing of employees. However, due to reorganizations or upcoming important modifications on the shop floor, the majority declined the invitation of the researchers. Moreover, even when individual determination of the time of screening is possible, the impact of prediction of an at risk group could be considered as rather stigmatizing from the viewpoint of both employers and employees. Consequently, the remaining companies, which agreed upon participation, might be relatively 'healthy companies', with no reorganization in progress, but with well functioning sickness absence policies, low levels of sickness absence in general, and professional health care. Frequently, these companies are particularly motivated to support their employees by means of thorough purposive interventions. Probably, additional significant effects on sickness absence and wellbeing of employees could be found when companies, like the non-participating ones in this study, would commit themselves to prediction and early intervention programs. 
In addition, the rationale of widespread objective screening at work should be considered. The mailing, gathering and processing of thousands of screening instruments is a time-consuming and quite expensive realization. The advantage is that no employees will be excluded from participation and neutral allocation is made possible. However, due to the low sensitivity of the screening instrument in question, many employees at risk will be missed by this procedure. Therefore, the disperse of questionnaires to certain at risk departments or positions within the company could be preferred. This would be logistically more attractive, and would pre-select a rather sensitive group of employees. The administration of the highly specific screening instrument to these employees might be an ideal combination in the objective selection process. For practical reasons, companies could opt for an electronic version of the screening instrument, instead of the hardcopy questionnaire, used in this study. However, most employees of a company should have access to a computer to enable this, what was not the case in the present study. If possible, the whole organizational process concerning the screening would be simplified. Thus, both the subjective and the objective selection procedures have certain advantages. It is up to the company in question to decide what suits best.

With the identification of at risk employees, one should settle on the optimal early intervention program. The results of this thesis are in favor of the coaching program, which can be classified in the category 'counseling' rather than 'therapy'. In fact, the employees who were qualified for participating in the coaching intervention, reported mild work or personal related problems, for which certain clinical interventions are too therapeutically. Also, the participation of the supervisor is an advantage, i.e. the association with the work environment is recommended by previous studies on related themes. $3^{11}$ Since there were considerable differences between characteristics of the employees at risk or on sick leave, and the employees not at risk, the preventive coaching intervention might be appropriate in the prevention of sickness absence. Nevertheless, due to the costs of the intervention and the lack of uniformity in the intervention, other potential beneficial programs, such as relaxation techniques, ${ }^{25}$ counseling, ${ }^{24}$ or cognitive behavioral techniques 32 should not be excluded. Optional modifications in the selection process, such as more purposefully allocation of the coaching, could probably affect the costs and the effectiveness of the program. Notwithstanding, these considerations warrant further research on prediction and early intervention in employees at risk for sickness absence due to psychosocial health complaints, in order to provide a sound basis for the development of preventive measurements at work. 


\section{Further research}

With the studies described in this thesis, a few issues in the field of occupational health practice were discussed. These issues were certainly not all-embracing. In the last part of this Epilogue, some recommendations for further research are given. As regards the identification of predictive factors for sickness absence due to psychosocial health complaints, study suggestions are both directed at clinicians and policymakers, and at researchers. The former could take important policy measures in consequence of the identified predictors. For example, exercise could be supported, job strain could be reduced, and attention could be paid to alcohol use and to the extent of unemployment in the community. Probably, these are obvious suggestions, but up to now, no summarizing study quantified the influence of these predictive factors on the occurrence of sick leave. Moreover, consideration of a large number of predictive factors could possibly reduce the economic and social impact, and modify the public health consequences of sickness absence due to psychosocial health complaints. With regard to the latter, a meta-analysis on predictive factors for all-causes sickness absence could be performed. As stated before, the partition of psychosocial complaints from all-causes sickness absence in the presented meta-analysis was a complex and rather indefinite process, of which the success could not be guaranteed. Now, all studies on predictors of sickness absence due to specific, explicitly reported somatic complaints were excluded. In further research, clusters on specific reasons for sickness absence could be formed in which independent meta-analyses are carried out. Concerning the development and validation of the presented screening instrument, it should be kept in mind that due to the low sensitivity of the instrument many employees at risk are not detected by the instrument. Increasing the sensitivity by changing the cutoff point will inevitably reduce the specificity and consequently increase the number of false positives. Therefore, implementation in a sensitive group of employees could be realized. The combination of these pre-selected employees with a quite specific screening instrument might result in advanced psychometrics of the questionnaire and better practical application possibilities. After identification of these at risk employees, the selection process to follow remains a rather personal choice of employers. Using the subjective method of personal enlistment, the eligibility of employees is not definite, though problems such as non-response and non-commitment are probably faced to a lesser degree. Conversely, objectively selected employees are actually those at risk for sickness absence, who will consequently benefit more from preventive coaching than others. When assessing the effect of other preventive intervention programs on sickness absence due to psychosocial 
health complaints and on general wellbeing in these selected employees, features of ultimate selected employees should, in any case, be compatible with the characteristics of the intervention under study. In addition, interventions with more uniformity in conceptual structure, applied methodologies and instruments could be considered. In general, more research into coaching is warranted. The concept is quite popular nowadays, but requires additional scientific support. In conclusion, the cost-effectiveness of the described methods in this thesis should be examined more thoroughly in an economic evaluation. That is, the effect of objective screening and a comprehensive coaching intervention could be significant, but expenses and efforts could prevent these methods from implementation in occupational health practice. 


\section{REFERENCES}

1 Kant I, Bultmann U, Schröer C, Beurskens A, Amelsvoort Lv, Swaen G. An epidemiological approach to study fatigue in the working population: The Maastricht cohort study. Occup Environ Med 2003;60 (supl 1):i32-i39.

2 Andrea H, Beurskens AJ, Metsemakers JF, van Amelsvoort LG, van den Brandt PA, van Schayck CP. Health problems and psychosocial work environment as predictors of long term sickness absence in employees who visited the occupational physician and/or general practitioner in relation to work: a prospective study. Occup Environ Med 2003;60(4):295-300.

Bultmann U, Kant IJ, Schroer CA, KasI SV. The relationship between psychosocial work characteristics and fatigue and psychological distress. Int Arch Occup Environ Health 2002;75(4):25966.

4 van Amelsvoort LG, Kant IJ, Beurskens AJ, Schroer CA, Swaen GM. Fatigue as a predictor of work disability. Occup Environ Med 2002;59(10):712-3.

5 Michie S, Williams S. Reducing work related psychological ill health and sickness absence: a systematic literature review. Occup Environ Med 2003;60(1):3-9.

6 Roelen CA, van der Pol TR, Koopmans PC, Groothoff JW. Identifying workers at risk of sickness absence by questionnaire. Occup Med (Lond) 2006;56(7):442-6.

7 North FM, Syme SL, Feeney A, Shipley M, Marmot M. Psychosocial work environment and sickness absence among British civil servants: the Whitehall II study. Am J Public Health 1996;86(3):332-40.

8 Rael EG, Stansfeld SA, Shipley M, Head J, Feeney A, Marmot M. Sickness absence in the Whitehall II study, London: the role of social support and material problems. J Epidemiol Community Health 1995;49(5):474-81.

9 Duijts SFA, Kant I, Swaen GMH, Brandt PAvd, Zeegers MPA. A meta-analysis identifies predictors of sickness absence. J of Clin Epidemiol 2007; in press.

10 Linton SJ, Boersma K. Early identification of patients at risk of developing a persistent back problem: the predictive validity of the Orebro Musculoskeletal Pain Questionnaire. Clin J Pain 2003;19(2):80-6.

11 Duijts SFA, Kant I, Landeweerd JA, Swaen GMH. Prediction of sickness absence: the development of a screening instrument. Occup Environ Med 2006;63:564-569.

12 Lamberts H, Wood M. ICPC, International Classification of Primary Care. Oxford: Oxford University Press; 1987.

13 Johns G. How often were you absent? A review of the use of self-reported absence data. Journal of Applied Psychology 1994;79:574-591.

14 Ferrie JE, Kivimaki M, Head J, Shipley MJ, Vahtera J, Marmot MG. A comparison of self-reported 
sickness absence with absences recorded in employers' registers: evidence from the Whitehall II Study. Occup Environ Med 2005;62:74-79. Rothman KJ, Greenland S. Modern Epidemiology. Philadelphia: Lippincott-Raven Publishers; 1998. Waddell G, Burton AK, Main CJ. Screening to identify people at risk of long-term incapacity for work - A conceptual and scientific review. Londen: Royal Society of Medicine Press; 2003.

17 Hofler M, Pfister H, Lieb R, Wittchen HU. The use of weights to account for non-response and drop-out. Soc Psychiatry Psychiatr Epidemiol 2005;40(4):291-9. Wagner JA. Participation's effects on performance and satisfaction: a reconsideration of the research evidence. Academy of Mangement Review 1994;19:312-330.

19 Schröer C. Verzuim wegens overspanning; een onderzoek naar de aard van overspanning, de hulpverlening en het verzuimbeloop.; 1993. Brenner H, Gefeller O. Variation of sensitivity, specificity, likelihood ratios and predictive values with disease prevalence. Stat Med 1997;16(9):981-91. Duijts SFA, Kant I, van den Brandt PA, Swaen GMH. The compatibility between characteristics of employees at risk for sickness absence and components of a preventive coaching intervention. Int J of Evide Bas Coach \& Ment 2007;5(1):19-29. Duijts SFA, Kant I, Brandt PAvd, Swaen GMH. Effectiveness of a preventive coaching intervention for employees at risk for sickness absence due to psychosocial health complaints: results of a randomized controlled trial. Occup Environ Med 2007; accepted pending revision.

Bassi L, Cheney S, Lewis E. Trends in workplace learning: supply and demand in interesting times. Training \& Development 1998;52:51-77.

24 McLeod J, Henderson M. For: does workplace counselling work? Br J Psychiatry 2003;182:103-4.

25 van der Klink JJ, Blonk RW, Schene AH, van Dijk FJ. The benefits of interventions for work-related stress. Am J Public Health 2001;91(2):270-6.

26 Nezu AM, Ronan GF. Life stress, current problems, problem solving, and depressive symptoms: an integrative model. J Consult Clin Psychol 1985;53(5):693-7.

27 Ursin H. Sensitization, somatization, and subjective health complaints. Int J Behav Med 1997;4(2):105-16.

28 Ziekteverzuimcijfers. Voorburg/ Heerlen: Centraal Bureau voor de Statistiek; 2007.

29 Wet Verbetering Poortwachter. The Hague: Ministry of Social Affairs and Employment; 2002.

30 Borritz M, Rugulies R, Christensen KB, Villadsen E, Kristensen TS. Burnout as a predictor of selfreported sickness absence among human service workers: prospective findings from three year follow up of the PUMA study. Occup Environ Med 2006;63(2):98-106.

31 Brouwers EP, Tiemens BG, Terluin B, Verhaak PF. Effectiveness of an intervention to reduce sick- 
ness absence in patients with emotional distress or minor mental disorders: a randomized controlled effectiveness trial. Gen Hosp Psychiatry 2006;28(3):223-9.

32 Huibers MJ, Beurskens AJ, Van Schayck CP, Bazelmans E, Metsemakers JF, Knottnerus JA, et al. Efficacy of cognitive-behavioural therapy by general practitioners for unexplained fatigue among employees: Randomised controlled trial. Br J Psychiatry 2004;184:240-6. 
SUMMARY 

Psychosocial health complaints, such as depression, fatigue, stress and work-family conflicts, are leading causes of sickness absence in the world nowadays. In the Netherlands, about one in three employees seen by their occupational physician are absent from work because of psychosocial health complaints. For the individual, reintegration after psychosocial absenteeism causes more difficulties and generally takes longer than return to work following physical health problems. For employers as well as for society, the consequences of this type of sickness absence involve enhanced costs and reduced productivity. From an occupational health care perspective, a promising strategy might be identification of employees at increased risk for sickness absence, and early intervention to prevent sickness absence due to psychosocial health complaints.

The current thesis deals with the prediction of employees at risk for sickness absence due to psychosocial health complaints, by means of a screening instrument. Also, the effectiveness of a preventive coaching intervention program for employees at risk for sickness absence due to psychosocial health complaints to prevent sick leave and to improve their general wellbeing, is a central subject of this study. Both themes form part of a randomized controlled trial, in which employees of several companies in the southeastern part of the Netherlands participated. The two main research objectives of this thesis are: (1) to develop and test a concise screening instrument for prediction of employees at increased risk for sickness absence due to psychosocial health complaints, and to assess the motivation of selected employees to participate in a developed early intervention program; (2) to assess the effect of preventive coaching for employees at risk for sickness absence due to psychosocial health complaints on sick leave and general wellbeing (Chapter 1).

Chapter 2 begins with a meta-analysis, which examines predictive factors for sickness absence due to psychosocial health complaints. The objective of this meta-analysis was to quantify the association between predictive factors and sickness absence, to assess clinical outcomes and heterogeneity, in order to enable the implementation of preventive measures. Eligible for inclusion were prospective studies that examined the association, and provided sufficient information to estimate summary odds ratios. In total, 20 prospective studies were included. Significant summary odds ratios for the occurrence of sick leave $>3$ days were found for being unmarried $1.37(95 \% \mathrm{Cl}$ 1.15-1.64), experiencing psychosomatic complaints 1.79 (95\% Cl 1.54-2.07), using medication 3.13 ( $95 \% \mathrm{Cl} 1.71-5.72$ ), having a burnout 2.34 (95\% $\mathrm{Cl} 1.59-3.45$ ), suffering from 
psychological problems 1.97 (95\% Cl 1.37-2.85), having low job control 1.28 (95\% Cl 1.231.33), having low decision latitude 1.33 (95\% Cl 1.16-1.56) and experiencing no fairness at work 1.30 ( $95 \% \mathrm{Cl} 1.18-1.45$ ). The meta-analysis shows that predictors of sickness absence can be identified. The results provide leads to public health interventions to successfully improve psychosocial health and to reduce sickness absence.

Chapter 3 describes the development of a concise screening instrument for early identification of employees at risk for sickness absence due to psychosocial health complaints. Data from the prospective Maastricht Cohort Study on 'Fatigue at Work' were used to identify items to be associated with an increased risk of sickness absence. The analytic procedures univariate logistic regression, backward stepwise linear regression and multiple logistic regression were successively applied. For both men and women, sum scores were calculated, and sensitivity and specificity rates of different cut-off points on the screening instrument were defined. In women, results showed that feeling depressed, having a burnout, being tired, being less interested in work, experiencing obligatory change in working days, and living alone, were strong predictors for sickness absence due to psychosocial health complaints. In men, statistically significant predictors were having a history of sickness absence, compulsive thinking, being mentally fatigued, finding it hard to relax, lack of supervisor support, and having no hobbies. A potential cut-off point of 10 on the screening instrument resulted in a sensitivity score of $41.7 \%$ for women and $38.9 \%$ for men, and a specificity score of $91.3 \%$ for women and $90.6 \%$ for men. This study shows that it is possible to identify predictive factors for sickness absence and to develop an instrument for early identification of employees at risk for sickness absence. The results of this study increase the possibility for both employers and policymakers to implement interventions directed at the prevention of sickness absence.

In chapter 4, the objective selection process of employees to participate in an early intervention, is compared with the traditional subjective selection method of personal enlistment. The hypothesis was that objectively selected employees were 'at risk' for sickness absence and eligible to participate in the intervention program. The dispatch of 8603 screening instruments formed the starting point of the objective selection process. Different stages of this process, throughout which employees either dropped out or were excluded, were described and compared with the subjective selection process. Characteristics of ineligible and ultimately selected employees, for the randomized trial, were described and quantified using sickness absence data. 
Overall response rate on the screening instrument was $42.0 \%$. Response bias was found for the parameters sex and age, but not for sickness absence. Sickness absence was higher in the 'at risk' ( $N=212)$ group (42\%) compared to the 'not at risk' $(\mathrm{N}=2503)$ group (25\%) (OR 2.17 Cl 1.63-2.89; $p=0.000)$. The selection process ended with the successful inclusion of 151 eligible, i.e. $2 \%$ of the approached employees in the trial. The study shows that objective selection of employees for preventive intervening may be effective. Despite methodological and practical problems, selected employees are actually those at risk for sickness absence, who will probably benefit more from the intervention program than others.

Chapter 5 deals with the psychometric characteristics and the external validation of the developed screening instrument for the identification of employees at risk for sickness absence due to psychosocial health complaints. Exploratory factor analysis was applied. Cronbach's alpha coefficient was used to determine internal consistency of the subscales. Sum scores on the screening instrument were correlated to absenteeism data to determine their potential for predicting sickness absence. The predictive value was investigated, using objective sickness absence data as criterion measure, and finally, sensitivity and specificity rates were calculated for the external validation. For both men and women, three interpretable factors were found. Sum scores on the instrument did not correlate well with sickness absence. The association between 'being at risk' (yes/no) and sickness absence (yes/no) was OR 3.09 ( $\mathrm{Cl} 1.47^{-}$ 6.47) for men and OR 1.97 ( $\mathrm{Cl}$ 1.44-2.69) for women. Sensitivity scores were rather low, whereas specificity scores were remarkably high. The results of this study provide the screening instrument a theoretic and scientific basis. Correlations for absence duration and absence frequency are not convincing, but predictive value is promising, when absence is treated as a dichotomous measure. Sensitivity and specificity are unvarying during the development and validation phases of the instrument.

In chapter 6, the compatibility between characteristics of employees 'at risk' for sickness absence and components of a preventive coaching intervention were assessed. Data from baseline questionnaires of the 'at risk' study population of a randomized trial, and of two reference groups of the prospective Maastricht Cohort Study were used to compare (mental) health and work related characteristics. Details of the intervention were described, and similarities between characteristics of the study population and components of the coaching intervention were discussed. Substantial differences between characteristics of the 'at risk' study population and the 'not at 
risk' reference group were found, which were all addressed during the coaching intervention. The contrast with the 'sick leave' reference group was less obvious. The 'at risk' study population could be indicated as the most beneficial population for this preventive intervention. The results show that preventive coaching is an appropriate intervention for employees 'at risk' for sickness absence.

Chapter 7 describes the effectiveness of a preventive coaching intervention on sickness absence due to psychosocial health complaints and on general wellbeing of employees. The study was carried out in three large companies in the Netherlands. Employees ( $N=151)$ at risk for sickness absence were identified, by means of a screening instrument, and randomized. The intervention group $(\mathrm{N}=76)$ received the preventive coaching program; the control group $(\mathrm{N}=75)$ received usual care. Self-administered questionnaires were sent to employees at six $\left(\mathrm{T}_{1}\right)$ and twelve $\left(\mathrm{T}_{2}\right)$ months follow-up, and subjective and objective sickness absence data were gathered. Primary outcome measure of the trial is self-reported sickness absence due to psychosocial health complaints; secondary outcome measures are objective sickness absence, selfrated health, psychological distress, anxious mood, coping, psychological work characteristics, need for recovery, fatigue and burnout. The results showed no effect of coaching on self-reported sickness absence due to psychosocial health complaints. Based on objective sickness absence data, a $14 \%$ reduction in sickness absence duration was achieved in the intervention group as compared to the control group (15.6 vs. 18.1 days). Employees who participated in the coaching, reported statistically significant and clinically relevant improved health, declined psychological distress, less burnout, less need for recovery, and an increased satisfaction with life. Adverse significant effects were found for job insecurity and training possibilities. This study shows that the coaching intervention has an effect on both objective duration of sick leave and general wellbeing of employees. For implementation of the preventive strategy further research is warranted.

In the epilogue, chapter 8 , some of the major findings described in the previous chapters of the thesis are reflected. The research themes and study objectives presented in chapter 1 were the basic principle of this chapter. Prediction of sickness absence due to psychosocial health complaints was the first concept to be reviewed on its main findings and methodological considerations. In addition, these issues were described and discussed on behalf of the second concept, the effectiveness of early intervention in employees at risk for sickness absence due to psychosocial health 
complaints. At the end, the chapter addressed overall implications for occupational health practice, and recommendations for further research were given. The findings show that prediction of at risk employees and early intervention might be promising methods. Irrespective of the useful information presented, it was emphasized that the methods are difficult and comprehensive. Companies should be willing to expose their employees to an overall screening process to identify an at risk group of employees, since the impact of prediction could be considered as rather stigmatizing from the viewpoint of both employers and employees. Also, the rationale of widespread objective screening at work should be considered, as the mailing, gathering and processing of thousands of screening instruments is a time-consuming and quite expensive realization. The advantage is that no employees will be excluded from participation and neutral allocation is made possible. The major disadvantage is the low sensitivity (high percentage false negatives) of the developed screening instrument (Werkwijzer). As a result of this, many employees with an increased risk for future sickness absence, who may benefit from early intervention, will not be detected through screening. Both the subjective and the objective selection procedures have certain advantages, and it is merely up to the company in question to decide what suits best. With the identification of at risk employees, one should settle on the proper early intervention program. Components of the coaching program are compatible with the characteristics of employees at risk, and the intervention shows statistically significant effects on several psychosocial health complaints and on objectively measured duration of sick leave. However, the clinical relevance of these results should be considered and, due to the costs and the lack of uniformity in the intervention, other potential beneficial programs, such as relaxation techniques, counseling, or cognitive behavioral techniques should not be excluded. For these reasons, further research on both prediction as well as early intervention in employees at risk for sickness absence due to psychosocial health complaints is warranted. 

SAMENVATTING

[SUMMARY IN DUTCH] 

Psychosociale gezondheidsklachten, zoals depressie, vermoeidheid, stress of werkthuis conflicten, zijn wereldwijd belangrijke oorzaken voor ziekteverzuim. In Nederland verzuimt ongeveer één op de drie medewerkers, die bij de bedrijfsarts op het spreekuur komen, vanwege psychosociale gezondheidsklachten. Voor het individu brengt reïntegratie na psychosociaal verzuim meer moeilijkheden met zich mee, en het duurt over het algemeen langer, dan terugkeer na verzuim vanwege fysieke gezondheidsklachten. Voor zowel werkgevers als de maatschappij heeft dit type ziekteverzuim hoge kosten en verminderde productiviteit tot gevolg. Vanuit een arbeidgerelateerd gezondheidsperspectief zou een veelbelovende strategie zijn: het identificeren van medewerkers die verhoogd risico lopen op verzuim, en vroegtijdig interveniëren om ziekteverzuim vanwege psychosociale klachten gezondheidsklachten te voorkomen.

In dit proefschrift wordt de predictie, met behulp van een screening instrument, van medewerkers die verhoogd risico lopen op verzuim vanwege psychosociale gezondheidsklachten beschreven. Tevens is de effectiviteit van een preventief coachingsprogramma, gericht op het voorkomen van verzuim en verbeteren van welzijn, voor medewerkers met verhoogd risico op verzuim vanwege psychosociale gezondheidsklachten, geëvalueerd. Beide thema's maken deel uit van een gerandomiseerde trial, waarin medewerkers van verschillende bedrijven in het zuidoosten van Nederland participeerden. De twee belangrijkste doelen van het onderzoek zijn: (1) het ontwikkelen en toetsen van een beknopt screeningsinstrument om te voorspellen welke medewerkers een verhoogd risico op verzuim vanwege psychosociale gezondheidsklachten hebben, en het beoordelen van de motivatie van geselecteerde medewerkers om deel te nemen in een ontwikkeld preventief interventie programma; (2) het beoordelen van het effect van het preventief coachingsprogramma voor medewerkers met verhoogd risico op verzuim vanwege psychosociale gezondheidsklachten op ziekteverzuim en algemeen welzijn (Hoofdstuk 1).

Hoofdstuk 2 betreft een meta-analyse naar predictieve factoren voor verzuim vanwege psychosociale gezondheidsklachten. Het doel van de meta-analyse was het kwantificeren van de associatie tussen predictieve factoren en ziekteverzuim, het beoordelen van klinische uitkomstmaten en heterogeniteit, om implementatie van preventieve maatregelen mogelijk te maken. Geschikt voor inclusie waren prospectieve studies naar deze associatie, die voldoende informatie verschaften om gepoolde odds ratios te schatten. In totaal zijn 20 prospectieve studies geïncludeerd. 
Significante gepoolde odds ratios voor het optreden van ziekteverzuim > 3 dagen zijn gevonden voor niet getrouwd zijn 1.37 (95\% Cl 1.15-1.64), ervaren van psychosomatische klachten 1.79 (95\% Cl 1.54-2.07), gebruik van medicatie 3.13 (95\% Cl 1.71-5.72), burnout 2.34 (95\% Cl 1.59-3.45), psychologische problemen 1.97 (95\% Cl 1.37-2.85), weinig controle over het werk 1.28 (95\% Cl 1.23-1.33), weinig beslissingsmogelijkheden 1.33 (95\% Cl 1.16-1.56) en ervaren van onrechtvaardigheid op de werkplek 1.30 (95\% Cl 1.18-1.45). De meta-analyse toont aan dat predictieve factoren voor ziekteverzuim geidentificeerd kunnen worden. De resultaten verschaffen aanknopingspunten voor interventies om psychosociale gezondheid te verbeteren en ziekteverzuim te verminderen.

Hoofdstuk 3 beschrijft de ontwikkeling van een beknopt screeningsinstrument voor het identificeren van medewerkers, die verhoogd risico lopen op verzuim vanwege psychosociale gezondheidsklachten. Data van de prospectieve Maastrichtse Cohort Studie naar 'Psychische Vermoeidheid in de Arbeidssituatie' zijn gebruikt om items te identificeren die geassocieerd zijn met een verhoogd risico op verzuim. Univariate logistische regressie, achterwaartse stapsgewijze lineaire regressie en multiple logistische regressie zijn achtereenvolgens toegepast. Voor zowel mannen als vrouwen zijn somscores berekend, en zijn sensitiviteit en specificiteit voor verschillende afkappunten op het screeningsinstrument onderzocht. Bij vrouwen waren depressief voelen, een burnout hebben, vermoeid zijn, minder geïnteresseerd in werk zijn, een verplichte verandering in werkdagen ervaren, en alleen wonen, sterke predictoren voor ziekteverzuim vanwege psychosociale gezondheidsklachten. Bij mannen bleken eerder ziekteverzuim, dwangmatige gedachten hebben, geestelijk vermoeid zijn, het moeilijk vinden om te ontspannen, gebrek aan ondersteuning van de leidinggevende, en geen hobby's hebben, statistisch significante predictoren. Een potentieel afkappunt van 10 op het screeningsinstrument resulteerde in een sensitiviteit van $41.7 \%$ voor vrouwen en $38.9 \%$ voor mannen, en een specificiteit van $91.3 \%$ voor vrouwen en $90.6 \%$ voor mannen. Deze studie toont aan dat het mogelijk is predictieve factoren voor ziekteverzuim te identificeren en een instrument te ontwikkelen voor vroege opsporing van medewerkers die verhoogd risico lopen op verzuim. De resultaten van de studie vergroten de mogelijkheid voor werkgevers en beleidsmakers om interventies te implementeren gericht op de preventie van ziekteverzuim. 
In hoofdstuk 4 is het objectieve selectie proces van medewerkers, voor deelname aan een preventieve interventie, vergeleken met de traditionele subjectieve selectiemethode, namelijk persoonlijke aanmelding. De hypothese was dat objectief geselecteerde medewerkers verhoogd risico lopen op verzuim en geschikt zijn om deel te nemen aan het interventie programma. Het verspreiden van 8603 screeningsinstrumenten vormde het startpunt van het objectieve selectieproces. Verschillende fasen in het proces, waarin medewerkers ofwel uitvielen of geëxcludeerd werden, zijn beschreven en vergeleken met het subjectieve selectieproces. Kenmerken van ongeschikte en uiteindelijk geselecteerde medewerkers voor de gerandomiseerde trial zijn beschreven en gekwantificeerd met behulp van ziekteverzuim data. De totale respons op het screeningsinstrument was $42.0 \%$. Responsbias werd gevonden voor geslacht en leeftijd, maar niet voor ziekteverzuim. Ziekteverzuim was hoger in de hoog risico groep $(\mathrm{N}=212 ; 42 \%)$ vergeleken met de laag risico groep ( $\mathrm{N}=2503 ; 25 \%)$ (OR 2.17 Cl 1.63-2.89; $\mathrm{p}=0.000$ ). Het selectieproces eindigde met de succesvolle inclusie van 151 geschikte, i.e. $2 \%$ van de benaderde, medewerkers in de trial. De studie toont aan dat objectieve selectie van medewerkers voor preventief interveniëren mogelijk is. Ondanks methodologische en praktische problemen hebben de geselecteerde medewerkers daadwerkelijk een verhoogd risico op verzuim. Zij zullen daarom hoogstwaarschijnlijk meer voordeel hebben van het interventieprogramma dan anderen.

Hoofdstuk 5 betreft de psychometrische karakteristieken en de externe validatie van het ontwikkelde screeningsinstrument voor de identificatie van medewerkers met een verhoogd risico op verzuim vanwege psychosociale gezondheidsklachten. Daarbij is exploratieve factoranalyse toegepast. Cronbach's alpha coefficient is berekend om de interne consistentie van de subschalen vast te stellen. Somscores op het screeningsinstrument zijn gecorreleerd met verzuimdata om de mogelijkheid voor de predictie van verzuim vast te stellen. De predictieve waarde is onderzocht, met behulp van verzuimdata als criteriummaat, en sensitiviteit en specificiteit zijn berekend ten behoeve van de externe validatie. Voor zowel mannen als vrouwen zijn drie te interpreteren variabelen gevonden. Somscores op het instrument correleerden niet goed met ziekteverzuim. De associatie tussen verhoogd risico lopen (ja/ nee) en ziekteverzuim ( $\mathrm{ja} / \mathrm{nee}$ ) was OR 3.09 ( $\mathrm{Cl}$ 1.47-6.47) voor mannen en OR 1.97 ( $\mathrm{Cl}$ 1.44-2.69) voor vrouwen. Sensitiviteitsscores waren behoorlijk laag, terwijl specificiteit aanzienlijk hoog was. De resultaten van deze studie verschaffen het screeningsinstrument een theoretische en wetenschappelijke basis. Correlaties voor verzuimduur en verzuim- 
frequentie zijn niet overtuigend, maar de predictieve waarde is veelbelovend, zeker wanneer verzuim wordt gezien als een dichotome uitkomstmaat. Sensitiviteit en specificiteit zijn ongewijzigd gedurende de ontwikkeling en validatie fasen van het instrument.

In hoofdstuk 6 is de compatibiliteit beoordeeld van karakteristieken van medewerkers die verhoogd risico lopen op verzuim en componenten van de preventieve coaching. Data van baseline vragenlijsten van de hoog risico populatie van de gerandomiseerde trial, en van twee referentie groepen uit de Maastrichtse Cohort Studie, zijn gebruikt om (mentale) gezondheid en werkgerelateerde karakteristieken met elkaar te vergelijken. Kenmerken van de interventie zijn beschreven, en overeenkomsten tussen karakteristieken van de studie populatie en componenten van de coaching zijn bediscussieerd. Substantiële verschillen tussen karakteristieken van de hoog risico populatie en de laag risico referentiegroep zijn gevonden, welke alle aan bod zijn gekomen tijdens de coaching. Het contrast met de verzuimende referentie groep was minder duidelijk. De hoog risico groep kan gezien worden als de meest geschikte populatie voor deze interventie. De resultaten tonen aan dat preventieve coaching een geschikte interventie is voor medewerkers die verhoogd risico lopen op verzuim.

Hoofdstuk 7 beschrijft de effectiviteit van een preventieve coachingsinterventie op ziekteverzuim vanwege psychosociale gezondheidsklachten en op algemeen welzijn van medewerkers. Het onderzoek is uitgevoerd in drie grote bedrijven in Nederland. Medewerkers ( $N=151$ ) die verhoogd risico lopen op verzuim zijn geidentificeerd met behulp van een screeningsinstrument, en gerandomiseerd. De interventiegroep $(\mathrm{N}=76)$ ontving het preventieve coachingsprogramma; de controle groep $(\mathrm{N}=75)$ ontving de standaard zorg. Vragenlijsten zijn verstuurd aan medewerkers na zes (T1) en twaalf (T12) maanden follow-up, en subjectieve en objectieve ziekteverzuimdata zijn verzameld. Primaire uitkomstmaat van de trial is zelfgerapporteerd ziekteverzuim ten gevolge van psychosociale gezondheidsklachten; secundaire uitkomstmaten zijn objectief verzuim, subjectief beoordeelde gezondheid, psychologische stress, angstige en ongeruste stemming, coping stijlen, psychologische arbeidskarakteristieken, herstelbehoefte, vermoeidheid en burnout. De resultaten toonden geen effect van coaching op zelfgerapporteerd verzuim vanwege psychosociale gezondheidsklachten. Een afname van $14 \%$ in verzuimduur in de interventie groep ten opzichte van de controlegroep werd gevonden op basis van objectieve verzuim data (15.6 vs 18.1 dagen). Medewerkers die participeerden in de coaching rapporteerden significant 
verbeterde gezondheid, minder psychologische stress, minder burnout, minder herstelbehoefte, minder depressieve en emotionele reactiepatronen en een toegenomen tevredenheid met het leven. Tegengestelde effecten zijn gevonden voor onzekerheid in het werk en opleidingsmogelijkheden. Deze studie toont dat de coaching interventie een effect heeft op zowel objectieve verzuimduur en algemeen welzijn van medewerkers. Echter, voor implementatie van deze strategie is meer onderzoek nodig.

In de epiloog, hoofdstuk 8, worden enkele belangrijke bevindingen uit de voorgaande hoofdstukken uit het proefschrift beschreven. De onderzoeksthema's en de doelen, zoals gepresenteerd in hoofdstuk 1, vormen het uitgangspunt van dit hoofdstuk. Predictie van ziekteverzuim vanwege psychosociale gezondheidsklachten was het eerste concept dat beoordeeld is op de belangrijkste bevindingen en methodologische overwegingen. Daaropvolgend zijn deze kwesties beschreven ten aanzien van het tweede concept, de effectiviteit van vroegtijdig interveniëren bij medewerkers die risico lopen op verzuim vanwege psychosociale gezondheidsklachten. Aan het eind beschrijft het hoofdstuk implicaties voor de arbeid gerelateerde gezondheidszorg, en aanbevelingen voor verder onderzoek worden gegeven. De bevindingen tonen aan dat predictie van medewerkers met verhoogd risico op verzuim en vroegtijdig interveniëren wellicht geschikte methoden zijn. Ondanks de gepresenteerde bruikbare informatie moet benadrukt worden dat deze methoden ingewikkeld en omvangrijk zijn. Bedrijven moeten bereid zijn om hun medewerkers bloot te stellen aan een screeningsproces, om een groep medewerkers met verhoogd risico te identificeren, omdat de impact van dergelijke predictie stigmatiserend voor zowel werkgevers als medewerkers kunnen zijn. Tevens moet de rationale achter de uitgebreide objectieve screening beschouwd worden, omdat de verzending, verzameling en verwerking van duizenden screening instrumenten een tijdrovende en dure aangelegenheid is. Het voordeel is dat geen medewerkers bij voorbaat geëxcludeerd worden van deelname en dat neutrale en objectieve toewijzing van de interventie mogelijk is. Het nadeel is de lage sensitiviteit (hoog percentage fout negatieven) van het screeningsinstrument (Werkwijzer). Hierdoor zullen veel medewerkers met een verhoogd risico op verzuim, die mogelijk baat hebben bij vroegtijdige interventie, niet worden opgespoord door middel van screening. Zowel de subjectieve als de objectieve selectieprocedure hebben bepaalde voordelen, en het hangt met name af van het bedrijf in kwestie om te besluiten wat het meest geschikt is. Na het identificeren van medewerkers met verhoogd risico op verzuim dient tevens een passend inter- 
ventie programma gekozen te worden. Componenten van de coaching sluiten aan bij de karakteristieken van de medewerkers die verhoogd risico lopen op verzuim, en de interventie toont statistisch significant effecten op verschillende psychosociale gezondheidsklachten en op objectief gemeten verzuimduur. Echter, de klinische relevantie van deze resultaten moet beschouwd worden en, vanwege de kosten en het gebrek aan uniformiteit van deze interventie, moeten andere potentieel effectieve programma's zoals relaxatietechnieken, counseling of cognitieve gedragstherapie, tevens overwogen worden. Om bovenstaande redenen is verder onderzoek nodig naar zowel de predictie als de wijze van vroegtijdig interveniëren bij medewerkers die verhoogd risico lopen op verzuim. 


\section{DANKWOORD}

De laatste witte pagina's gaan veranderen in wellicht het meest gelezen stuk van mijn proefschrift: het dankwoord. Op deze plek wil ik iedereen bedanken die de afgelopen jaren een bijdrage heeft geleverd. Een aantal personen wil ik hierbij in het bijzonder noemen.

Op de eerste plaats mijn co-promotor Gerard Swaen, die mijn sollicitatie zeer snel organiseerde en vervolgens bereid was maanden te wachten. Vanaf de eerste dag kon ik bij je binnenlopen wanneer dat nodig was, en liepen we buiten verder (soms wel erg ver) just for fun. Want je kunt altijd blijven lopen, nietwaar? Ook na je vertrek naar Dow Chemical ben je een belangrijk aanspreekpunt voor mij gebleven. Mijn co-promotor IJmert Kant nam daarmee de rol van eerste begeleider over. IJmert, jij vond me regelmatig eigenwijs en we moesten in het begin even wennen aan elkaar. Maar er was geen Haarlemmerolie voor nodig om onze samenwerking goed te laten verlopen. Je stond open voor vragen, nam de tijd om ze te beantwoorden en gaf me de ruimte om me te ontwikkelen. Mijn promotor Piet van den Brandt werd in een later stadium bij het project betrokken. Piet, ik heb jouw overkoepelende visie en concrete besluiten als zeer waardevol ervaren. Bedankt voor het snel en kritisch becommentariëren van de artikelen. De jaren bij de afdeling epidemiologie waren erg leerzaam en dat heb ik mede aan jullie te danken!

Ook Ludovic van Amelsvoort, Nicole Jansen en Danielle Mohren van arbeidsepidemiologie wil ik hartelijk bedanken voor hun bijdrage en samenwerking. Ik zal de veelvuldige uitjes naar Thembi zeker missen! En natuurlijk de aio's van deze groep: Stephanie Leone, Monique Lexis en Lore De Raeve. Bedankt voor de gezellige lunches, wandelingetjes en coffee breaks. Na heel wat mellow mornings en heavenly hazels ben ik nog steeds op zoek naar een favoriet! Fijn dat er altijd een stoel klaar stond om 'even op neer te ploffen'. Jullie steun en adviezen waren en zijn erg belangrijk voor me. Stephanie, bedankt dat je mijn paranimf wilt zijn en vandaag naast me wilt staan! Tevens wil ik Jos Slangen bedanken. Jij stond altijd voor me klaar om een overload aan vragenlijsten weg te werken, en met 100-en-1 andere dingen kon ik bij je terecht. Veel dank daarvoor. 
Naast de mensen van arbeidsepidemiologie wil ik alle oud-collega's van, onder andere, de afdeling epidemiologie bedanken voor hun betrokkenheid. In het bijzonder wil ik Ans Bouman, Mirian Brink, Shireen van den Broek, Nick Broers (STAT), Carin de Brouwer, Christel van Gool, Daniel Kotz (HAG), Ischa Kummeling, Madelon PijlsJohannesma (MAASTRO), Nathalie Slangen, Kim Smits, Bianca Snijders, Stefan de Vogel, Astrid Visschers-Pleijers (O\&O) en Gwenn Wetzels noemen. Een speciaal woord van dank gaat uit naar de aio's die deelnamen aan het Promovendi Overleg Epidemiologie en Huisartsgeneeskunde, het POEH. Ik heb de bijeenkomsten als leerzaam en gezellig ervaren en ik hoop dat het overleg nog lange tijd blijft voortbestaan. Tevens wil ik Patty Nelemans, Bart Staal en Maartje Kevenaar, mijn eerste kamergenoten, bedanken. Jullie hebben de drukte rondom de organisatie van het project, inclusief de duizenden vragenlijsten, van dichtbij meegemaakt en doorstaan. Patty, ook na mijn verhuizing naar een andere kamer namen wij regelmatig de tijd om bij te praten. Een volgende verhuizing heeft de afstand nog iets groter gemaakt, maar het contact zal er hopelijk niet minder om worden. Mijn collega's van het NKI-AvL wil ik bedanken voor hun betrokkenheid bij de laatste afrondingen.

Dit boek had er nooit gelegen zonder de deelname en medewerking van de verschillende bedrijven, de duizenden medewerkers, en Capability, de aanbieder van de preventieve coaching. Om met de laatste te beginnen: de coaches van Capability hebben een enorme bijdrage geleverd aan dit onderzoek. Bedankt Gaby Tuguntke, Mart van Klooster, Corrie Drissen, Mia Vergoossen, Frank van den Eerenbeemt, Jos Sleijpen, Harry Linders, Ellie de Schrijver, Annelies Manders en Aadje Muysken. Tevens wil ik Ad Jansen, Joos Jacobs en Frans Bonants van Capability bedanken voor hun bijdrage aan het organisatorisch vormgeven van dit onderzoek. De bedrijven Orbis Medisch en Zorgconcern, de Technische Universiteit Eindhoven en de Universiteit Maastricht namen met in totaal 9210 medewerkers deel aan het onderzoek. Het enthousiasme, de betrokkenheid en de inspanningen van de contactpersonen binnen deze instellingen hebben het project van de grond gebracht en bijgedragen aan een goede afloop ervan. Els Knapen, Linda van Teijlingen en Claire Voeten van Orbis Medisch en Zorgconcern, Janny de Vries en Pierre Schroder van de Universiteit Maastricht, en Esther Schmal en Trees Klaver van de Technische Universiteit Eindhoven wil ik in het bijzonder bedanken voor hun inzet. Daarnaast wil ik alle medewerkers bedanken die de moeite genomen hebben één of meerdere vragenlijsten in te vullen, en speciaal de medewerkers die deelgenomen hebben aan de preventieve coaching. 
Dank ook aan Sigrid Joha. Toen ik zelf even geen vragenlijst meer kon zien, schoot jij te hulp met het verzendklaar maken hiervan en verwerking van de respons. Een speciaal woord van dank aan Jos Bruystens. Naast de opmaak van vragenlijsten, folders en posters voor het onderzoek, heb ik de lay-out van dit proefschrift aan jou te danken. Je nam regelmatig de tijd om bij te praten en ik heb onze gesprekken als zeer waardevol ervaren. Ik hoop dat we elkaar ook in de toekomst nog regelmatig zullen spreken.

Maurice, mijn paranimf. Ik wil je danken voor je onvoorwaardelijke steun. Jij weet precies wat je moet zeggen op het juiste moment. Mijn werkbezoek aan Birmingham was erg leerzaam en de tussenliggende weekendjes in the UK zeer gezellig. Ik hoop dat er nog velen zullen volgen. Zover woon ik inmiddels niet meer bij je vandaan! Ik ben er trots op dat je vandaag als paranimf naast me staat.

Tot slot: vrienden, familie, pap en mam. Bij de laatste regels van mijn proefschrift val ik stil. Geen woorden kunnen omschrijven wat jullie steun voor mij betekent. Dank voor alles!

Saskia Duijts,

Amsterdam, 2007 



\section{ABOUT THE AUTHOR}

Saskia Duijts was born on April 25, 1978 in Sittard, the Netherlands. After graduating from secondary school (VWO) at the Bisschoppelijk College in Sittard in 1996, she studied Occupational Therapy at the College of Amsterdam and graduated in 2000. She finished her study Health Sciences at Maastricht University within the next two years, with a major in Health Education and Promotion. From November 2002 till April 2007, she worked as a researcher at the department of Epidemiology, Maastricht University, on a project on the effectiveness of prediction and early intervention in employees at risk for sickness absence due to psychosocial health complaints, which was funded by Zorg Onderzoek Nederland. This project resulted in the present thesis. During the first year, she completed a major in Epidemiology. In July and August 2005, she visited the Department of Public Health and Epidemiology at the University of Birmingham (UK) to work on a study presented in this thesis. Since May 2007, she has the position of post-doctoral research fellow at the Netherlands Cancer Institute in Amsterdam (NKI-AvL) on a project evaluating the effectiveness of cognitive behavioral therapy and physical exercise for climacteric symptoms in breast cancer patients experiencing treatment-induced menopause. 



\section{LIST OF PUBLICATIONS}

Saskia F.A. Duijts, Maurice P.A. Zeegers and Bart van den Borne. The association between stressful life events and breast cancer risk: a meta-analysis. Int J Cancer 2003; 107: 1023-1029

Saskia F.A. Duijts. Maurice P.A. Zeegers. Is the Occurrence of Breast Cancer Associated with the Prevalence of Stressful Events During Life? Breast Cancer 2004; 16: 49-53

Gerard M.H. Swaen, Saskia F.A. Duijts. Epidemiologic evidence for the carcinogenicity of vinyl chloride monomer. Scand J Work Environ Health 2005; 31(3): 233-5

Saskia F.A. Duijts. Congress of the World Federation of Occupational Therapists. Nederlands Tijdschrift voor Ergotherapie 2005; 33: 232

Saskia F.A. Duijts, IJmert Kant, Jan A. Landeweerd, Gerard M.H. Swaen. Prediction of sickness absence: the development of a screening instrument. Occup Environ Med 2006; 63: 564-569

Saskia F.A. Duijts, IJmert Kant, Gerard M.H. Swaen, Piet A. van den Brandt, Maurice P.A. Zeegers. A meta-analysis of observational studies identifies predictors of sickness absence. J Clinical Epidemiology 2007; in press

Saskia F.A. Duijts, IJmert Kant, Piet A. van den Brandt, Gerard M.H. Swaen. Advantages and disadvantages of an objective selection process for early intervention in employees at risk for sickness absence. BMC Public health, 2007; 7: 67.

Saskia F.A. Duijts, IJmert Kant, Piet A. van den Brandt, Gerard M.H. Swaen. The compatibility between characteristics of employees at risk for sickness absence and components of a preventive coaching intervention International Journal of Evidence Based coaching and Mentoring, 2007: 5(1); 19-29 


\section{SUBMITTED MANUSCRIPTS}

Saskia F.A. Duijts, IJmert Kant, Piet A. van den Brandt, Gerard M.H. Swaen. Psychometric characteristics and external validation of a screening instrument to identify employees at risk for sickness absence due to psychosocial health complaints.

Saskia F.A. Duijts, IJmert Kant, Piet A. van den Brandt, Gerard M.H. Swaen. The effectiveness of a preventive coaching intervention for employees at risk for sickness absence: results of a randomized controlled trial. 

